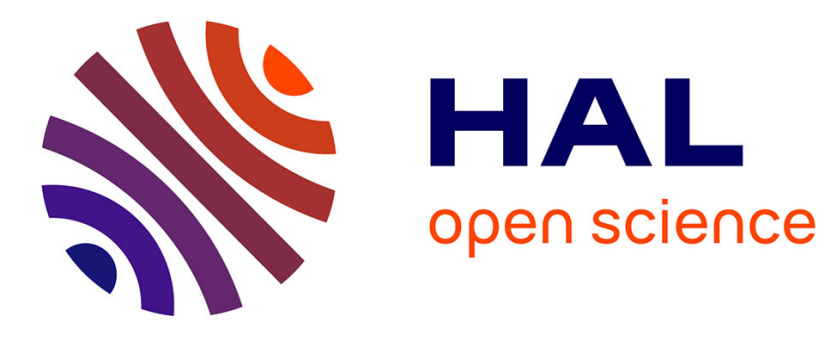

\title{
Pyrido-imidazodiazepinones as a new class of reversible inhibitors of human kallikrein 7
}

\author{
Dominique P Arama, Feryel Soualmia, Vincent Lisowski, Jean-François \\ Longevial, Elodie Bosc, Ludovic T Maillard, Jean Martinez, Nicolas Masurier, \\ Chahrazade El Amri
}

\section{To cite this version:}

Dominique P Arama, Feryel Soualmia, Vincent Lisowski, Jean-François Longevial, Elodie Bosc, et al.. Pyrido-imidazodiazepinones as a new class of reversible inhibitors of human kallikrein 7 . European Journal of Medicinal Chemistry, 2015, 93, pp.202-213. 10.1016/j.ejmech.2015.02.008 . hal-01120269

\section{HAL Id: hal-01120269 https://hal.sorbonne-universite.fr/hal-01120269}

Submitted on 25 Feb 2015

HAL is a multi-disciplinary open access archive for the deposit and dissemination of scientific research documents, whether they are published or not. The documents may come from teaching and research institutions in France or abroad, or from public or private research centers.
L'archive ouverte pluridisciplinaire HAL, est destinée au dépôt et à la diffusion de documents scientifiques de niveau recherche, publiés ou non, émanant des établissements d'enseignement et de recherche français ou étrangers, des laboratoires publics ou privés. 


\section{PYRIDO-IMIDAZODIAZEPINONES AS A NEW CLASS OF REVERSIBLE INHIBITORS OF HUMAN KALLIKREIN 7}

Dominique P. Arama, ${ }^{\text {a† }}$ Feryel Soualmia, ${ }^{\text {b }}{ }^{b}$ Vincent Lisowski, ${ }^{\text {a }}$ Jean-François Longevial, ${ }^{a}$ Elodie Bosc, ${ }^{b}$ Ludovic T. Maillard, ${ }^{a}$ Jean Martinez, ${ }^{a}$ Nicolas Masurier, ${ }^{a *}$ Chahrazade El Amrib*

a Institut des Biomolécules Max Mousseron, UMR 5247, CNRS, Université de Montpellier, UFR des Sciences Pharmaceutiques et Biologiques, 15 Avenue Charles Flahault, 34093 Montpellier Cedex 5, France

b Sorbonne Universités, UPMC Univ Paris 06, UMR 8256, B2A, Biological Adaptation and Ageing, Integrated Cellular Ageing and Inflammation, Molecular \& Functional Enzymology, 7 Quai St Bernard, F-75005 Paris.

† These authors contributed equally to the work.

*Corresponding authors: Nicolas Masurier. Tel: + (33) 4117596 42, Fax: + (33) 4 117596 41, E-mail: nicolas.masurier@univ-montp1.fr; Chahrazade El Amri. Tel: + (33) 1442769 52, Fax: + (33) 44275140 , E-mail: chahrazade.el_amri@upmc.fr

\section{ABBREVIATIONS USED}

AMC, 7-amino-4-methylcoumarin; DCM, dichloromethane; DMEM, Dulbecco's Modified Eagle Medium; DMSO, dimethyl sulfoxide; EDCI, 1-Ethyl-3-(3dimethylaminopropyl)carbodiimide hydrochloride; HOBt, hydroxybenzotriazole; IP, imidazo[1,2-a]pyridine; KLK5, kallikrein-related peptidase 5; KLK7, kallikrein-related peptidase 7; KLK8, kallikrein-related peptidase 8; KLK14, kallikrein-related peptidase 14; LEKTI, lymphoepithelial Kazal-type-related inhibitor; PDB, Protein Data Bank; TFA, trifluoroacetic acid; THF, tetrahydrofuran; XTT, 2,3-Bis-(2-Methoxy-4-Nitro-5sulfophenyl)-2H-Tetrazolium-5-Carboxanilide.

\section{Author contributions}

The manuscript was written through contributions of all authors. All authors have given approval to the final version of the manuscript.

\section{Notes}

The authors declare no competing financial interest. 


\section{Abstract:}

The human tissue kallikrein-7 (KLK7) is a chymotryptic serine protease member of tissue kallikrein family. KLK7 is involved in skin homeostasis and inflammation. Excess of KLK7 activity is also associated with tumor metastasis processes, especially in ovarian carcinomas, prostatic and pancreatic cancers. Development of Kallikrein 7 inhibitors is thus of great interest in oncology but also for treating skin diseases. Most of the developed synthetic inhibitors present several drawbacks such as poor selectivity and unsuitable physico-chemical properties for in vivo use. Recently, we described a practical sequence for the synthesis of imidazopyridinefused [1,3]-diazepines. Here, we report the identification of pyridoimidazodiazepinone core as a new potential scaffold to develop selective and competitive inhibitors of kallikrein-related peptidase 7 . Structure-activity relationships (SAR), inhibition mechanisms and selectivity as well as cytotoxicity against selected cancer cell lines were investigated.

Keywords: imidazo[1,2-a]pyridine, polyfused heterocycles, diazepinones, serine protease, human tissue kallikrein 7, non-covalent inhibitors 


\section{Introduction}

Tumor invasion and dissemination are complex and multi-step processes involving several key cellular events. Among the many events leading to metastasis, loss of intercellular adhesion is one of the earliest phenomenon, which could lead to cells dissemination [1]. One of the most well characterized mechanisms by which tumor cells can lose adhesion is by up-regulating the expression of extracellular proteases, which are able to cleave one or more of these cellular adhesion proteins. Among these various families of proteases, the human tissue kallikrein serine proteases (KLKs) are known to be over-expressed in various cancers [2, 3].

In this context, kallikrein 7 (KLK7) a chymotryptic enzyme, $[4,5]$ was reported to be implicated in several tumor metastasis processes, especially in ovarian carcinomas, pancreatic cancers, by the hydrolysis of several cadherin subtypes [6, 7]. KLK7 facilitates metastasis via degradation of extracellular matrix components such as fibronectin, desmosomal proteins particularly desmogleins 1 and 2, thus reducing cell-cell adhesion. In prostatic cancers, KLK7 induces epithelial to mesenchymal transition-like changes in prostate carcinoma cells, implying a role in prostate cancer invasion and progression [8]. Furthermore, KLK7 like other kallikreins such as KLK5, KLK8, KLK14 and matriptase plays an important role in normal skin desquamation [911]. Such enzymes can hydrolyze extracellular proteins that are part of intercellular adhesion structures such as corneodesmosomes in the stratum corneum [12]. As a consequence, mutation in the Spink5 gene of LEKTI, the physiological inhibitor of skin kallikreins, is responsible of the Netherton syndrome, a lethal recessive autosomal skin disorder [13]. Recently, in an organotypic human skin culture used as a model system of Netherton Syndrome, it has been shown that genetic inhibition of KLK5 and KLK7 ameliorates epidermal architecture demonstrating the relevance of these two enzymes as targets for treating this disease [14]. On the other hand, KLK7 transgenic mice exhibit a phenotype comparable to psoriasis with cutaneous hyperproliferation and immune cell infiltration [15]. Obese subjects often suffer from psoriatic lesions associated with high levels of adipokines such as chemerine. BeckSickinger and coll. have recently shown that KLK7 mediated pro-chemerine processing contributing thus to the development of these psoriatic lesions [16].

Consequently, the development of KLK7 inhibitors to control unopposed proteolytic cascades could represent a potential therapeutic approach to avoid or decrease 
metastasis associated with over-expression of KLK7 as well as for treating some skin disorders. Among the reported inhibitors of KLK7 [17], a few consist in peptide derivatives such as chloromethylketones [5], LEKTI-derived peptides [18] and sunflower trypsin inhibitor (SFTI-1) peptide derivatives [19]. More recently some heterocyclic compounds such as natural isocoumarins (as 8,8'-paepalantine) [20] isomannide derivatives [21, 22] or a mercaptobenzimidazolyl-quinazoline derivative [23] have also shown significant activities against KLK7 (Figure 1). All of them are reversible KLK7 inhibitors with moderate activity $\left(10<\mathrm{IC}_{50}<200 \mu \mathrm{M}\right)$. Additionally, some acyl-1,2,4-triazoles were reported to be more potent inhibitors $\left(0.04<\mathrm{IC}_{50}<3.5\right.$ $\mu \mathrm{M})$, with the ability to form transient covalent complexes (acyl-enzymes) with both KLK7 and KLK5 [24]. Since, most of the identified inhibitors suffer from low selectivity, moderate activity and unsuitable physico-chemical properties for in vivo use, the identification of new chemical scaffold for potent and reversible inhibition of KLK7 is thus needed.

A survey of the literature shows that some compounds bearing various heterocyclic pharmacophores can be found as KLK7 inhibitors. However, very few structureactivity relationships were carried out in these series and no co-crystallization of small molecules in the active site of KLK7 has been reported yet. So, crucial determinants for KLK7 specific targeting and inhibition still need to be addressed. All these points prompted us to screen some heterocyclic derivatives from our internal library to study their potential inhibiting activity against KLK7. We report herein the identification of the pyrido-imidazodiazepinone structure as a new potential scaffold to develop selective and competitive KLK7 inhibitors. Structure-activity relationship (SAR), inhibition mechanisms and selectivity, as well as biological evaluations against selected cancer cells were investigated.

\subsection{Screening of the diazepinone library and rationale for the synthesis of analogs}

Due to the heterogeneity of the heterocyclic scaffolds used to obtain KLK7 inhibition, 65 heterocyclic derivatives from our internal library were chosen for an initial screening (data not shown), including imidazo[1,2-a]pyridine (IP) and 1,3-thiazole derivatives, due to our particular interest in these heterocyclic scaffolds [25-31].

Compounds were all tested at the single dose of $50 \mu \mathrm{M}$. Among them, a pyridoimidazodiazepin-5-one showed an inhibition capability higher than 30\% (compound 
1a, Table 1) $\left(I C_{50}=57 \pm 1.0 \mu \mathrm{M}\right)$. The reversibility of the inhibition was evaluated by dilution of the reaction mixture after 15 and 60 min incubation of 1a with KLK7 at pH8 and $37^{\circ} \mathrm{C}$. The enzymatic activity was immediately restored in agreement with no formation of a covalent bond between the protease and the inhibitor. LineweaverBurk double reciprocal plot was used to determine the mechanism of action of compound 1a. Plots are consistent with a competitive inhibitor behavior with an inhibition constant $\mathrm{K}_{\mathrm{i}}$ of $50.6 \pm 0.8 \mu \mathrm{M}$ (see Figure $\mathrm{S} 1, \mathrm{SI}$ ). It is worth noting that no noticeable inhibition was observed at $50 \mu \mathrm{M}$ on other screened serine proteases (KLK5, KLK8 and KLK14), meaning that compound 1a had a selective action on KLK7.

A SAR study was then initiated, starting from compound 1a. A set of 30 new pyridoimidazodiazepinones as well as 9 acyl-IP derivatives, which can be seen as "opened pyrido-imidazodiazepinones", were synthesized and their potency was evaluated against KLK7 and other serine proteases to check selectivity.

\subsection{Rationale for the synthesis of optimized diazepinone analogs}

Modifications at positions 2, 3, 4 and 5 of the diazepinone core were envisioned (Figure 2). Synthesis of "opened-diazepinones" that possessed a higher flexibility was also investigated.

Pyrido-imidazodiazepinones 1a-ad were synthesized starting from 2-amino-imidazo[1,2-a]pyridine 5 by selective $C-3$ acylation of the IP nucleus (Scheme 1), using 7 different $\mathrm{N}$-Boc amino-acids (Boc-Phe-OH, Boc-o-Phe-OH, Boc-Ala-OH, Boc$\mathrm{Ser}(\mathrm{Bn})-\mathrm{OH}$, Boc-1-Nal-OH, Boc-Tyr(Bn)-OH, Boc-N-Me-Phe-OH) according to our previously reported methodology [25, 32]. C-3 acylated compounds 4a-g were isolated in $27 \%$ to $88 \%$ yield after chromatography on alumina gel. Only traces of the corresponding $\mathrm{N}$-acylated derivatives were detected by LC-MS analysis in the crude. After Boc removal in acidic media (by using concentrated hydrochloric acid or a mixture of trifluoroacetic acid/dichloromethane $(50 / 50 \mathrm{v} / \mathrm{v}))$, the resulting 2-amino-3acyl-imidazo-[1,2-a]pyridines 3a-g were isolated in basic medium, without further purification. Diamines 3a-g were then successively reacted with a set of aldehydes in chloroform at reflux for one night. Intermediate aminals were then oxidized without isolation, using a mixture of lead tetraacetate and iodine, to lead to pyridoimidazodiazepinones $1 \mathrm{a}-\mathbf{1} \mathbf{w}$ that were purified by chromatography on alumina gel. 
The pyrido-imidazodiazepine-2,5-dione 1aa was synthesized by intracarbonylation of diamine 2a, using $1,1^{\prime}$-carbonyldiimidazole in acetonitrile at $60^{\circ} \mathrm{C}$ and was isolated in $78 \%$ yield [32]. "Opened derivatives" 2 a-i were synthesized by a coupling reaction between the diamine $\mathbf{3 a}$ and a set of commercially available carboxylic acids. Compounds 2a-i were isolated after purification on an alumina gel column, in 20 to $89 \%$ yield. As the diamine $3 a$ possesses two free amines, the position of the $\mathrm{N}$ acylation was investigated. The structure of the resulting coupling product was ascertained by ${ }^{1} \mathrm{H}-{ }^{13} \mathrm{C}$ HMBC analysis of compound $2 \mathrm{a}\left(\mathrm{R}^{1}=\mathrm{Ph}\right)$, which showed a correlation between the $\mathrm{CH}_{\alpha}$ of the phenylalanine residue $(5.85 \mathrm{ppm})$ and the carbonyl signal of the amide (168.7 ppm), which unambiguously proved the $\mathrm{N}$ acylation position (see Figure S2, SI). This result confirmed that the aromatic amine in position 2 of the IP nucleus was poorly reactive, as previously observed [32].

Benzyl protected derivatives $\mathbf{1} \mathbf{u}$ and $\mathbf{1} \mathbf{v}$ were treated by a solution of $33 \%$ bromhydric acid in acetic acid to offer the corresponding hydroxy derivatives $\mathbf{1 a b}$ and $\mathbf{1 a c}$ in 93 and $99 \%$ yields respectively (Scheme 2 ). The 5 -hydroxy derivative 1ad was obtained as a mixture of diastereoisomers after reduction of compound 10, using sodium borohydride in methanol (Scheme 2). Finally, phenol derivatives $\mathbf{1 x - z}$ were obtained by demethylation of the methoxy derivatives $11-n$ in $45-81 \%$ yields, using a $1 \mathrm{M}$ boron tribromide dichloromethane solution (Scheme 1).

\subsection{Structure-activity relationships}

As our initial hit (compound 1a) possesses a chiral center, the significance of the stereochemistry was first investigated. Compared to compound 1a, which showed a moderate activity $\left(\mathrm{IC}_{50}=57 \pm 1 \mu \mathrm{M}\right)$, its $(R)$-enantiomer (compound 1e) led to a decrease of the inhibitory potency $\left(\mathrm{IC}_{50}=95.9 \pm 1.7 \mu \mathrm{M}\right)$, suggesting that the $(S)$ configuration is important to maintain inhibition in these series (Table 1). Modulation of position 2 of the diazepinone ring $\left(R^{1}\right)$ was then studied. Replacement of the aryl group by an aliphatic substituent (compound $\mathbf{1 j}$ ) or by a carbonyl group (urea derivative 1aa) completely abolished the inhibition. Introduction of a phenyl (compound 1f) or a 3-pyridinyl group (compound 1i) also led to a loss of KLK7 inhibition. Introduction of an electro-withdrawing group on the para position of the phenyl group was also unfavorable (compounds $\mathbf{1 g}$ and $\mathbf{1 h}$ ). The inhibiting capacity 
was preserved when a para-methyl- or a para-methoxyphenyl group was present (compounds 1c or $\mathbf{1 d}$ ), although the activity was lower than that of compound $\mathbf{1 a}$ $\left(\mathrm{IC}_{50} \sim 70 \mu \mathrm{M}\right)$.

The inhibitory potency observed with compound 1a, 1c and $1 \mathrm{~d}$ prompted us to further investigate compounds bearing methyl- or methoxyphenyl substituents at $R^{1}$. In the methyl series, the meta derivative (compound 1b) was inactive, whereas the 2,4dimethyl derivative (compound $\mathbf{1 k}$ ) showed a weaker activity compared to the two corresponding monomethyl derivatives (1a and 1c). In the methoxy series, the orthomethoxy and the meta-methoxyphenyl derivatives (1I and $\mathbf{1 m}$ ) were inactive. Some inhibition was recovered in the case of 2,5-dimethoxy- and 3,4,5-trimethoxyphenyl derivatives (compounds $\mathbf{1 n}$ and $\mathbf{1 p}$ ). The best result was obtained with the 3,4dimethoxyphenyl derivative 10, which showed the higher potency $\left(\mathrm{IC}_{50}=33.5 \mu \mathrm{M}\right)$. Whereas some methoxy derivatives exhibited different inhibition potencies, their corresponding phenol derivatives (compounds $\mathbf{1 x}$ to $\mathbf{1 z}$ ) were totally inactive. These results suggest that one or several methoxy groups can be involved in hydrogen bonding within the KLK7 active site.

Study of the position 4 of the diazepine ring was then carried out, keeping constant the 2-methylphenyl or the 3,4-dimethoxyphenyl groups at $\mathrm{R}^{1}$ (Figure 2). Replacement of the benzyl group at $\mathrm{R}^{3}$ by a methyl group (compounds $\mathbf{1 r}$ and $\mathbf{1 s}$ ) or a hydroxymethyl group (compound $\mathbf{1 a b}$ ) led to a loss of activity, suggesting that an aromatic group at this position is important for the interaction with the target. Introduction of bulkier groups like 1-naphtylmethyl or 4-benzyloxybenzyle (compounds 1q and 1v) or short elongation of the chain (compounds 1t and $\mathbf{1 u}$ ) also led to inactive compounds. A 4-hydroxybenzyl substituent in $\mathrm{R}^{3}$ was also unfavorable for KLK7 inhibition (compound 1ac). These results suggest that no modification is tolerated at $\mathrm{R}^{3}$ and a benzyl group is crucial to obtain KLK7 inhibition.

Finally, methylation of the diazepine $N-3$ or reduction of the carbonyl in position 5 of the most active compound 10 led to a loss of activity (compounds $\mathbf{1} \mathbf{w}$ and $\mathbf{1 a d}$ respectively). These results suggest that the $\mathrm{NH}$ and the carbonyl of the diazepine ring could be implicated in important interactions with the KLK7 binding site.

Finally, "opened diazepinone" series was investigated (compounds 2a-i). Only two derivatives bearing a benzyl or a 2-methylphenyl substituent at $\mathrm{R}^{1}$ (compounds $\mathbf{2 e}$ and $\mathbf{2 g}$, Scheme 1 and Table 1$)$ showed a weak KLK7 inhibition activity $\left(\mathrm{IC}_{50}>100\right.$ $\mu \mathrm{M})$. Although the flexibility of compounds 2 was higher than that of the diazepinone 
derivatives, which could eventually lead to a better molecular recognition, the increase of conformational entropy in such molecules was unfavorable to the activity. This result suggests that the presence of the diazepine ring is crucial for the inhibition potency.

Starting from compound 1a, which showed moderate inhibition potency against KLK7 $\left(\mathrm{IC}_{50}=57.0 \mu \mathrm{M}\right)$, modifications of positions 2, 3, 4 and 5 of the diazepinone ring were investigated. The SAR study indicated that position 3, 4 and 5 could not be modified to preserve potency. Replacement of the 2-methylphenyl substituent by a 3,4dimethoxyphenyl group led to a slight increase of the inhibition potency i.e. compound $10\left(\mathrm{IC}_{50}=33.5 \mu \mathrm{M}\right)$ (Figure $\left.3 \mathrm{~A}\right)$, which was selected for further studies.

\subsection{Mechanism of inhibition by compound 10}

As already observed with compound 1a, when using compound 10, the inhibition was reversed by dilution, in agreement with no formation of a stable covalent adduct between KLK7 and compound 10 (Figure 3B-C). Lineweaver-Burk double reciprocal plots showed that compound $\mathbf{1 0}$ is a competitive inhibitor indicating that 10 exclusively binds to the free enzyme (Figure $3 C$ ). The $K_{i}$ value for KLK7 was determined to be $27 \pm 1.8 \mu \mathrm{M}$ corresponding to an acceptable good affinity. The selectivity of compound 10 was then evaluated against three other human tissue kallikreins (KLK5, KLK8 and KLK14). No significant inhibition was observed at a 50 $\mu \mathrm{M}$ concentration, indicating that compound 10 was selective for kallikrein 7 .

\subsection{Structural basis for the inhibition}

Models of 10/KLK7 complexes were built to corroborate the mechanistic data and to propose some structural basis for the inhibition. The lowest energy model of docking of compound 10 into KLK7 showed several intermolecular interactions that are represented in Figure 4. The docking results suggest that the IP nucleus of compound 10 occupies the $S_{1}$ ' pocket of the protease active site, the diazepinone ring being located in the $S_{1}$ pocket while the benzyl group is directed toward pocket $\mathrm{S}_{2}$. The catalytic residue Ser195 of KLK7 might also be implicated in two hydrogen bonds with the two nitrogens of the IP ring. Finally, a key hydrogen bond between Asn 189 and one of the two methoxy groups could explain the higher affinity obtained 
with compound 10, compared to $1 \mathrm{~m}$ that bears only one meta methoxy group. This polar contact will be taken into account in the design of further optimized derivatives.

\subsection{Cytotoxicity potency towards cancer cell lines}

Since KLK7 is involved in tumor progression through its proteolytic activity, we investigated the anticancer potential of the most potent compounds. The cytotoxic effects of 23 derivatives including compound 10 were evaluated on three human cancer cell lines, i.e. the HeLa tumor cell line, the human prostatic PC-3 cell line [33] and the human colorectal adenocarcinoma SW-620 [34]. In particular, a recent study pointed out that aberrant expression of KLK7 in colon cancer cells and tissues is involved in cell proliferation resulting in human colon tumorogenesis [35].

Compounds were first screened at a $100 \mu \mathrm{M}$ concentration by measuring cellular death using the colorimetric XTT assay. Only derivatives exhibiting cytotoxic effects over $50 \%$ of cell death were retained. Several derivatives were found cytotoxic on cancer cell lines, including compounds $\mathbf{1 k}, \mathbf{1 n}, \mathbf{1 0}$ and $\mathbf{1 p}$ (Table 2) and their $\mathrm{EC}_{50}$ determined.

Overall, the HeLa cell line was the most sensitive toward these molecules, followed by PC-3 and SW-620. Interestingly compound 10 reported as the best KLK7 inhibitor displayed a noticeable cytotoxic effect on both HeLa and PC-3 cells lines. Moreover, one can also notice that $\mathbf{1 0}$ is the only compound that displays an effect, although moderate, on PC-3 cells $\left(E_{50}=64.8 \mu \mathrm{M}\right)$, while compound $\mathbf{1 k}$ is specific of SW-620 cell line. This selective behavior of 10 on PC-3 is particularly of great interest since KLK7 is highly expressed in prostate tissue and is believed to participate to cancer progression by its role in the induction of the epithelial-mesenchymal transition on in vitro cellular models [8].

\section{Conclusion}

Starting from an initial screening of 65 in-house heterocyclic derivatives, a pyridoimidazodiazepinone 1a was identified to be a moderate inhibitor of KLK7 $\left(I_{50}=57\right.$ $\mu \mathrm{M}$ and $\left.\mathrm{K}_{\mathrm{i}}=50 \mu \mathrm{M}\right)$. Enzymatic studies showed that this derivative is a reversible and competitive KLK7 inhibitor. Compound 1a was shown to have selective action toward 
KLK7, when compared to others tested serine proteases, suggesting its potential as a good starting point to design potent selective, competitive and reversible KLK7 inhibitors. A SAR program was then initiated to identify the structural requirement for KLK7 inhibition. Modulation of positions 2, 3, 4 and 5 of the diazepinone ring and "opened diazepine" derivatives were investigated. First, the diazepinone ring has shown to be crucial for KLK7 inhibition. In addition, a (S)-benzyl substituent in position 4 of the diazepine, a carbonyl group in position 5 , a NH in position 3 gave the best results. The phenyl ring at position 2 tolerates some modulations, i.e. substitution by one or two methyl or methoxy groups led to the most potent compounds. This study led to the discovery of compound 10, which is approximately twice more active than our initial hit $1 \mathrm{a}\left(\mathrm{K}_{\mathrm{i}}=27 \mu \mathrm{M}\right.$ compared to $50 \mu \mathrm{M}$ for compound 1a). Moreover some analogs, including compound 10, were shown to exhibit a cytotoxic effect, although moderate, against selected colon and prostate cancer cell lines. A detailed study of the cellular events involving KLK7 with optimized compounds could be of great interest to address the correlation between KLK7 inhibition and potential anticancer activity.

\section{Experimental}

\subsection{General}

Commercially available reagents and solvents were used without further purification. Reactions were monitored by HPLC using an analytical Chromolith Speed Rod RP-C18 $185 \mathrm{Pm}$ column (50x4.6 mm, $5 \mathrm{~mm}$ ) using a flow rate of 3.0 $\mathrm{mL} / \mathrm{min}$, and a gradient of $100 / 0$ to $0 / 100$ eluents $A / B$ over $5 \mathrm{~min}$, in which eluents $\mathrm{A}=\mathrm{H}_{2} \mathrm{O} / 0.1 \%$ TFA and $\mathrm{B}=\mathrm{CH}_{3} \mathrm{CN} / 0.1 \%$ TFA. Detection was at $214 \mathrm{~nm}$ using a Photodiode Array Detector. Retention times are reported as follows: $\operatorname{Tr}(\min ) .{ }^{1} \mathrm{H}$ and ${ }^{13} \mathrm{C}$ NMR spectra were recorded at room temperature in deuterated solvents. Chemical shifts $(\delta)$ are given in parts per million relative to the solvent $\left[{ }^{1} \mathrm{H}: \delta\left(\mathrm{CDCl}_{3}\right)\right.$ $=7.26 \mathrm{ppm},\left(\mathrm{DMSO} \mathrm{d}_{6}\right)=2.50 \mathrm{ppm} ;\left(\mathrm{CD}_{3} \mathrm{OD}\right)=3.31 \mathrm{ppm} ;{ }^{13} \mathrm{C}: \delta\left(\mathrm{CDCl}_{3}\right)=77.2$ ppm, $\left(\right.$ DMSO $\left.d_{6}\right)=39.5 \mathrm{ppm} ;\left(\mathrm{CD}_{3} \mathrm{OD}\right)=49.0 \mathrm{ppm}$ ]. The following abbreviations are used to designate the signal multiplicities: $s$ (singlet), $d$ (doublet), $t$ (triplet), $q$ (quartet), $\mathrm{m}$ (multiplet), bs (broad singlet). Analytical thin-layer chromatography (TLC) was performed using aluminium-backed silica gel plates coated with a $0.2 \mathrm{~mm}$ thickness of silica gel or with aluminium oxide 60 F254, neutral. LC-MS spectra (ESI) were recorded on a HPLC using an analytical Chromolith Speed Rod RP-C18 185 
Pm column $(50 \times 4.6 \mathrm{~mm}, 5 \mathrm{~mm})$; solvent $\mathrm{A}, \mathrm{H}_{2} \mathrm{O} / \mathrm{HCOOH} 0.1 \%$; solvent $\mathrm{B}$, $\mathrm{CH}_{3} \mathrm{CN} / \mathrm{HCOOH} 0.1 \%$; gradient, $0 \%$ solvent $\mathrm{B}$ to $100 \%$ solvent $\mathrm{B}$ in solvent $\mathrm{A}$ in 3 min; flow rate, $3.0 \mathrm{~mL}$ min-1. High-resolution mass spectrometric analyses were performed with a time-of-flight mass spectrometer fitted with an electrospray ionisation source. All measurements were performed in the positive ion mode. Melting points $(\mathrm{mp})$ are uncorrected and were recorded on a capillary melting point apparatus.

Compounds 5, 3a-c, 4a-c, 1a-d, 1f-j and 1aa were synthesized according to our previous reported procedures and the spectral characteristics were in agreement with the published data [25, 32].

\subsection{Synthesis of compounds $\mathbf{4 d - g}$}

To a suspension of $0.5 \mathrm{~g}$ of trifluoro- $N$-imidazo[1,2-a]pyridin-2-ylacetamide (2.18 $\mathrm{mmol}$ ) in $9 \mathrm{~mL}$ of an aqueous $5 \mathrm{~N}$ sodium hydroxide solution was added $0.5 \mathrm{~mL}$ of THF. The solution was stirred at $40^{\circ} \mathrm{C}$ for $2 \mathrm{~h}$. The solution was extracted with dichloromethane $(3 \times 20 \mathrm{~mL})$. The organic layer was dried over $\mathrm{Na}_{2} \mathrm{SO}_{4}$, filtered, and the solvent was removed in vacuo. The residue was dissolved in $20 \mathrm{~mL}$ of DCM and Boc-1-Nal-OH (2.4 mmol, 1.1 equiv.) [or Boc-Tyr(Bn)-OH or Boc-Ser(Bn)-OH or Boc$\mathrm{N}$-Me-Phe-OH], HOBt (325 mg, 2.4 mmol, 1.1 equiv.), EDCl (460 mg, 2.4 mmol, 1.1 equiv.) and triethylamine (334 $\mu \mathrm{L}, 2.4 \mathrm{mmol}, 1.1$ equiv.) were added at $0^{\circ} \mathrm{C}$. The solution was stirred at $\mathrm{rt}$ for $4 \mathrm{~h}$. The solution was then washed with saturated $\mathrm{NaHCO}_{3}$ aqueous solution $\left(2 \times 50 \mathrm{~mL}\right.$ ). The organic layer was dried over $\mathrm{Na}_{2} \mathrm{SO}_{4}$, filtered, and the solvent was concentrated in vacuo. The residue was purified by chromatography $\left(\mathrm{Al}_{2} \mathrm{O}_{3}, \mathrm{DCM} / \mathrm{EtOH} 99 / 1 \mathrm{v} / \mathrm{v}\right)$ to offer compounds $\mathbf{4 d - g}$.

4.2.1 (2S)-2-Boc-amino-1-(2-aminoimidazo[1,2-a]pyridin-3-yl)-3-(1-naphtyl)propan1-one $(4 d)$

Yellow solid ( $m=0.297 \mathrm{~g}, 63.5 \%$ ); $\mathrm{mp}: 208.0-210.2^{\circ} \mathrm{C} ;[\alpha]_{\mathrm{D}}{ }^{20}=+3.6^{\circ}\left(c 0.5, \mathrm{CHCl}_{3}\right)$; ${ }^{1} \mathrm{H} \mathrm{NMR}\left(\mathrm{CDCl}_{3}, 300 \mathrm{MHz}\right): \delta$ ppm $1.33(\mathrm{~s}, 9 \mathrm{H}), 3.50-3.70(\mathrm{~m}, 2 \mathrm{H}), 5.46(\mathrm{t}, 1 \mathrm{H}, \mathrm{J}=8.4$ $\mathrm{Hz}$ ), 5.57 (d, 1H, J=9.3 Hz), 5.86 (bs, 2H), 6.85 (bs, 1H), 7.29-7.49 (m, 6H), 7.66 (d, $1 \mathrm{H}, J=7.8 \mathrm{~Hz}), 7.78(\mathrm{~d}, 1 \mathrm{H}, J=7.8 \mathrm{~Hz}), 8.12(\mathrm{~d}, 1 \mathrm{H}, J=8.7 \mathrm{~Hz}), 9.60(\mathrm{bs}, 1 \mathrm{H}) ;{ }^{13} \mathrm{C}$ NMR $\left(\mathrm{CDCl}_{3}, 75 \mathrm{MHz}\right): \delta$ ppm 28.1 (3C), 35.6, 54.7, 80.3, 113.0, 113.9, 115.8, 123.3, $125.1,125.5,126.2,127.3,127.5,128.7,129.1,130.7,132.0,132.7,133.7,147.2$, 156.4, 158.1, 184.8; FT-IR $\left(\mathrm{cm}^{-1}\right)$ : 3329, 3189, 2971, 1679, 1588, 1497, 1449, 1366, 
1342, 1253, 1162, 1055, 762 ; HPLC, $\operatorname{Tr}=1.81 \mathrm{~min} ; \mathrm{MS}\left(E S I^{+}\right): \mathrm{m} / \mathrm{z} 431.3[\mathrm{M}+\mathrm{H}]^{+}$; HRMS calcd for $\mathrm{C}_{25} \mathrm{H}_{27} \mathrm{~N}_{4} \mathrm{O}_{3} 431.2083$, found 431.2085.

4.2.2 (2S)-2-Boc-amino-1-(2-aminoimidazo[1,2-a]pyridin-3-yl)-3-benzyloxy-propan1-one $(4 \mathrm{e})$

Yellow solid ( $\mathrm{m}=0.488 \mathrm{~g}, 54.5 \%) ; \mathrm{mp}: 123-124 \mathrm{C}$; $[\alpha]_{\mathrm{D}}{ }^{20}=+3.66^{\circ}\left(\mathrm{c} \mathrm{1.5}, \mathrm{CHCl}_{3}\right) ;{ }^{1} \mathrm{H}$ NMR (CDCl, $300 \mathrm{MHz}): \delta$ ppm $1.46(\mathrm{~s}, 9 \mathrm{H}), 3.77(\mathrm{t}, 1 \mathrm{H}, J=9.0 \mathrm{~Hz}), 3.89(\mathrm{dd}, 1 \mathrm{H}, J$ = 6.0, $9.0 \mathrm{~Hz}$ ), $4.54(\mathrm{~s}, 2 \mathrm{H}), 5.30(\mathrm{dd}, 1 \mathrm{H}, J=6.0,12.0 \mathrm{~Hz}), 5.79(\mathrm{~d}, 1 \mathrm{H}, J=9.0 \mathrm{~Hz}$ ), 5.89 (bs, 2H), $6.90(\mathrm{t}, 1 \mathrm{H}, J=9.0 \mathrm{~Hz}$ ), $7.21-7.33(\mathrm{~m}, 5 \mathrm{H}), 7.37-7.47(\mathrm{~m}, 2 \mathrm{H}), 9.62(\mathrm{~d}$, $1 \mathrm{H}, J=6.0 \mathrm{~Hz}$ ); ${ }^{13} \mathrm{C} \mathrm{NMR}\left(\mathrm{CDCl}_{3}, 75 \mathrm{MHz}\right): \delta \mathrm{ppm} 28.4(3 \mathrm{C}), 54.1,71.7,73.6,80.2$, $109.1,113.1,114.3,127.7$ (2C), 127.9, 128.4 (2C), 129.4, 130.7, 137.2, 147.8, 155.8, 159.1, 184.1; FT-IR $\left(\mathrm{cm}^{-1}\right): 3356,3204,2970,2849,1678,1631,1578,1456$,

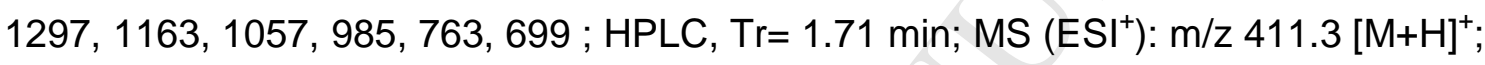
HRMS calcd for $\mathrm{C}_{22} \mathrm{H}_{27} \mathrm{~N}_{4} \mathrm{O}_{4} 411.2032$, found 411.2035.

4.2.3 (2S)-2-Boc-amino-1-(2-aminoimidazo[1,2-a]pyridin-3-yl)-3-(4-benzyloxyphenyl)propan-1-one (4f)

Light yellow solid $(\mathrm{m}=0.561 \mathrm{~g}, 53 \%)$; $\mathrm{mp}: 108.1-120.0^{\circ} \mathrm{C}$; $[\alpha]_{\mathrm{D}}{ }^{20}=+64.08^{\circ}(\mathrm{c} 0.76$, $\left.\mathrm{CHCl}_{3}\right) ;{ }^{1} \mathrm{H}$ NMR $\left(\mathrm{CDCl}_{3}, 300 \mathrm{MHz}\right): \delta \mathrm{ppm} 1.36(\mathrm{~s}, 9 \mathrm{H}), 2.95$ (dd, $1 \mathrm{H}, J=15.0,9.0$ $\mathrm{Hz}$ ), 3.11 (dd, $1 \mathrm{H}, J=15.0,9.0 \mathrm{~Hz}$ ), $4.95(\mathrm{~s}, 2 \mathrm{H}), 5.20$ (bs, $1 \mathrm{H}$ ), 5.50 (d, $1 \mathrm{H}, J=6.0$ $\mathrm{Hz}$ ), $5.89(\mathrm{bs}, 1 \mathrm{H}), 6.83(\mathrm{~m}, 3 \mathrm{H}), 7.12(\mathrm{~d}, 2 \mathrm{H}, J=9.0 \mathrm{~Hz}), 7.27-7.42(\mathrm{~m}, 8 \mathrm{H}), 9.60(\mathrm{bs}$, $1 \mathrm{H}) ;{ }^{13} \mathrm{C} \mathrm{NMR}\left(\mathrm{CDCl}_{3}, 100 \mathrm{MHz}\right): \delta \mathrm{ppm} 28.5$ (3C), 38.0, 55.7, 70.2, 80.7, 108.5, 113.2, 114.3, $115.0(2 \mathrm{C}), 127.6(2 \mathrm{C}), 128.1,128.7$ (2C), 129.3, 129.4, $130.4(2 \mathrm{C})$, 130.8, 137.3, 147.7, 156.7, 157.8, 158.7, 185.1 ; FT-IR $\left(\mathrm{cm}^{-1}\right): 3330,3207,2976$, 1681, 1581, 1510, 1496, 1450, 1366, 1343, 1242, 1161, 1074, 1045, 1013, 857, 762, 735, 695 ; HPLC, $\mathrm{Tr}=3.38 \mathrm{~min}$; MS $\left(\mathrm{ESI}^{+}\right): \mathrm{m} / \mathrm{z} 487.3[\mathrm{M}+\mathrm{H}]^{+}$; HRMS calcd for $\mathrm{C}_{28} \mathrm{H}_{31} \mathrm{~N}_{4} \mathrm{O}_{4} 487.2346$, found 487.2345 .

4.2.4 (2S)-2-Boc-N-methylamino-1-(2-aminoimidazo[1,2-a]pyridin-3-yl)-3-(4phenyl)propan-1-one $(\mathbf{4 g})$

Yellow solid ( $\mathrm{m}=0.578 \mathrm{~g}, 67 \%)$, mp: $58.5-61.4^{\circ} \mathrm{C} ;[\alpha]_{D}^{20}=-164.9^{\circ}\left(c 1.05, \mathrm{CHCl}_{3}\right)$ ; ${ }^{1} \mathrm{H}$ NMR $\left(\mathrm{CDCl}_{3}, 400 \mathrm{MHz}\right)$ : $\delta \mathrm{ppm} 1.31(\mathrm{~s}, 9 \mathrm{H}), 2.83(\mathrm{~s}, 3 \mathrm{H}), 3.12(\mathrm{~m}, 2 \mathrm{H}), 5.63(\mathrm{t}$, $1 \mathrm{H}, J=8.0 \mathrm{~Hz}$ ), $6.27(\mathrm{~s}, 2 \mathrm{H}), 6.82(\mathrm{t}, 1 \mathrm{H}, J=8.0 \mathrm{~Hz}$ ), 7.14 (t, $1 \mathrm{H}, J=8.0 \mathrm{~Hz}$ ), $7.22-$ 
$7.29(\mathrm{~m}, 5 \mathrm{H}), 7.37(\mathrm{t}, 1 \mathrm{H}, J=8.0 \mathrm{~Hz}), 9.75(\mathrm{bs}, 1 \mathrm{H}) ;{ }^{13} \mathrm{C} \mathrm{NMR}\left(\mathrm{CDCl}_{3}, 100 \mathrm{MHz}\right): \delta$ ppm 28.2 (3C), 29.7, 34.5, 59.2, 81.0, 108.5, 112.9, 113.9, 126.5, 128.4 (2C), 129.4, 129.8 (2C), 130.8, 137.5, 147.8, 157.7, 158.1, 182.3 ; FT-IR $\left(\mathrm{cm}^{-1}\right): 3331,3216$, 2974, 2928, 1666, 1627, 1591, 1524, 1496, 1444, 1387, 1366, 1341, 1264, 1140, 1060, 1012, 951, 849, 760, 697 ; HPLC, $\mathrm{Tr}=3.36 \mathrm{~min} ; \mathrm{MS}\left(\mathrm{ESI}^{+}\right): \mathrm{m} / \mathrm{z} 395.0[\mathrm{M}+\mathrm{H}]^{+}$; HRMS calcd for $\mathrm{C}_{22} \mathrm{H}_{27} \mathrm{~N}_{4} \mathrm{O}_{3} 395.2083$, found 395.2081.

\subsection{General procedure for the synthesis of diazepinones}

A solution of compound $4 \mathrm{a}-\mathrm{f}(0.33 \mathrm{mmol})$ in $12 \mathrm{~N}$ aqueous hydrochloric acid $(3 \mathrm{~mL})$ was stirred a room temperature for $1 \mathrm{~h}$. The solution was treated with $28 \%$ aqueous ammonia solution until pH 12 and then extracted with chloroform $(3 \times 20 \mathrm{~mL})$. The organic layer was dried over $\mathrm{Na}_{2} \mathrm{SO}_{4}$, filtered, and the solvent was concentrated in vacuo to lead compounds 3a-f, which were used in the next step without further purification. To a solution of 3a-f in chloroform $(2 \mathrm{~mL})$ was added 1 equiv. of the appropriate aldehyde. The solution was stirred at $60^{\circ} \mathrm{C}$ for $6 \mathrm{~h}$. After cooling, the mixture was pooled to a solution of iodine $(91 \mathrm{mg}, 0.36 \mathrm{mmol}, 1.1$ equiv) in chloroform $(4 \mathrm{~mL})$. Finally, a solution of lead tetraacetate $(161 \mathrm{mg}, 0.36 \mathrm{mmol}, 1.1$ equiv) in chloroform (6 mL) was added. The solution was stirred at room temperature for 1-6 $\mathrm{h}$ (monitoring by TLC). The solution was washed with $10 \% \mathrm{~m} / \mathrm{v}$ sodium thiosulfate aqueous solution $(3 \times 30 \mathrm{~mL})$ and then with saturated $\mathrm{NaHCO}_{3}$ aqueous solution $(2 \times 30 \mathrm{~mL})$. The organic layer was dried over $\mathrm{Na}_{2} \mathrm{SO}_{4}$, filtered, and the solvent was evaporated in vacuo. The residue was purified by chromatography on alumina, eluted by DCM/EtOH 99/1 v/v.

4.3.1 (4R)-4-benzyl-2-(2-methylphenyl)-3,4-dihydro-5H-pyrido[1',2':1,2]imidazo[4,5$\mathrm{d}][1,3]$ diazepin-5-one (1e)

Yellow solid ( $\mathrm{m}=0.117 \mathrm{~g}, 37.5 \%)$; $\mathrm{mp}: 135.5-136.5^{\circ} \mathrm{C} ;[\alpha]_{\mathrm{D}}^{20}=+9.1^{\circ}\left(\mathrm{c} 1, \mathrm{CHCl}_{3}\right)$; other data were in agreement with those published for its $S$ enantiomer.[25]

\subsection{2 (4S)-4-benzyl-2-(2,4-dimethylphenyl)-3,4-dihydro-5H-pyrido[1',2':1,2]imidazo} [4,5-d][1,3]diazepin-5-one (1k)

Yellow solid ( $\mathrm{m}=0.080 \mathrm{~g}, 38 \%)$; $\mathrm{mp}: 107.0-108.0^{\circ} \mathrm{C} ;[\alpha]_{D}{ }^{20}=-20.2^{\circ}\left(c 1, \mathrm{CHCl}_{3}\right) ;{ }^{1} \mathrm{H}$ $\operatorname{NMR}\left(\mathrm{CDCl}_{3}, 300 \mathrm{MHz}\right): \delta \mathrm{ppm} 2.12(\mathrm{~s}, 3 \mathrm{H}), 2.21$ (s, 3H), 3.25 (dd, $1 \mathrm{H}, J=9.0,12.0$ $\mathrm{Hz}$ ), 3.51 (dd, $1 \mathrm{H}, J=6.0,12.0 \mathrm{~Hz}$ ), 4.20 (bs, 1H), $5.93(\mathrm{bs}, 1 \mathrm{H}), 6.89(\mathrm{~m}, 3 \mathrm{H}), 7.19$ 
(m, 8H), $9.40(\mathrm{~d}, 1 \mathrm{H}, J=6.0 \mathrm{~Hz}) ;{ }^{13} \mathrm{C} \mathrm{NMR}\left(\mathrm{CDCl}_{3}, 75 \mathrm{MHz}\right): \delta \mathrm{ppm} 20.4,21.4,36.9$, 60.5, 111.9, 113.9, 115.2, 126.5, 126.8 (2C), 128.4, 128.5 (2C), 129.9, 130.1, 131.6, 132.0, 138.5, 141.5, 145.4, 152.6, 152.7, 156.8, 159.2, 181.6 ; FT-IR $\left(\mathrm{cm}^{-1}\right): 3027$, 2956, 2923, 1732, 1645, 1633, 1556, 1523, 1480, 1421, 1335, 1299, 1247, 1122, 1094, 1073, 1044, 949, 898, 820, 761 ; HPLC, $\left.\operatorname{Tr}=1.60 \mathrm{~min} ; \mathrm{MS}(\mathrm{ESI})^{+}\right): \mathrm{m} / \mathrm{z} 395.1$ $[\mathrm{M}+\mathrm{H}]^{+}$; HRMS calcd for $\mathrm{C}_{25} \mathrm{H}_{23} \mathrm{~N}_{4} \mathrm{O} 395.1872$, found 395.1858 .

4.3.3 (4S)-4-benzyl-2-(2-methoxyphenyl)-3,4-dihydro-5H-pyrido[1',2':1,2]imidazo[4,5d][1,3]diazepin-5-one (11)

Yellow solid ( $m=0.255 \mathrm{~g}, 72 \%)$; $\mathrm{mp}$ : $104.0-105.0^{\circ} \mathrm{C} ;[\alpha]_{D}{ }^{20}=-24.86^{\circ}\left(\mathrm{c} 1.5, \mathrm{CHCl}_{3}\right)$; ${ }^{1} \mathrm{HNMR}\left(\mathrm{CDCl}_{3}, 300 \mathrm{MHz}\right)$ : $\delta$ ppm $3.09(\mathrm{~m}, 1 \mathrm{H}), 3.32(\mathrm{~m}, 1 \mathrm{H}), 3.60(\mathrm{~s}, 3 \mathrm{H}), 4.24(\mathrm{dd}$, $1 \mathrm{H}, J=9.0,6.0 \mathrm{~Hz}), 6.80(\mathrm{~d}, 1 \mathrm{H}, J=9.0 \mathrm{~Hz}), 6.99(\mathrm{~m}, 2 \mathrm{H}), 7.20-7.24(\mathrm{~m}, 6 \mathrm{H}), 7.35-$ $7.46(\mathrm{~m}, 3 \mathrm{H}), 8.22(\mathrm{bs}, 1 \mathrm{H}), 9.50(\mathrm{~d}, 1 \mathrm{H}, J=6.0 \mathrm{~Hz}) ;{ }^{13} \mathrm{C} \mathrm{NMR}\left(\mathrm{CDCl}_{3}, 75 \mathrm{MHz}\right): \delta$ ppm 36.5, 56.0, 66.4, 111.6, 112.6, 113.8, 116.0, 121.5, 122.3, 126.7 (2C), 128.6, 128.7 (2C), 129.8, 129.9, 130.6, 133.1, 133.3, 138.1, 146.5, 156.3, 158.1, 181.9 ; FTIR $\left(\mathrm{cm}^{-1}\right): 660,680,694,722,741,842,904,921,978,1024,1042,1073,1106$, $1126,1163,1182,1240,1269,1297,1335,1453,1481,1524,1562,1601,1622$, 1645, 2971 ; HPLC, $\mathrm{Tr}=1.34 \mathrm{~min} ; \mathrm{MS}\left(\mathrm{ESI}^{+}\right): \mathrm{m} / \mathrm{z} 397.1[\mathrm{M}+\mathrm{H}]^{+}$; HRMS calcd for $\mathrm{C}_{24} \mathrm{H}_{21} \mathrm{~N}_{4} \mathrm{O}_{2} 397.1665$, found 397.1655 .

4.3.4 (4S)-4-benzyl-2-(3-methoxyphenyl)-3,4-dihydro-5H-pyrido[1',2':1,2]imidazo[4,5d][1,3]diazepin-5-one (1m)

Brown dough ( $m=0.130 \mathrm{~g}, 94 \%)$; $\mathrm{mp}: 66.0-67.0^{\circ} \mathrm{C}$; $[\alpha]_{D}{ }^{20}=+3.2^{\circ}(c 0.375$, DMSO); ${ }^{1} \mathrm{H}$ NMR (DMSO- $d_{6}, 400 \mathrm{MHz}$ ): $\delta \mathrm{ppm} 2.96(\mathrm{dd}, 1 \mathrm{H}, J=12.0,8.0 \mathrm{~Hz}$ ), $3.26(\mathrm{dd}, 1 \mathrm{H}$, $J=12.0,4.0 \mathrm{~Hz}), 3.75(\mathrm{~s}, 3 \mathrm{H}), 4.56(\mathrm{dd}, 1 \mathrm{H}, J=12.0,4.0 \mathrm{~Hz}), 6.97-7.03(\mathrm{~m}, 1 \mathrm{H})$, 7.13-7.50 (m, 10H), 7.90-7.97 (m, 2H), $9.54(\mathrm{~d}, 1 \mathrm{H}, J=8.0 \mathrm{~Hz}) ;{ }^{13} \mathrm{C}$ NMR (DMSO- $d_{6}$, $100 \mathrm{MHz}$ ): $\delta \mathrm{ppm} 34.7,55.4,63.7,111.7,114.8,115.1,116.4,120.2,122.7,127.0$ (2C), 128.5, 128.6 (2C), 129.4, 129.8, 133.4, 136.1, 143.4, 150.1, 158.0, 158.3, 159.0, 180.3 ; FT-IR $\left(\mathrm{cm}^{-1}\right)$ : 2963, 1648, 1596, 1580, 1519, 1488, 1466, 1454, 1417, 1332, 1292, 1259, 1177, 1129, 1029, $762 ; \mathrm{HPLC}, \mathrm{Tr}=1.42 \mathrm{~min} ; \mathrm{MS}\left(\mathrm{ESI}^{+}\right): \mathrm{m} / \mathrm{z}$ $397.1[\mathrm{M}+\mathrm{H}]^{+}$; HRMS calcd for $\mathrm{C}_{24} \mathrm{H}_{21} \mathrm{~N}_{4} \mathrm{O}_{2} 397.1665$, found 397.1654 .

4.3.5 (4S)-4-benzyl-2-(2,5-dimethoxyphenyl)-3,4-dihydro-5H-pyrido[1',2':1,2]imidazo [4,5-d][1,3]diazepin-5-one (1n) 
Yellow solid ( $\mathrm{m}=0.089 \mathrm{~g}, 39 \%) ; \mathrm{mp}: 155.0-156.0^{\circ} \mathrm{C} ;[\alpha]_{\mathrm{D}}{ }^{20}=-12.0^{\circ}\left(\mathrm{c} 1, \mathrm{CHCl}_{3}\right) ;{ }^{1} \mathrm{H}$ $\operatorname{NMR}\left(\mathrm{CDCl}_{3}, 300 \mathrm{MHz}\right): \delta \mathrm{ppm} 3.13(\mathrm{~m}, 1 \mathrm{H}), 3.31(\mathrm{~m}, 1 \mathrm{H}), 3.59(\mathrm{~s}, 3 \mathrm{H}), 3.79(\mathrm{~s}, 3 \mathrm{H})$, $4.25(\mathrm{~m}, 1 \mathrm{H}), 6.76(\mathrm{~d}, 1 \mathrm{H}, J=9.0 \mathrm{~Hz}), 6.92-7.03(\mathrm{~m}, 2 \mathrm{H}), 7.16-7.24(\mathrm{~m}, 6 \mathrm{H}), 7.47(\mathrm{t}$, $2 \mathrm{H}, J=6.0 \mathrm{~Hz}), 7.80(\mathrm{bs}, 1 \mathrm{H}), 9.54(\mathrm{~d}, 1 \mathrm{H}, J=6.0 \mathrm{~Hz}) ;{ }^{13} \mathrm{C} \mathrm{NMR}\left(\mathrm{CDCl}_{3}, 75 \mathrm{MHz}\right): \delta$ ppm 36.5, 54.2 (from ${ }^{1} \mathrm{H}^{13} \mathrm{C}$ HSQC correlation), 56.2, 56.7, 112.6, 113.4, 113.9, 116.0, 120.3, 126.5, 126.7, 128.6, 128.7, 129.8, 129.9, 130.7, 134.2, 138.0, 143.2, 146.4, 152.5, 154.1, 182.0; FT-IR ( $\left.\mathrm{cm}^{-1}\right): 3019,2928,2832,1647,1635,1565,1526$, $1480,1460,1448,1412,1335,1318,1268,1240,1220,1178,1099,1074,1042$, 1024, 961, 941, 902, 870, 813, 755, 740, 697, 676,; HPLC, $\operatorname{Tr}=1.66$ min ; MS $\left(E^{+} I^{+}\right):$ $\mathrm{m} / \mathrm{z} 427.1[\mathrm{M}+\mathrm{H}]^{+} ; \mathrm{HRMS}$ calcd for $\mathrm{C}_{25} \mathrm{H}_{23} \mathrm{~N}_{4} \mathrm{O}_{3} 427.1770$, found 427.1778 .

4.3.6 (4S)-4-benzyl-2-(3,4-dimethoxyphenyl)-3,4-dihydro-5H-pyrido[1',2':1,2]imidazo [4,5-d][1,3]diazepin-5-one (10)

Yellow solid ( $\mathrm{m}=0.115 \mathrm{~g}, 77 \%)$; $\mathrm{mp}$ : $136.0-137.0^{\circ} \mathrm{C} ;[\alpha]_{\mathrm{D}}{ }^{20}=+36.8^{\circ}(\mathrm{c} 1, \mathrm{DMSO})$; ${ }^{1} \mathrm{H}$ NMR (DMSO- $d_{6}, 400 \mathrm{MHz}$ ): $\delta \mathrm{ppm}$ 2.90-3.17 (m, 3H), $3.70(\mathrm{~s}, 3 \mathrm{H}), 3.81(\mathrm{~s}, 3 \mathrm{H})$, 4.15 (bs, $1 \mathrm{H}$ ), 6.97 (d, $1 \mathrm{H}, J=8.0 \mathrm{~Hz}$ ), 7.14 (bs, $1 \mathrm{H}$ ), 7.17 (td, $1 \mathrm{H}, J=8.0,4.0 \mathrm{~Hz}$ ), 7.24-7.32 (m, 6H), 7.64-7.70 (m, 2H), $9.47\left(\mathrm{~d}, 1 \mathrm{H}, J=8.0 \mathrm{~Hz}\right.$ ); ${ }^{13} \mathrm{C}$ NMR (DMSO- $d_{6}$, $100 \mathrm{MHz}$ ): $\delta \mathrm{ppm} 35.1,54.9,55.4,55.6,108.4,110.8,112.3,113.6,115.7,122.6$, $125.3,126.5,127.3$ (2C), 127.8, 128.3 (2C), 129.5, 129.7, 130.5, 136.7, 146.1, 147.9, 151.8, 180.1; FT-IR $\left(\mathrm{cm}^{-1}\right): 2925,2853,699,739,764,814,840,937,973$, $1021,1080,1140,1173,1231,1261,1335,1435,1462,1496,1510,1557,1599$, 1623 ; HPLC, $\mathrm{Tr}=1.33 \mathrm{~min}$; MS $\left(\mathrm{ESI}^{+}\right): \mathrm{m} / \mathrm{z} 427.0[\mathrm{M}+\mathrm{H}]^{+}$; HRMS calcd for $\mathrm{C}_{25} \mathrm{H}_{23} \mathrm{~N}_{4} \mathrm{O}_{3} 427.1770$, found 427.1774 .

4.3.7 (4S)-4-benzyl-2-(3,4,5-trimethoxyphenyl)-3,4-dihydro-5H-pyrido[1',2':1,2] imidazo[4,5-d][1,3]diazepin-5-one (1p)

Yellow solid ( $\mathrm{m}=0.192 \mathrm{~g}, 59 \%)$; $\mathrm{mp}: 119.0-120.0^{\circ} \mathrm{C} ;[\alpha]_{\mathrm{D}}^{20}=+22.98^{\circ}\left(\mathrm{c} 0.87, \mathrm{CHCl}_{3}\right)$ ; ${ }^{1} \mathrm{H} \mathrm{NMR}\left(\mathrm{CDCl}_{3}, 300 \mathrm{MHz}\right): \delta$ ppm 3.35 (bs, $\left.1 \mathrm{H}\right), 3.70(\mathrm{~s}, 6 \mathrm{H}), 3.82(\mathrm{~s}, 4 \mathrm{H}), 4.31$ (bs, $1 \mathrm{H}), 6.82(\mathrm{bs}, 2 \mathrm{H}), 7.03(\mathrm{td}, 1 \mathrm{H}, J=14.5,6.9 \mathrm{~Hz}), 7.33(\mathrm{~m}, 8 \mathrm{H}), 9.58(\mathrm{bs}, 1 \mathrm{H}) ;{ }^{13} \mathrm{C}$ $\mathrm{NMR}\left(\mathrm{CDCl}_{3}, 100 \mathrm{MHz}\right)$ : $\delta$ ppm 29.9, 36.5, 56.4 (2C), 61.0, 105.1, $106.8(2 \mathrm{C}), 112.1$, 114.2, 115.9, 127.1, 128.8 (2C), 128.9, 129.9 (2C), 130.9, 141.7, 146.2, 153.1 (2C), 159.7, 166.5, 182.3 ; FT-IR $\left(\mathrm{cm}^{-1}\right): 2937,2836,1719,1625,1559,1462,1409,1333$, 
1232, 1122, 1000, 763, $700 ; \mathrm{HPLC}, \mathrm{Tr}=1.50 \mathrm{~min} ; \mathrm{MS}\left(\mathrm{ESI}^{+}\right): \mathrm{m} / \mathrm{z} 457.1[\mathrm{M}+\mathrm{H}]^{+}$; HRMS calcd for $\mathrm{C}_{25} \mathrm{H}_{25} \mathrm{~N}_{4} \mathrm{O}_{4} 457.1876$, found 457.1874 .

4.3.8 (4S)-4-(1-naphthyl)methyl-2-(2-methylphenyl)-3,4-dihydro-5H-pyrido[1',2':1,2] imidazo[4,5-d][1,3]diazepin-5-one (1q)

Yellow solid ( $\mathrm{m}=0.105 \mathrm{~g}, 45 \%$ ); $\mathrm{mp}: 134.4-135.4^{\mathrm{C}} \mathrm{C} ; \mathrm{\alpha}_{\mathrm{D}}{ }^{20}=+29.4^{\circ}\left(\mathrm{c} 0.5, \mathrm{CHCl}_{3}\right)$; ${ }^{1} \mathrm{H}$ NMR $\left(\mathrm{CDCl}_{3}, 300 \mathrm{MHz}\right)$ : $\delta$ ppm 2.20 (s, 3H), 3.71 (bs, $\left.1 \mathrm{H}\right), 4.18$ (bs, 2H), 6.9 (t, $1 \mathrm{H}, J=9.0 \mathrm{~Hz}$ ), 7.12-7.19 (m, 4H), 7.30-7.48 (m, 5H), $7.61(\mathrm{bs}, 1 \mathrm{H}), 7.76(\mathrm{~d}, 1 \mathrm{H}, J=$ $9.0 \mathrm{~Hz}$ ), 7.85 (dd, $2 \mathrm{H}, J=9.0,3.0 \mathrm{~Hz}$ ), $8.05(\mathrm{dd}, 1 \mathrm{H}, J=9.0,3.0 \mathrm{~Hz}$ ), $9.48(\mathrm{~d}, 1 \mathrm{H}, J=$ $9.0 \mathrm{~Hz}$ ); ${ }^{13} \mathrm{C} \mathrm{NMR}\left(\mathrm{CDCl}_{3}, 75 \mathrm{MHz}\right): \delta \mathrm{ppm} 20.4,33.9,53.5$ (from ${ }^{1} \mathrm{H}^{-13} \mathrm{C} \mathrm{HSQC}$ correlation), 113.7, 115.3, 120.2, 121.8, 124.0, 125.6, 126.0 (2C), 127.3, 128.4, 128.6, 128.9, 130.3, 130.7, 131.2, 132.3 (2C), 134.1, 135.6, 138.4, 145.6, 156.1, 157.4, 159.5, 181.2 ; FT-IR $\left(\mathrm{cm}^{-1}\right): 2927,1691,1632,1556,1523,1480,1421,1335$, 1301, 1247, 1162, 1124, 760 ; HPLC, $\operatorname{Tr}=1.69 \mathrm{~min} ; \mathrm{MS}\left(\mathrm{ESI}^{+}\right): \mathrm{m} / \mathrm{z} 431.2[\mathrm{M}+\mathrm{H}]^{+}$; HRMS calcd for $\mathrm{C}_{28} \mathrm{H}_{23} \mathrm{~N}_{4} \mathrm{O} 431.1872$, found 431.1873 .

4.3.9 (4S)-4-methyl-2-(2-methylphenyl)-3,4-dihydro-5H-pyrido[1',2':1,2]-imidazo[4,5$\mathrm{d}][1,3]$ diazepin-5-one (1r)

White solid $\left(\mathrm{m}=0.023 \mathrm{~g}, 8 \%\right.$ ); $\mathrm{mp}: 124.0^{\circ} \mathrm{C}-125.0^{\circ} \mathrm{C} ;[\alpha]_{\mathrm{D}}{ }^{20}=-41.04^{\circ}$ ( c 0.57 , $\left.\mathrm{CHCl}_{3}\right) ;{ }^{1} \mathrm{H}$ NMR $\left(\mathrm{CDCl}_{3}, 400 \mathrm{MHz}\right): \delta$ ppm $1.68(\mathrm{bs}, 3 \mathrm{H}), 2.42(\mathrm{~s}, 3 \mathrm{H}), 4.09-4.16(\mathrm{~m}$, $1 \mathrm{H}), 6.93(\mathrm{t}, 1 \mathrm{H}, J=8.0 \mathrm{~Hz}), 7.17-7.35(\mathrm{~m}, 6 \mathrm{H}), 7.61(\mathrm{~d}, 1 \mathrm{H}, J=8.0 \mathrm{~Hz}), 9.48(\mathrm{~d}, 1 \mathrm{H}$, $J=8.0 \mathrm{~Hz}) ;{ }^{13} \mathrm{C} \mathrm{NMR}\left(\mathrm{CDCl}_{3}, 100 \mathrm{MHz}\right): \delta \mathrm{ppm} 16.6,20.3,63.4,111.7,113.4,114.8$, $126.0,128.2,130.0$ (2C), 130.5, 131.0, 131.1, 135.6, 137.9, 145.4, 154.6, 182.5; FTIR $\left(\mathrm{cm}^{-1}\right): 2929,1645,1627,1558,1523,1482,1419,1337,1300,1248,757$; HPLC, $\mathrm{Tr}=1.14 \mathrm{~min} ; \mathrm{MS}\left(\mathrm{ESI}^{+}\right): \mathrm{m} / \mathrm{z} 305.3[\mathrm{M}+\mathrm{H}]^{+}$; HRMS calcd for $\mathrm{C}_{18} \mathrm{H}_{17} \mathrm{~N}_{4} \mathrm{O} 305.1402$, found 305.1404 .

4.3.10

(4S)-4-methyl-2-(3,4-dimethoxyphenyl)-3,4-dihydro-5H-pyrido[1',2':1,2] imidazo[4,5-d][1,3]diazepin-5-one (1s)

Brown solid ( $\mathrm{m}=0.006 \mathrm{~g}, 6 \%) ; \mathrm{mp}: 102.0-103.0^{\circ} \mathrm{C} ;[\alpha]_{\mathrm{D}}{ }^{20}=-40.8^{\circ}\left(\mathrm{c} 0.25, \mathrm{CHCl}_{3}\right) ;{ }^{1} \mathrm{H}$ NMR $\left(\mathrm{CDCl}_{3}, 300 \mathrm{MHz}\right): \delta$ ppm 1.61 (bs, 3H), 3.90 (s, 3H), 3.94 (s, 3H), 4.66 (bs, $1 \mathrm{H}), 6.84(\mathrm{~d}, 1 \mathrm{H}, J=9.0 \mathrm{~Hz}), 6.97(\mathrm{t}, 1 \mathrm{H}, J=9.0 \mathrm{~Hz}), 7.45-7.48(\mathrm{~m}, 3 \mathrm{H}), 7.67$ (bs, $1 \mathrm{H}), 8.07$ (bs, $1 \mathrm{H}), 9.53(\mathrm{~d}, 1 \mathrm{H}, J=6.0 \mathrm{~Hz}) ;{ }^{13} \mathrm{C} \mathrm{NMR}\left(\mathrm{CDCl}_{3}, 75 \mathrm{MHz}\right): \delta \mathrm{ppm} 16.4$, 
$56.1,56.2,56.3,109.7,110.6,112.3,113.7,115.9,116.1,117.6,121.5,128.0$, 128.6, 129.9, 130.2, 149.3, 152.5, 183.1; HPLC, Tr= $1.10 \mathrm{~min} ; \mathrm{MS}\left(E S I^{+}\right): \mathrm{m} / \mathrm{z} 351.2$ $[\mathrm{M}+\mathrm{H}]^{+} ; \mathrm{HRMS}$ calcd for $\mathrm{C}_{19} \mathrm{H}_{19} \mathrm{~N}_{4} \mathrm{O}_{3} 351.1457$, found 351.1458 .

4.3.11 (4S)-4-benzyloxymethyl-2-(2-methylphenyl)-3,4-dihydro-5H-pyrido[1',2':1,2] imidazo[4,5-d][1,3]diazepin-5-one (1t)

Yellow solid ( $m=0.036 \mathrm{~g}, 31 \%$ ); $\mathrm{mp}: 102.0-103.0^{\circ} \mathrm{C} ;[\alpha]_{D}{ }^{20}=-8.25^{\circ}\left(c 0.4, \mathrm{CHCl}_{3}\right) ;{ }^{1} \mathrm{H}$ NMR ( $\mathrm{CDCl}_{3}, 300 \mathrm{MHz}$ ): $\delta$ ppm 2.41 (bs, 3H), 4.10 (bs, $1 \mathrm{H}$ ), 4.25 (dd, $1 \mathrm{H}, J=9.0$, $6.0 \mathrm{~Hz}$ ), $4.54(\mathrm{~m}, 1 \mathrm{H}), 4.71(\mathrm{bs}, 2 \mathrm{H}), 6.93(\mathrm{t}, 1 \mathrm{H}, J=6.0 \mathrm{~Hz}$ ), 7.17 (dd, $3 \mathrm{H}, J=9.0$, $6.0 \mathrm{~Hz}), 7.29-7.39(\mathrm{~m}, 8 \mathrm{H}), 7.63(\mathrm{~d}, 1 \mathrm{H}, J=6.0 \mathrm{~Hz}), 9.47(\mathrm{~d}, 1 \mathrm{H}, J=6.0 \mathrm{~Hz}) ;{ }^{13} \mathrm{C}$ $\mathrm{NMR}\left(\mathrm{CDCl}_{3}, 100 \mathrm{MHz}\right): \delta$ ppm 29.8, 69.9, 73.7, 73.8, 113.8, 115.3, 126.0, 126.1, 126.2, 127.8 (2C), 128.0, 128.5 (2C), 128.6, 130.4, 130.8, 130.9, 131.2, 131.3, 135.6, 138.3, 138.4, 145.7, 180.6; FT-IR $\left(\mathrm{cm}^{-1}\right): 3055,3023,2923,2853,2246$, 1634, 1558, 1523, 1421, 1336, 1250, 1097, 907, 762, 729, 696 ; HPLC, Tr= 1.55 min; MS $\left(\mathrm{ESI}^{+}\right): \mathrm{m} / \mathrm{z} 411.3[\mathrm{M}+\mathrm{H}]^{+}$; HRMS calcd for $\mathrm{C}_{25} \mathrm{H}_{23} \mathrm{~N}_{4} \mathrm{O}_{2} 411.1821$, found 411.1825 .

4.3.12 (4S)-4-benzyloxymethyl-2-(3,4-dimethoxyphenyl)-3,4-dihydro-5H-pyrido [1',2':1,2]imidazo[4,5-d][1,3]diazepin-5-one (1u)

Yellow solid $(\mathrm{m}=0.069 \mathrm{~g}, 47 \%) ; \mathrm{mp}: 80.5-81.5^{\circ} \mathrm{C} ;[\alpha]_{D}{ }^{20}=-27.0^{\circ}\left(c 0.8, \mathrm{CHCl}_{3}\right) ;{ }^{1} \mathrm{H}$ NMR $\left(\mathrm{CDCl}_{3}, 300 \mathrm{MHz}\right): \delta$ ppm $3.82(\mathrm{~s}, 3 \mathrm{H}), 3.89$ (bs, 5H), 4.26 (bs, $\left.1 \mathrm{H}\right), 4.60$ (bs, 2H), $6.79(\mathrm{~d}, 1 \mathrm{H}, J=6.0 \mathrm{~Hz}$ ), $6.98(\mathrm{t}, 1 \mathrm{H}, J=6.0 \mathrm{~Hz}$ ), 7.30-7.52 (m, 8H), 7.66 (bs,

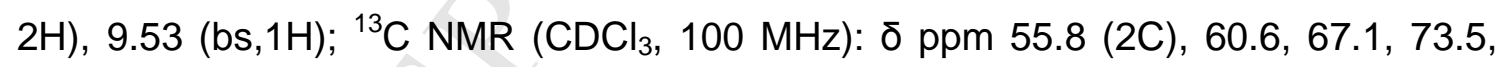
$110.2,111.7,113.5,116.5,121.9,122.9,127.9$ (2C), $128.4(2 \mathrm{C}), 130.1,137.0$, $142.5,147.1,148.9,150.8,152.3,158.5,159.0,160.7,181.1$; FT-IR $\left(\mathrm{cm}^{-1}\right): 3216$, 2931, 2853, 1622, 1559, 1508, 1462, 1427, 1334, 1233, 1132, 1094, 1020, 764, 738, 697; HPLC, $\mathrm{Tr}=1.54 \mathrm{~min} ; \mathrm{MS}\left(\mathrm{ESI}^{+}\right): \mathrm{m} / \mathrm{z} 457.3[\mathrm{M}+\mathrm{H}]^{+}$; HRMS calcd for $\mathrm{C}_{26} \mathrm{H}_{25} \mathrm{~N}_{4} \mathrm{O}_{4}$ 457.1876, found 457.1873 .

4.3.13 (4S)-4-(4-benzyloxy)benzyl-2-(3,4-dimethoxyphenyl)-3,4-dihydro-5H-pyrido [1',2':1,2]imidazo[4,5-d][1,3]diazepin-5-one (1v)

Orange solid ( $\mathrm{m}=0.134 \mathrm{~g}, 65 \%)$; $\mathrm{mp}: 129.0-130.0^{\circ} \mathrm{C} ;[\alpha]_{\mathrm{D}}^{20}=+3.93^{\circ}\left(\mathrm{c} 1.5, \mathrm{CHCl}_{3}\right)$; ${ }^{1} \mathrm{H}$ NMR $\left(\mathrm{CDCl}_{3}, 300 \mathrm{MHz}\right)$ : $\delta$ ppm 3.71-3.78 (bs, 4H), 3.81-3.88 (bs, 4H), 4.18 (bs, 
$1 \mathrm{H}), 5.02(\mathrm{~s}, 2 \mathrm{H}), 6.64(\mathrm{~d}, 1 \mathrm{H}, J=6.0 \mathrm{~Hz}), 6.90(\mathrm{~d}, 2 \mathrm{H}, J=9.0 \mathrm{~Hz}), 6.98(\mathrm{t}, 1 \mathrm{H}, J=$ $6.0 \mathrm{~Hz}), 7.19-7.45(\mathrm{~m}, 12 \mathrm{H}), 9.53(\mathrm{~d}, 1 \mathrm{H}, J=6.0 \mathrm{~Hz}) ;{ }^{13} \mathrm{C} \mathrm{NMR}\left(\mathrm{CDCl}_{3}, 100 \mathrm{MHz}\right): \delta$ ppm 30.2, 31.4, 35.8, 56.5, 70.6, 110.8, 112.8, 113.1, 113.2, 114.4, 115.4, 115.6 (2C), 116.5, 123.0, 127.4, 127.9 (2C), 128.5, 129.1 (2C), 131.0, 131.2 (2C), 132.5, 137.4, 146.7, 149.4, 153.1, 153.8, 158.4, 183.0; FT-IR $\left(\mathrm{cm}^{-1}\right): 3031,2932,2837$, 1730, 1624, 1557, 1510, 1461, 1425, 1335, 1260, 1231, 1140, 1020, 811, 764, 736, 695; HPLC, $\mathrm{Tr}=3.08 \mathrm{~min} ; \mathrm{MS}\left(\mathrm{ESI}^{+}\right): \mathrm{m} / \mathrm{z} 533.2[\mathrm{M}+\mathrm{H}]^{+}$; HRMS calcd for $\mathrm{C}_{32} \mathrm{H}_{29} \mathrm{~N}_{4} \mathrm{O}_{4}$ 533.2194, found 533.2189.

4.3.14 (S)-4-benzyl-2-(3,4-dimethoxyphenyl)-3-methyl-3H-pyrido[1',2':1,2]imidazo [4,5-d][1,3]diazepin-5(4H)-one (1w)

Yellow solid ( $\mathrm{m}=0.120 \mathrm{~g}, 54 \%$ ); $\mathrm{mp}: 217.0-218.0^{\circ} \mathrm{C}$; $[\alpha]_{\mathrm{D}}^{20}=+174.1^{\circ}\left(\mathrm{c} 0.39, \mathrm{CHCl}_{3}\right)$; ${ }^{1} \mathrm{H} \mathrm{NMR}\left(\mathrm{CDCl}_{3}, 300 \mathrm{MHz}\right): \delta$ ppm 2.69 (bs, 1H), 2.73 (bs, 1H), 2.98 (s, 3H), 3.71 (s, $3 \mathrm{H}), 3.86(\mathrm{~s}, 3 \mathrm{H}), 4.32(\mathrm{bs}, 1 \mathrm{H}), 6.67(\mathrm{~d}, 1 \mathrm{H}, J=8.4 \mathrm{~Hz}), 6.85(\mathrm{~s}, 2 \mathrm{H}), 6.98(\mathrm{td}, 1 \mathrm{H}, J$ $=5.7,6.9 \mathrm{~Hz}$ ), 7.28 (bs, $5 \mathrm{H}), 7.50$ (td, $1 \mathrm{H}, J=7.1,14.6 \mathrm{~Hz}$ ), 7.69 (d, $1 \mathrm{H}, J=8.9 \mathrm{~Hz}$ ), $9.55(\mathrm{~d}, 1 \mathrm{H} \mathrm{J}=6.9 \mathrm{~Hz}) ;{ }^{13} \mathrm{C} \mathrm{NMR}\left(\mathrm{CDCl}_{3}, 100 \mathrm{MHz}\right): \delta \mathrm{ppm} 29.9,34.3,45.6,56.2$, 72.4, 110.3, 112.8, 113.7, 113.9, 116.9, 125.4, 127.4, 128.4 (2C), 128.6, 129.0 (2C), 129.6, 130.4, 136.7, 147.4, 148.5, 151.95, 158.5, 160.7, 183.0; FT-IR $\left(\mathrm{cm}^{-1}\right): 3055$, 3000, 2928, 2837, 1624, 1543, 1515, 1478, 1455, 1436, 1359, 1340, 1262, 1126, 1019, 879, 817, 757, 706; HPLC, $\mathrm{Tr}=2.45 \mathrm{~min} ; \mathrm{MS}\left(\mathrm{ESI}^{+}\right): \mathrm{m} / \mathrm{z} 441.2[\mathrm{M}+\mathrm{H}]^{+} ; \mathrm{HRMS}$ calcd for $\mathrm{C}_{26} \mathrm{H}_{25} \mathrm{~N}_{4} \mathrm{O}_{3} 441.1931$, found 429.1927 .

\subsection{General procedure for synthesis of phenol derivatives $\mathbf{1 x - z}$}

To a solution of compound 11-n (100 mg) in DCM (10 mL) at $0^{\circ} \mathrm{C}$, was added a solution of boron tribromide $1 \mathrm{M}$ in DCM (6 equiv.). The resulting mixture was stirred at $\mathrm{rt}$ for $3 \mathrm{~h}$ (monitoring by TLC). The reaction was quenched by adding distilled water $(30 \mathrm{~mL})$. The solution was extracted with ethyl acetate; the organic layer was dried over $\mathrm{Na}_{2} \mathrm{SO}_{4}$, filtered and the solvent was removed under reduced pressure. The residue was dissolved in ethyl acetate and precipitated by addition of diethyl ether. The precipitate was then filtered over Buchner funnel and washed with diethyl ether to afford phenol derivatives $\mathbf{1} \mathbf{x}-\mathbf{z}$. 
4.4.1 (4S)-4-benzyl-2-(2-hydroxyphenyl)-3,4-dihydro-5H-pyrido[1',2':1,2]imidazo-[4,5$\mathrm{d}][1,3]$ diazepin-5-one (1x)

Brown solid ( $m=0.117 \mathrm{~g}, 81 \%)$; $\mathrm{mp}$ : $187.0-188.0^{\circ} \mathrm{C}$; $[\alpha]_{\mathrm{D}}^{20}=+35.2^{\circ}(c 0.25$, DMSO); ${ }^{1} \mathrm{H}$ NMR (DMSO-d $\left.d_{6}, 300 \mathrm{MHz}\right): \delta \mathrm{ppm} 2.90(\mathrm{~m}, 1 \mathrm{H}), 3.15(\mathrm{~m}, 1 \mathrm{H}), 4.41(\mathrm{~m}, 1 \mathrm{H}), 6.70$ $(\mathrm{m}, 1 \mathrm{H}), 6.86(\mathrm{~m}, 1 \mathrm{H}), 7.17(\mathrm{~m}, 9 \mathrm{H}), 7.35(\mathrm{~m}, 1 \mathrm{H}), 7.80(\mathrm{bs}, 2 \mathrm{H}), 9.47(\mathrm{~m}, 1 \mathrm{H}) ;{ }^{13} \mathrm{C}$ NMR (DMSO- $\left.d_{6}, 75 \mathrm{MHz}\right): \delta \mathrm{ppm} 35.0,64.0,112.1,114.8,114.9,116.1,117.6$, 118.2, 126.8, 128.0, 128.4 (2C), 129.4 (2C), 131.6, 134.7, 136.5, 145.8, 150.1, 152.8, 159.1, 160.9, 181.2; FT-IR $\left(\mathrm{cm}^{-1}\right): 3034,2924,1724,1636,1611,1583$, 1515, 1488, 1454, 1424, 1340, 1310, 1257, 1152, 1117, 1080, 1031, 749; HPLC, Tr= 1.56 min; $M S\left(E S I^{+}\right): \mathrm{m} / \mathrm{z} 383.0[\mathrm{M}+\mathrm{H}]^{+}$; HRMS calcd for $\mathrm{C}_{23} \mathrm{H}_{19} \mathrm{~N}_{4} \mathrm{O}_{2} 383.1502$, found 383.1511.

4.4.2 (4S)-4-benzyl-2-(3-hydroxyphenyl)-3,4-dihydro-5H-pyrido[1',2':1,2]imidazo-[4,5d][1,3]diazepin-5-one (1y)

Yellow solid ( $m=0.030 \mathrm{~g}, 45 \%)$; $\mathrm{mp}$ : $145.0-146.0^{\circ} \mathrm{C} ;[\alpha]_{\mathrm{D}}{ }^{20}=-5.0^{\circ}(c 1.0, \mathrm{MeOH}) ;{ }^{1} \mathrm{H}$ NMR (CD $\left.\mathrm{CD}_{3} \mathrm{OD}, 300 \mathrm{MHz}\right): \delta \mathrm{ppm} 3.03(\mathrm{dd}, 1 \mathrm{H}, J=12.0,9.0 \mathrm{~Hz}), 3.37(\mathrm{dd}, 1 \mathrm{H}, J=$ 12.0, $6.0 \mathrm{~Hz}$ ), $4.68(\mathrm{dd}, 1 \mathrm{H}, J=12.0,6.0 \mathrm{~Hz}), 6.83(\mathrm{~d}, 1 \mathrm{H}, J=6.0 \mathrm{~Hz}) ; 6.98(\mathrm{bs}, 1 \mathrm{H})$, 7.15 (dd, $2 \mathrm{H}, J=9.0,6.0 \mathrm{~Hz}$ ), 7.29-7.38 (m, 7H), $7.43(\mathrm{t}, 1 \mathrm{H}, J=6.0 \mathrm{~Hz}), 7.85-7.96$ $(\mathrm{m}, 2 \mathrm{H}), 9.66(\mathrm{~d}, 1 \mathrm{H}, J=6.0 \mathrm{~Hz}) ;{ }^{13} \mathrm{C}$ NMR $\left(\mathrm{CD}_{3} \mathrm{OD}, 75 \mathrm{MHz}\right): \delta \mathrm{ppm} 36.9,66.2$, 116.4, 117.7, 118.2, 122.5, 123.1, 128.8 (2C), 129.6 (2C), 129.9, 130.2, 130.3, 130.7, 131.4, 131.8, 132.1, 134.8, 136.7, 159.5, 163.7, 181.4; FT-IR $\left(\mathrm{cm}^{-1}\right): 2930$, 1779, 1650, 1594, 1530, 1450, 1420, 1331, 1296, 1264, 1244, 1197, 1126, 1080, 1033, 795; HPLC, $\mathrm{Tr}=1.32 \mathrm{~min} ; \mathrm{MS}\left(\mathrm{ESI}^{+}\right): \mathrm{m} / \mathrm{z} 383.1[\mathrm{M}+\mathrm{H}]^{+}$; HRMS calcd for $\mathrm{C}_{23} \mathrm{H}_{19} \mathrm{~N}_{4} \mathrm{O}_{2}$ 383.1508, found 383.1495.

4.4.3 (4S)-4-benzyl-2-(2,5-dihydroxyphenyl)-3,4-dihydro-5H-pyrido[1',2':1,2]imidazo[4,5-d][1,3]diazepin-5-one (1z)

Yellow solid $(m=0.037 \mathrm{~g}, 79 \%)$; $\mathrm{mp}: 260.5-261.5^{\circ} \mathrm{C} ;[\alpha]_{\mathrm{D}}^{20}=+81,48^{\circ}(\mathrm{c} \quad 0.405$, DMSO) ; ${ }^{1} \mathrm{H}$ NMR (DMSO-d, $300 \mathrm{MHz}$ ): $\delta$ ppm 2.82-3.01 (m, 3H), 3.61 (bs, $1 \mathrm{H}$ ), $4.25(\mathrm{~m}, 1 \mathrm{H}), 6.76(\mathrm{~m}, 1 \mathrm{H}), 6.91$ (bs, $1 \mathrm{H}), 7.14-7.25(\mathrm{~m}, 7 \mathrm{H}), 7.76-7.78(\mathrm{~m}, 2 \mathrm{H}), 8.64$ (d, $1 \mathrm{H}, J=3.4 \mathrm{~Hz}$ ), $9.46(\mathrm{~d}, 1 \mathrm{H}, J=3.4 \mathrm{~Hz}) ;{ }^{13} \mathrm{C}$ NMR (DMSO-d, $100 \mathrm{MHz}$ ): $\delta \mathrm{ppm}$ $35.1,63.3,112.6,113.6,114.2,114.9,116.2,118.2,122.2,126.7,128.3,128.4$ (2C), $129.0,129.3(2 \mathrm{C}), 131.0,136.6,146.4,148.7,154.7,158.9,182.2 ; \mathrm{FT}-\mathrm{IR}\left(\mathrm{cm}^{-1}\right)$ : 
3234, 2396, 1724, 1622, 1544, 1480, 1417, 1340, 1249, 1219, 1130, 823; HPLC, Tr= $1.358 \mathrm{~min} ; \mathrm{MS}\left(\mathrm{ESI}^{+}\right): \mathrm{m} / \mathrm{z} 399.2[\mathrm{M}+\mathrm{H}]^{+}$; HRMS calcd for $\mathrm{C}_{23} \mathrm{H}_{19} \mathrm{~N}_{4} \mathrm{O}_{3} 399.1457$, found 399.1459 .

\subsection{General procedure for synthesis of deprotected derivatives 1ab-ac}

A solution of compound $\mathbf{1} \mathbf{u}-\mathbf{v}(95 \mathrm{mg})$ in $\mathrm{DCM}$ was cooled at $0^{\circ} \mathrm{C}$. A mixture of $\mathrm{HBr}$ $33 \%$ in acetic acid $(5 \mathrm{~mL})$ was added and the resulting solution was stirred for $3 \mathrm{~h}$ (monitoring by TLC) at room temperature. The solvent was then removed under reduced pressure to afford compound 1ab-ac.

4.5.1 (4S)-4-hydroxymethyl-2-(3,4-dimethoxyphenyl)-3,4-dihydro-5H-pyrido[1',2':1,2] imi-dazo[4,5-d][1,3]diazepin-5-one (1ab)

Brown gum $(\mathrm{m}=0.030 \mathrm{~g}, 93 \%) ;[\alpha]_{\mathrm{D}}{ }^{20}=+16.0^{\circ}$ ( $c 0.175$, DMSO); ${ }^{1} \mathrm{H}$ NMR (DMSO$\left.d_{6}, 400 \mathrm{MHz}\right): \delta$ ppm 3.81-3.86 (m, 4H), $3.91(\mathrm{~s}, 6 \mathrm{H}), 4.44(\mathrm{~m}, 1 \mathrm{H}), 7.28(\mathrm{~d}, 1 \mathrm{H}, J=$ $8.0 \mathrm{~Hz}), 7.42-7.49(\mathrm{~m}, 1 \mathrm{H}), 7.56(\mathrm{~d}, 1 \mathrm{H}, J=4.0 \mathrm{~Hz}), 7.63(\mathrm{dd}, 1 \mathrm{H}, J=12.0 \mathrm{~Hz}, J=$ $4.0 \mathrm{~Hz}$ ), $7.92\left(\mathrm{~d}, 2 \mathrm{H}, J=4.0 \mathrm{~Hz}\right.$ ), $9.52\left(\mathrm{~d}, 1 \mathrm{H}, J=8.0 \mathrm{~Hz}\right.$ ); ${ }^{13} \mathrm{C}$ NMR (DMSO- $d_{6}, 100$ $\mathrm{MHz})$ : $\delta$ ppm 55.9, 56.2, 60.0, 65.3, 111.5, 112.1, 113.9, 115.8, 116.4, 120.1, 125.6, 128.6, 133.2, 144.6, 148.3, 148.8, 154.6, 160.9, 179.4; FT-IR $\left(\mathrm{cm}^{-1}\right): 3380,3206$, 3027, 2928, 1708, 1647, 1589, 1512, 1489, 1319, 1272, 1222, 1170, 1013, 810, 747; HPLC, $\mathrm{Tr}=1.7 \mathrm{~min} ; \mathrm{MS} \quad\left(\mathrm{ESI}^{+}\right): \mathrm{m} / \mathrm{z} \quad 367.2 \quad[\mathrm{M}+\mathrm{H}]^{+}$; HRMS calcd for $\mathrm{C}_{19} \mathrm{H}_{19} \mathrm{~N}_{4} \mathrm{O}_{4}$ 367.1406, found 367.1405.

4.5.2 (4S)-4-(4-hydroxyphenyl)-2-(3,4-dimethoxyphenyl)-3,4-dihydro-5H-pyrido [1',2':1,2]imidazo[4,5-d][1,3]diazepin-5-one (1ac)

Yellow solid ( $m=0.080 \mathrm{~g}, 99 \%)$; $\mathrm{mp}$ : $167.0-168.0^{\circ} \mathrm{C} ;[\alpha]_{\mathrm{D}}{ }^{20}=+36.4^{\circ}(c 0.75$, DMSO); ${ }^{1} \mathrm{H}$ NMR (DMSO-d, $\left.300 \mathrm{MHz}\right)$ : $\delta$ ppm $2.72(\mathrm{~m}, 1 \mathrm{H}), 2.97(\mathrm{~m}, 1 \mathrm{H}), 3.72(\mathrm{~s}, 3 \mathrm{H}), 3.83$ $(\mathrm{s}, 3 \mathrm{H}), 4.25(\mathrm{~d}, 1 \mathrm{H}, J=8.1 \mathrm{~Hz}), 6.68(\mathrm{~d}, 1 \mathrm{H}, J=6.0 \mathrm{~Hz}), 7.04-7.34(\mathrm{~m}, 9 \mathrm{H}), 7.74(\mathrm{bs}$, $1 \mathrm{H}$ ), $9.29\left(\mathrm{~s}, 1 \mathrm{H}\right.$ ), $9.48\left(\mathrm{~d}, 1 \mathrm{H}, J=6.0 \mathrm{~Hz}\right.$ ); ${ }^{13} \mathrm{C} \mathrm{NMR}$ (DMSO-d, $100 \mathrm{MHz}$ ): $\delta \mathrm{ppm}$ 34.2, 55.4, 55.8, 64.0, 111.0, 112.0, 112.7, 114.5, 115.2 (2C), 115.7, 123.6, 123.9, 126.7, 128.0, 130.4 (2C), 131.3, 135.2, 145.7, 148.0, 152.6, 156.2, 158.0, 182.1; FTIR $\left(\mathrm{cm}^{-1}\right)$ : 3230, 3087, 3031, 2916, 1722, 1613, 1591, 1557, 1510, 1462, 1337, 1236, $1175,1141,1111,1021,843,811,762,694 ; \mathrm{HPLC}, \mathrm{Tr}=2.44 \mathrm{~min} ; \mathrm{MS}\left(\mathrm{ESI}^{+}\right): \mathrm{m} / \mathrm{z}$ $443.2[\mathrm{M}+\mathrm{H}]^{+}$; HRMS calcd for $\mathrm{C}_{25} \mathrm{H}_{23} \mathrm{~N}_{4} \mathrm{O}_{4} 443.1722$, found 443.1719 . 
4.8 Synthesis of (4S)-4-benzyl-2-(3,4-dimethoxyphenyl)-4,5-dihydro-3H-pyrido [1',2':1,2]imidazo[4,5-d][1,3]diazepin-5-ol (1ad)

A solution of compound 10 (200 mg, $0.047 \mathrm{mmol})$ in $\mathrm{MeOH}(2 \mathrm{~mL})$ was cooled at $0^{\circ} \mathrm{C}$. Then $\mathrm{NaBH}_{4}$ (3 equiv., $53.5 \mathrm{mg}, 1.4 \mathrm{mmol}$ ) was added and the mixture was stirred at $0^{\circ} \mathrm{C}$ for $3 \mathrm{~h}$ (monitoring by TLC). After reaction completion, $1 \mathrm{~mL}$ of saturated $\mathrm{NaHCO}_{3}$ aqueous solution was added to quench the reaction. The solvent was then removed and the resulting residue was dissolved in ethyl acetate. The solution was washed with saturated $\mathrm{NaHCO}_{3}$ aqueous solution. The organic layer was dried over $\mathrm{Na}_{2} \mathrm{SO}_{4}$, filtered and the solvent was removed under reduced pressure to afford compound $1 \mathrm{ad}$ as a light yellow solid $(\mathrm{m}=30 \mathrm{mg}, 15 \%)$. Mp: $174.0^{\circ} \mathrm{C}-175.0^{\circ} \mathrm{C}$; $[\alpha]_{D}{ }^{20}$ $=-45.31^{\circ}$ ( c 0.49, DMSO); ${ }^{1} \mathrm{H}$ NMR (DMSO-d, $\left.400 \mathrm{MHz}\right): \delta p p m 1.23(\mathrm{~s}, 1 \mathrm{H}), 3.72(\mathrm{~s}$, $4 \mathrm{H}$ ), 3.81 (s, 5H), $5.40(\mathrm{~s}, 1 \mathrm{H}), 5.87$ (bs, 1H), 6.99 (bs, 2H), 7.00 (bs, 1H), 7.11-7.35 (m, 5H), 7.49 (bs, 3H), 8.36 (bs, $1 \mathrm{H}$ ); ${ }^{13} \mathrm{C}$ NMR (DMSO-d, $100 \mathrm{MHz}$ ): $\delta$ ppm 36.1, 55.5, 55.6, 60.0, 66.5, 110.9, 112.1, 112.3, 112.9, 115.5, 118.9, 122.8, 124.4, 125.0, 126.5, 128.5 (2C), 129.4 (2C), 138.9, 141.2, 144.9, 148.0, 152.0, 158.0; FT-IR( $\left(\mathrm{cm}^{-1}\right)$ : 3379, 2921, 2869, 2853, 1702, 1597, 1570, 1501, 1455, 1414, 1350, 1267, 1100, 1027, 948, 746, 707; HPLC, Tr= $2.27 \mathrm{~min} ; \mathrm{MS}\left(\mathrm{ESI}^{+}\right): \mathrm{m} / \mathrm{z} 429.2[\mathrm{M}+\mathrm{H}]^{+}$; HRMS calcd for $\mathrm{C}_{25} \mathrm{H}_{25} \mathrm{~N}_{4} \mathrm{O}_{3} 429.1924$, found 429.1927.

\subsection{General procedure for synthesis of opened derivatives $2 a-i$}

To a solution of diamine derivative $3 \mathbf{a}(100 \mathrm{mg})$ in DCM $(10 \mathrm{~mL})$ at $0^{\circ} \mathrm{C}$, were added $\mathrm{HOBt}$ (1.1 equiv.), $\mathrm{EDCl}$ (1.1 equiv.) and $\mathrm{Et}_{3} \mathrm{~N}$ (1.1 equiv.) and the resulting mixture was stirred at $0^{\circ} \mathrm{C}$ for $30 \mathrm{~min}$. The solution was the $\mathrm{n}$ stirred at it for $6 \mathrm{~h}$ (monitoring by TLC). The solution was washed with saturated $\mathrm{NaHCO}_{3}$ aqueous solution $(3 \times 30$ $\mathrm{mL}$ ). The organic layers were combined, dried over $\mathrm{Na}_{2} \mathrm{SO}_{4}$, filtered and the solvent was removed under reduced pressure. The residue was dissolved in dichloromethane and filtered through alumina gel using sintered glass Buchner funnel. The solvent was removed in vacuo to afford pure opened derivatives 2a-i.

4.6.1 (S)-N-(1-(2-amino-imidazo[1,2-a]pyridin-3-yl)-1-oxo-3-phenylpropan-2yl)benzamide (2a) 
White solid ( $m=0.038 \mathrm{~g}, 68 \%$ ); $\mathrm{mp}: 214.0-215.0^{\circ} \mathrm{C} ;[\alpha]_{\mathrm{D}}^{20}=+96.59^{\circ}\left(\mathrm{c} 0.44, \mathrm{CHCl}_{3}\right)$; ${ }^{1} \mathrm{H} \mathrm{NMR}\left(\mathrm{CDCl}_{3}, 300 \mathrm{MHz}\right): \delta$ ppm $3.24(\mathrm{dd}, 1 \mathrm{H}, J=9.0,6.0 \mathrm{~Hz}), 3.35(\mathrm{dd}, 1 \mathrm{H}, J=$ 9.0, 6.0 Hz), 5.78 (dd, $1 \mathrm{H}, J=12.0,3.0 \mathrm{~Hz}$ ), 6.22 (bs, 2H), 6.65 (td, $1 \mathrm{H}, J=6.0,3.0$ $\mathrm{Hz}), 7.13(\mathrm{t}, 1 \mathrm{H}, J=6.0 \mathrm{~Hz}), 7.20(\mathrm{t}, 2 \mathrm{H}, J=6.0 \mathrm{~Hz}), 7.26-7.30(\mathrm{~m}, 4 \mathrm{H}), 7.33(\mathrm{t}, 2 \mathrm{H}, J$ $=6.0 \mathrm{~Hz}), 7.39-7.48(\mathrm{~m}, 2 \mathrm{H}), 7.68(\mathrm{~d}, 2 \mathrm{H}, J=6.0 \mathrm{~Hz}), 9.60(\mathrm{~d}, 1 \mathrm{H}, J=6.0 \mathrm{~Hz}) ;{ }^{13} \mathrm{C}$ $\operatorname{NMR}\left(\mathrm{CDCl}_{3}, 75 \mathrm{MHz}\right)$ : $\delta$ ppm 38.6, 54.8, 108.5, 113.2, 114.3, 127.0, 127.2 (2C), 128.7 (4C), 129.3 (2C), 129.8, 131.1, 132.1, 133.6, 136.7, 148.0, 159.3, 168.3, 184.2; FT-IR $\left(\mathrm{cm}^{-1}\right): 3311,3184,1633,1574,1526,1495,1455,1339,1263,1054$, 760, 695; HPLC, $\mathrm{Tr}=1.62 \mathrm{~min} ; \mathrm{MS}\left(\mathrm{ESI}^{+}\right): \mathrm{m} / \mathrm{z} 385.2[\mathrm{M}+\mathrm{H}]^{+}$; HRMS calcd for $\mathrm{C}_{23} \mathrm{H}_{21} \mathrm{~N}_{4} \mathrm{O}_{2}$ 385.1665, found 385.1665.

4.6.2 (S)-N-(1-(2-amino-imidazo[1,2-a]pyridin-3-yl)-1-oxo-3-phenylpropan-2yl)picolinamide (2b)

Yellow solid ( $\mathrm{m}=0.045 \mathrm{~g}, 53 \%) ; \mathrm{mp}: 74.0-75.0^{\circ} \mathrm{C} ;[\alpha]_{\mathrm{D}}{ }^{20}=+62.8^{\circ}\left(c 0.53, \mathrm{CHCl}_{3}\right) ;{ }^{1} \mathrm{H}$ NMR $\left(\mathrm{CDCl}_{3}, 300 \mathrm{MHz}\right): \delta$ ppm $3.23(\mathrm{dd}, 1 \mathrm{H}, J=13.6,7.4 \mathrm{~Hz}), 3.40(\mathrm{dd}, 1 \mathrm{H}, J=$ 13.7, $7.0 \mathrm{~Hz}$ ), 5.78 (dd, $1 \mathrm{H}, J=16.9,7.3 \mathrm{~Hz}$ ), 6.86 (td, $1 \mathrm{H}, J=6.8,1.4 \mathrm{~Hz}), 7.11-7.44$ $(\mathrm{m}, 10 \mathrm{H}), 7.8(\mathrm{td}, 1 \mathrm{H}, J=7.7,1.8 \mathrm{~Hz}), 8.10(\mathrm{~d}, 1 \mathrm{H}, J=7.9 \mathrm{~Hz}), 8.57(\mathrm{~d}, 1 \mathrm{H}, J=4.0$ $\mathrm{Hz}), 8.78(\mathrm{~d}, 1 \mathrm{H}, J=9.5 \mathrm{~Hz}), 9.64(\mathrm{bs}, 1 \mathrm{H}) ;{ }^{13} \mathrm{C} \mathrm{NMR}\left(\mathrm{CDCl}_{3}, 75 \mathrm{MHz}\right): \delta \mathrm{ppm} 38.6$, 54.5, 108.7, 113.2, 114.4, 122.5, 126.7, 126.8, 127.4, 128.6 (2C), 129.3 (2C), 130.9, 136.9, 137.5, 147.9, 148.6, 149.1, 159.1, 165.2, 183.7; FT-IR $\left(\mathrm{cm}^{-1}\right): 3312,3187$, 3026, 1659, 1577, 1523, 1495, 1448, 1339, 1265, 1223, 1146, 1063, 753, 698; HPLC, $\mathrm{Tr}=1.59 \mathrm{~min} ; \mathrm{MS}\left(\mathrm{ESI}^{+}\right): \mathrm{m} / \mathrm{z} 386.2[\mathrm{M}+\mathrm{H}]^{+}$; HRMS calcd for $\mathrm{C}_{22} \mathrm{H}_{20} \mathrm{~N}_{5} \mathrm{O}_{2}$ 386.1617 , found 386.1618 .

4.6.3 (S)-N-(1-(2-amino-imidazo[1,2-a]pyridin-3-yl)-1-oxo-3-phenylpropan-2$y$ l)isonicotinamide (2c)

Yellow solid ( $\mathrm{m}=0.086 \mathrm{~g}, 80 \%)$; $\mathrm{mp}$ : 205.0-206.0 $\mathrm{C}$; $[\alpha]_{\mathrm{D}}{ }^{20}=+69.5^{\circ}\left(c 0.4, \mathrm{CHCl}_{3}\right)$; ${ }^{1} \mathrm{H} \mathrm{NMR}\left(\mathrm{CDCl}_{3}, 300 \mathrm{MHz}\right): \delta$ ppm $3.30(\mathrm{dd}, 1 \mathrm{H}, J=13.8,7.4 \mathrm{~Hz}), 3.4(\mathrm{dd}, 1 \mathrm{H}, J=$ 13.8, $6.7 \mathrm{~Hz}), 5.76(\mathrm{dd}, 1 \mathrm{H}, J=15.5,6.9 \mathrm{~Hz}), 5.98(\mathrm{~s}, 2 \mathrm{H}), 6.9(\mathrm{td}, 1 \mathrm{H}, J=6.9,1.3$ $\mathrm{Hz}), 7.14-7.23(\mathrm{~m}, 4 \mathrm{H}), 7.30(\mathrm{~d}, 1 \mathrm{H}, J=8.7 \mathrm{~Hz}), 7.44(\mathrm{td}, 1 \mathrm{H}, J=7.0,1.1 \mathrm{~Hz}), 7.53$ $(\mathrm{d}, 4 \mathrm{H}, J=6.0 \mathrm{~Hz}), 8.67$ (dd, $2 \mathrm{H}, J=4.6,1.4 \mathrm{~Hz}), 9.55$ (bs, $1 \mathrm{H}) ;{ }^{13} \mathrm{C} \mathrm{NMR}\left(\mathrm{CDCl}_{3}, 75\right.$ $\mathrm{MHz})$ : $\delta$ ppm 38.6, 55.1, 108.5, 113.5, 114.5, 121.0 (2C), 127.2, 128.5, 128.7 (2C), $129.3(2 \mathrm{C}), 129.8,131.4,136.3,140.8,148.1,150.7$ (2C), 159.2, 166.4 ; FT-IR $\left(\mathrm{cm}^{-1}\right)$ 
: 3311, 3188, 1650, 1579, 1495, 1455, 1339, 1310, 1265, 1063, 846, 752, 696, 667 ; $\mathrm{HPLC}, \mathrm{Tr}=1.19 \mathrm{~min} ; \mathrm{MS}\left(\mathrm{ESI}^{+}\right): \mathrm{m} / \mathrm{z} 386.2[\mathrm{M}+\mathrm{H}]^{+}$; HRMS calcd for $\mathrm{C}_{22} \mathrm{H}_{20} \mathrm{~N}_{5} \mathrm{O}_{2}$ 386.1617, found 386.1619.

4.6.4 (S)-N-(1-(2-amino-imidazo[1,2-a]pyridin-3-yl)-1-oxo-3-phenylpropan-2-yl)-1Hpyrrole-2-carboxamide (2d)

Yellow solid $(m=0.117 \mathrm{~g}, 88 \%)$; $\mathrm{mp}: 197.5-198.5^{\circ} \mathrm{C}$; $[\alpha]_{D}{ }^{20}=+15.8^{\circ}$ ( $c 0.54$, DMSO); ${ }^{1} \mathrm{H}$ NMR (DMSO- $\left.d_{6}, 300 \mathrm{MHz}\right): \delta \mathrm{ppm} 3.15(\mathrm{~m}, 2 \mathrm{H}), 5.46(\mathrm{dd}, 1 \mathrm{H}, J=13.0,7.0 \mathrm{~Hz}$ ), $6.1(\mathrm{~m}, 1 \mathrm{H}), 6.87(\mathrm{~m}, 1 \mathrm{H}), 6.95(\mathrm{t}, 1 \mathrm{H}, J=8.1 \mathrm{~Hz}), 7.02(\mathrm{~m}, 1 \mathrm{H}), 7.1-7.25(\mathrm{~m}, 7 \mathrm{H})$, $7.33(\mathrm{t}, 1 \mathrm{H}, J=7.2 \mathrm{~Hz}), 7.48(\mathrm{t}, 1 \mathrm{H}, J=7.4 \mathrm{~Hz}), 8.8(\mathrm{~d}, 1 \mathrm{H}, J=8.7 \mathrm{~Hz}), 9.55(\mathrm{~d}, 1 \mathrm{H}, J$ $=6.6 \mathrm{~Hz}$ ), $11.48(\mathrm{~s}, 1 \mathrm{H}) ;{ }^{13} \mathrm{C}$ NMR (DMSO- $\left.d_{6}, 75 \mathrm{MHz}\right): \delta \mathrm{ppm} 37.0,54.3,107.3$, $108.8,111.6,112.6,113.6,122.1,124.8,126.2,128.0$ (2C), 128.3, 129.0 (2C), $130.7,138.0,147.2,158.8,161.2$, 184.0; FT-IR $\left(\mathrm{cm}^{-1}\right): 3305,3194,1577,1556$, 1495, 1442, 1338, 1264, 1193, 1129, 1041, 844, 733, 696; HPLC, Tr= 1.54 min; MS $\left(\mathrm{ESI}^{+}\right): \mathrm{m} / \mathrm{z} 374.2[\mathrm{M}+\mathrm{H}]^{+}$; HRMS calcd for $\mathrm{C}_{21} \mathrm{H}_{20} \mathrm{~N}_{5} \mathrm{O}_{2} 374.1617$, found 374.1616.

4.6.5 (S)-N-(1-(2-amino-imidazo[1,2-a]pyridin-3-yl)-1-oxo-3-phenylpropan-2-yl)-2methylbenzamide (2e)

White solid ( $\mathrm{m}=0.111 \mathrm{~g}, 76 \%)$; mp: 87.0-88.0 $0^{\circ}$; $[\alpha]_{D}^{20}=+31.1^{\circ}\left(\mathrm{c} \mathrm{1.0}, \mathrm{CHCl}_{3}\right) ;{ }^{1} \mathrm{H}$ $\operatorname{NMR}\left(\mathrm{CDCl}_{3}, 300 \mathrm{MHz}\right): \delta$ ppm 1.86 (bs, $\left.1 \mathrm{H}\right), 2.21$ (s, 3H), $3.26(\mathrm{dd}, 1 \mathrm{H}, J=13.9$, $8.3 \mathrm{~Hz}$ ), 3.33 (dd, $1 \mathrm{H}, J=13.9,6.3 \mathrm{~Hz}$ ), 5.80 (dd, $1 \mathrm{H}, J=13.9,8.3 \mathrm{~Hz}), 6.31(\mathrm{~s}, 2 \mathrm{H})$, $6.84(\mathrm{td}, 1 \mathrm{H}, J=13.8,6.9 \mathrm{~Hz}), 7.22(\mathrm{~m}, 10 \mathrm{H}), 7.38(\mathrm{td}, 1 \mathrm{H}, J=15.8,6.9 \mathrm{~Hz}), 9.55$ (bs, $1 \mathrm{H}) ;{ }^{13} \mathrm{C} \mathrm{NMR}\left(\mathrm{CDCl}_{3}, 75 \mathrm{MHz}\right): \delta \mathrm{ppm} 19.7,38.4,54.8,113.2,114.3,125.7$, 126.9, 127.0, 127.3, 128.6 (2C), 128.7, 129.4 (2C), 130.2, 131.0, 131.1, 135.3, 136.3, 136.8, 148.1, 159.3, 170.9, 184.0 ; FT-IR $\left(\mathrm{cm}^{-1}\right): 3331,3179,2828,1731$, 1633, 1578, 1526, 1496, 1452, 1338, 1318, 1203, 1158, 1056, 735, 698 ; HPLC, Tr= $1.70 \mathrm{~min} ; \mathrm{MS}\left(\mathrm{ESI}^{+}\right): \mathrm{m} / \mathrm{z} 399.1[\mathrm{M}+\mathrm{H}]^{+}$; HRMS calcd for $\mathrm{C}_{24} \mathrm{H}_{23} \mathrm{~N}_{4} \mathrm{O}_{2} 399.1821$, found 399.1820 .

4.6.6 (S)-N-(1-(2-amino-imidazo[1,2-a]pyridin-3-yl)-1-oxo-3-phenylpropan-2-yl)-3,4dimethoxybenzamide (2f)

White solid ( $\mathrm{m}=0.141 \mathrm{~g}, 89 \%)$, mp: 85.0-86.0 ${ }^{\circ} \mathrm{C} ;[\alpha]_{\mathrm{D}}{ }^{20}=+47.2^{\circ}\left(\mathrm{c} 1.0, \mathrm{CHCl}_{3}\right) ;{ }^{1} \mathrm{H}$ $\operatorname{NMR}\left(\mathrm{CDCl}_{3}, 300 \mathrm{MHz}\right): \delta \mathrm{ppm} 1.99(\mathrm{bs}, 1 \mathrm{H}), 3.25(\mathrm{dd}, 1 \mathrm{H}, J=12.0,6.0 \mathrm{~Hz}), 3.34$ 
(dd, $1 \mathrm{H}, J=15.0,6.0 \mathrm{~Hz}$ ), $3.83(\mathrm{~s}, 3 \mathrm{H}) 3.86(\mathrm{~s}, 3 \mathrm{H}), 5.77(\mathrm{dd}, 1 \mathrm{H}, J=15.0,6.0 \mathrm{~Hz}$ ), $6.27(\mathrm{bs}, 2 \mathrm{H}), 6.72(\mathrm{~d}, 1 \mathrm{H}, J=9.0 \mathrm{~Hz}), 6.82(\mathrm{td}, 1 \mathrm{H}, J=6.0,3.0 \mathrm{~Hz}), 7.11-7.24(\mathrm{~m}$, $4 \mathrm{H}), 7.29-7.42(\mathrm{~m}, 5 \mathrm{H}) 9.59$ (bs, $1 \mathrm{H}) ;{ }^{13} \mathrm{C} \mathrm{NMR}\left(\mathrm{CDCl}_{3}, 75 \mathrm{MHz}\right): \delta \mathrm{ppm} 38.6,54.8$, 56.1 (2C), 110.4, 110.7, 113.2, 114.4, 120.0, 126.0, 126.9, 128.6 (2C), 128.9, 129.3 (2C), 130.3, 131.1, 136.7, 148.0, 149.1, 152.3, 159.3, 167.9, 184.5 ; FT-IR $\left(\mathrm{cm}^{-1}\right)$ : $3331,2925,2852,1724,1577,1542,1494,1440,1339,1262,1229,1055,1019$, 757, 698 ; HPLC, $\mathrm{Tr}=1.35 \mathrm{~min} ; \mathrm{MS}\left(\mathrm{ESI}^{+}\right): \mathrm{m} / \mathrm{z} 445.1[\mathrm{M}+\mathrm{H}]^{+}$; HRMS calcd for $\mathrm{C}_{25} \mathrm{H}_{25} \mathrm{~N}_{4} \mathrm{O}_{4} 445.1876$, found 445.1877 .

4.6.7 (S)-N-(1-(2-amino-imidazo[1,2-a]pyridin-3-yl)-1-oxo-3-phenylpropan-2-yl)-2phenylacetamide (2g)

Yellow solid ( $m=0.120 \mathrm{~g}, 84 \%$ ); $\mathrm{mp}$ : $161.0-162.0^{\circ} \mathrm{C}$; $[\alpha]_{\mathrm{D}}^{20}=+23.8^{\circ}(c 0.5$, DMSO) ; ${ }^{1} \mathrm{H}$ NMR (DMSO d $\left.6,300 \mathrm{MHz}\right): \delta \mathrm{ppm} 3.06(\mathrm{dd}, 1 \mathrm{H}, J=13.6,8.0 \mathrm{~Hz}), 3.15(\mathrm{dd}, 1 \mathrm{H}, J$ $=13.6,6.0 \mathrm{~Hz}$ ), $3.35(\mathrm{bs}, 1 \mathrm{H}), 3.48(\mathrm{~d}, 1 \mathrm{H}, J=14.0 \mathrm{~Hz}), 3.55(\mathrm{~d}, 1 \mathrm{H}, J=14.0 \mathrm{~Hz})$, $5.33(\mathrm{dd}, 1 \mathrm{H}, J=13.0,8.0 \mathrm{~Hz}), 6.96(\mathrm{~s}, 2 \mathrm{H}), 7.02(\mathrm{t}, 1 \mathrm{H}, J=6.8 \mathrm{~Hz}), 7.21(\mathrm{~m}, 10 \mathrm{H})$, $7.36(\mathrm{~d}, 1 \mathrm{H}, J=8.7 \mathrm{~Hz}), 7.54(\mathrm{t}, 1 \mathrm{H}, J=8.0 \mathrm{~Hz}), 9.15(\mathrm{~d}, 1 \mathrm{H}, J=8.0 \mathrm{~Hz}) ;{ }^{13} \mathrm{C} N M R$ (DMSO $d_{6}, 75 \mathrm{MHz}$ ) : $\delta$ ppm 37.1, 41.5, 54.4, 107.1, 112.7, 113.6, 126.2, 126.3, 128.0 (2C), 128.1 (2C), 129.0 (2C), 129.1 (2C), 130.8, 135.8, 136.9, 137.6, 147.2, 158.8, 171.4, 183.7; FT-IR $\left(\mathrm{cm}^{-1}\right): 694,716,759,1065,1264,1317,1337,1454$, 1494, 1574, 1522, 1646, 1630, 2922, 3003, 3195, 3326 ; HPLC, Tr=1.6 min ; $\mathrm{MS}\left(\mathrm{ESI}^{+}\right): \mathrm{m} / \mathrm{z} 399.1[\mathrm{M}+\mathrm{H}]^{+}$; HRMS calcd for $\mathrm{C}_{24} \mathrm{H}_{23} \mathrm{~N}_{4} \mathrm{O}_{2} 399.1821$, found 399.1818

4.6.8 (S)-N-(1-(2-amino-imidazo[1,2-a]pyridin-3-yl)-1-oxo-3-phenylpropan-2yl)cinnamamide (2h)

Yellow solid ( $\mathrm{m}=0.017 \mathrm{~g}, 20 \%$ ); $\mathrm{mp}: 85.0-86.0^{\circ} \mathrm{C} ;[\alpha]_{\mathrm{D}}{ }^{20}=+16.5^{\circ}\left(\mathrm{c} 0.6, \mathrm{CHCl}_{3}\right) ;{ }^{1} \mathrm{H}$ NMR $\left(\mathrm{CDCl}_{3}, 300 \mathrm{MHz}\right): \delta \mathrm{ppm} 3.08(\mathrm{dd}, 1 \mathrm{H}, J=13.8,7.5 \mathrm{~Hz}$ ), $3.21(\mathrm{dd}, 1 \mathrm{H}, J=$ 13.9, $6.6 \mathrm{~Hz}$ ), $5.64(\mathrm{dd}, 1 \mathrm{H}, J=15.9,7.4 \mathrm{~Hz}), 6.15(\mathrm{~s}, 2 \mathrm{H}), 6.28(\mathrm{~d}, 1 \mathrm{H}, J=15.6 \mathrm{~Hz})$, $6.76(\mathrm{t}, 1 \mathrm{H}, J=6.8 \mathrm{~Hz}), 6.98-7.30(\mathrm{~m}, 13 \mathrm{H}), 7.44(\mathrm{~d}, 1 \mathrm{H}, J=15.6 \mathrm{~Hz}), 9.50(\mathrm{bs}, 1 \mathrm{H})$; ${ }^{13} \mathrm{C}$ NMR $\left(\mathrm{CDCl}_{3}, 75 \mathrm{MHz}\right): \delta \mathrm{ppm} 38.6,54.6,108.6,113.3,114.4,119.7,127.0$, $128.0(2 \mathrm{C}), 128.3,128.6(2 \mathrm{C}), 128.9$ (2C), $129.3(2 \mathrm{C}), 130.1,131.1,134.6,136.7$, 142.4, 148.2, 159.6, 166.8, 184.6; FT-IR $\left(\mathrm{cm}^{-1}\right): 3285$, 3185, 2974, 1720, 1574, 1494, 
1455, 1337, 1265, 1221, 979, 753, 731, 683; HPLC, Tr=1.5 min; MS $\left(E S I^{+}\right): \mathrm{m} / \mathrm{z}$ $411.1[\mathrm{M}+\mathrm{H}]^{+} ;$HRMS calcd for $\mathrm{C}_{25} \mathrm{H}_{23} \mathrm{~N}_{4} \mathrm{O}_{2} 411.1821$, found 411.1821

4.6.9 (S)-N-(1-(2-amino-imidazo[1,2-a]pyridin-3-yl)-1-oxo-3-phenylpropan-2-yl)-3phenylpropanamide (2i)

White solid ( $m=0.085 \mathrm{~g}, 59 \%)$; mp: $69.0^{\circ} \mathrm{C}-70.0^{\circ} \mathrm{C} ;[\alpha]_{\mathrm{D}}^{20}=+69.0^{\circ}\left(c 1.0, \mathrm{CHCl}_{3}\right)$; ${ }^{1} \mathrm{H} \mathrm{NMR}\left(\mathrm{CDCl}_{3}, 300 \mathrm{MHz}\right): \delta \mathrm{ppm} 2.43(\mathrm{t}, 2 \mathrm{H}, J=9.0 \mathrm{~Hz}), 2.83(\mathrm{t}, 2 \mathrm{H}, J=9.0 \mathrm{~Hz})$, $3.04(\mathrm{dd}, 1 \mathrm{H}, J=12.0,6.0 \mathrm{~Hz}$ ), $3.18(\mathrm{dd}, 1 \mathrm{H}, J=15.0,6.0 \mathrm{~Hz}$ ), $5.58(\mathrm{dd}, 1 \mathrm{H}, J=$ 15.0, $6.0 \mathrm{~Hz}$ ), 6.29 (bs, 2H), $6.81(\mathrm{td}, 1 \mathrm{H}, J=9.0,3.0 \mathrm{~Hz}), 6.94-7.18(\mathrm{~m}, 11 \mathrm{H}), 7.28$ (bs, $1 \mathrm{H}$ ), 7.37 (td, $1 \mathrm{H}, J=9.0,3.0 \mathrm{~Hz}$ ), 9.58 (bs, $1 \mathrm{H}) ;{ }^{13} \mathrm{C} \mathrm{NMR}\left(\mathrm{CDCl}_{3}, 75 \mathrm{MHz}\right): \delta$ ppm 31.6, 38.0, 38.3, 54.2, 108.4, 113.2, 114.3, 126.3, 126.9, 128.3 (4C), 128.4, 128.6 (2C), 129.2 (2C), 131.1, 136.8, 140.5, 148.0, 159.4, 173.2, 184.3; FT-IR $\left(\mathrm{cm}^{-1}\right)$ : 3325, 3178, 3028, 1734, 1644, 1571, 1495, 1452, 1339, 1264, 1065, 762; HPLC, Tr= 1.6 min; MS $\left(\mathrm{ESI}^{+}\right): \mathrm{m} / \mathrm{z} 413.3[\mathrm{M}+\mathrm{H}]^{+} ;$HRMS calcd for $\mathrm{C}_{25} \mathrm{H}_{25} \mathrm{~N}_{4} \mathrm{O}_{2} 413.1978$, found 413.1981 .

\subsection{Enzyme and inhibition assays.}

The enzyme activities of KLK5, KLK7, KLK8 and KLK14 (R\&D Systems, France) were determined using 96-well plates monitored using a BMG Fluostar apparatus. The hydrolysis of the appropriate fluorogenic substrate was measured $\left(\lambda_{\text {exc }}=360 \mathrm{~nm}, \lambda_{\text {em }}=460 \mathrm{~nm}\right)$ for $15 \mathrm{~min}$ at $37^{\circ} \mathrm{C}$ in the presence of untreated enzyme (control) and treated enzyme incubated with a test compound. Substrates (Bachem, Weil am Rhein, Germany) were previously dissolved in DMSO, with the final solvent concentration kept constant at $2 \%(\mathrm{v} / \mathrm{v})$. The composition of the activity buffers was (pH 8.0): $50 \mathrm{mM}$ Tris- $\mathrm{HCl}$, Tween $200.01 \%(\mathrm{v} / \mathrm{v})$ and $150 \mathrm{mM} \mathrm{NaCl}$ for KLK5, $1 \mathrm{M} \mathrm{NaCl}$ for KLK7 and KLK14. The final concentrations were $0.6 \mathrm{nM}$ (KLK5), $100 \mu \mathrm{M}$ (Boc-Val-Pro-Arg-AMC); 7.6 nM (KLK7), $40 \mu \mathrm{M}$ (Suc-Leu-Leu-Val-Tyr-AMC);

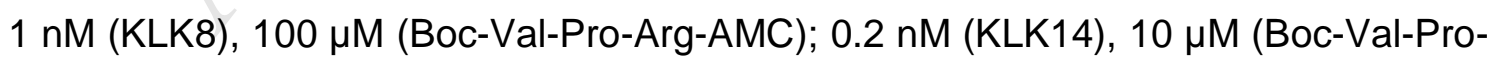
Arg-AMC). Compounds were tested in triplicate for different concentrations to detect their inhibitory potency. The enzyme and the inhibitors were incubated for $15 \mathrm{~min}$ before the determination of the enzyme activity. Initial rates determined in control experiments $\left(V_{0}\right)$ were considered to be $100 \%$ of the proteinase activity; initial rates 
$\left(\mathrm{V}_{\mathrm{i}}\right)$ that were below $100 \%$ in the presence of a tested compound were considered to be inhibitions. The inhibitory activity of compounds was expressed as $\mathrm{IC}_{50}$ (inhibitor concentrations giving $50 \%$ inhibition). The values of $\mathrm{IC}_{50}$ were calculated by fitting the experimental data either to equation $1: \%$ Inhibition $=100 \times\left(1-\mathrm{V}_{\mathrm{i}} / \mathrm{V}_{0}\right)=100[\mathrm{I}]_{0} /\left(\mathrm{IC}_{50}+\right.$ $\left.[I]_{0}\right)$, or equation 2, \% Inhibition $=100[]_{0}{ }^{\mathrm{nH}} /\left(\mathrm{IC}_{50}{ }^{\mathrm{nH}}+[]_{0}{ }^{\mathrm{nH}}\right)$ with $\mathrm{n}_{\mathrm{H}}=$ Hill number.

\subsection{Mechanisms of inhibition}

Reversibility was analysed by diluting the reaction mixtures (dilution factor of 40 ) after 15 and 60 min preincubation of the enzyme with inhibitor. Aliquots of reaction mixtures $(2.5 \mu \mathrm{L})$ were added to $97.5 \mu \mathrm{L}$ of buffer containing the fluorogenic substrate (experimental conditions identical to the routine protocol used for a given enzyme). The mechanism of inhibition was determined by varying substrate and inhibitor concentrations and using classical Lineweaver-Burk plots.

\subsection{Structure-based Molecular Docking.}

The docking study of compound 10 was carried out using the docking engine Molegro virtual docker version 5.5.0. The enzyme structures used for the docking were obtained from 2QXH PDB file corresponding to KLK7 complexed with succinylAla-Ala-Pro-Phe chloromethylketone inhibitor. Heteroatoms and ligands were removed from the crystal structures and hydrogen atoms were added. The scoring function Moldock Score and the Moldock SE search algorithm were used; the resolution of the grid for estimation of the computed binding affinity was $0.3 \AA$ with a radius of $15 \AA$ around the catalytic triad residues. Fifteen runs were launched and up to 50 (maximum) poses subsequently analyzed. Figures were prepared with Pymol (DeLano Scientific LLC, San Carlos, CA, USA).

\subsection{Cell culture and cytotoxicity assay.}

PC3 and SW-60 cells were kindly supplied by Dr Dalila Darmoul (INSERM U976, Université Paris Diderot, and Sorbonne Paris Cité). Cells were spread at a rate of 5000 cells per well of 96 -well plates in $100 \mu \mathrm{L}$ of medium/well consisting of DMEM medium complemented with fetal bovine serum (10\%), penicillin $(100 \mu \mathrm{g} / \mathrm{mL})$ and streptomycin $(100 \mu \mathrm{g} / \mathrm{mL})$, at $37^{\circ} \mathrm{C}$ and $5 \%$ of $\mathrm{CO}_{2} .20 \mathrm{~h}$ after seeding the cells, $1 \mu \mathrm{L}$ of different concentrations of each inhibitor previously dissolved in DMSO was added to the wells. An equivalent volume of DMSO was used in controls for a final DMSO 
concentration of $1 \%(\mathrm{v} / \mathrm{v})$. For each condition, at least three wells were measured. 48 to $72 \mathrm{~h}$ after incubation, culture medium was removed and replaced by $100 \mu \mathrm{L}$ of new medium/well (without phenol red) supplemented with XTT $(0,3 \mathrm{mg} / \mathrm{mL})$ and PMS $(8,3$ $\mu \mathrm{M})$. After $3 \mathrm{~h}$ incubation the absorbance at $485 \mathrm{~nm}$ was read. The XTT assay is based on the mitochondrial deshydrogenase activity. The relative cell viability was expressed as a percentage to the viability of cells treated with DMSO only.

\section{References}

[1] G.P. Gupta, J. Massagué, Cancer Metastasis: Building a Framework, Cell, 127 (2006) 679-695.

[2] C.A. Borgono, E.P. Diamandis, The emerging roles of human tissue kallikreins in cancer, Nat. Rev. Cancer, 4 (2004) 876-890.

[3] C.A. Borgono, I.P. Michael, E.P. Diamandis, Human tissue kallikreins: physiologic roles and applications in cancer, Mol. Cancer Res., 2 (2004) 257-280.

[4] M. Debela, V. Magdolen, N. Schechter, M. Valachova, F. Lottspeich, C.S. Craik, Y. Choe, W. Bode, P. Goettig, Specificity profiling of seven human tissue kallikreins reveals individual subsite preferences, J. Biol. Chem., 281 (2006) 25678-25688.

[5] M. Debela, P. Hess, V. Magdolen, N.M. Schechter, T. Steiner, R. Huber, W. Bode, P. Goettig, Chymotryptic specificity determinants in the $1.0 \mathrm{~A}$ structure of the zincinhibited human tissue kallikrein 7, Proc. Natl Acad. Sci. U.S.A., 104 (2007) 1608616091.

[6] V.C. Ramani, R.S. Haun, Expression of kallikrein 7 diminishes pancreatic cancer cell adhesion to vitronectin and enhances urokinase-type plasminogen activator receptor shedding, Pancreas, 37 (2008) 399-404.

[7] M. Devetzi, T. Trangas, A. Scorilas, D. Xynopoulos, M. Talieri, Parallel overexpression and clinical significance of kallikrein-related peptidases 7 and 14 (KLK7KLK14) in colon cancer, Thromb. Haemost., 109 (2013) 716-725.

[8] L. Mo, Zhang, J., Shi, J., Xuan, Q., Yang, X., Qin, M., Lee, C., Klocker, H., Li, QQ., Mo, Z., Human kallikrein 7 induces epithelial-mesenchymal transition-like changes in prostate carcinoma cells: a role in prostate cancer invasion and progression., Anticancer Res., 30 (2010) 3413-3420.

[9] C.A. Borgono, I.P. Michael, N. Komatsu, A. Jayakumar, R. Kapadia, G.L. Clayman, G. Sotiropoulou, E.P. Diamandis, A potential role for multiple tissue kallikrein serine proteases in epidermal desquamation, J. Biol. Chem., 282 (2007) 3640-3652.

[10] T. Egelrud, M. Brattsand, P. Kreutzmann, M. Walden, K. Vitzithum, U.C. Marx, W.G. Forssmann, H.J. Magert, hK5 and hK7, two serine proteinases abundant in human skin, are inhibited by LEKTI domain 6, Br J Dermatol, 153 (2005) 1200-1203.

[11] M. Brattsand, K. Stefansson, C. Lundh, Y. Haasum, T. Egelrud, A proteolytic cascade of kallikreins in the stratum corneum, J. Invest. Dermatol., 124 (2005) 198203.

[12] C. Caubet, N. Jonca, M. Brattsand, M. Guerrin, D. Bernard, R. Schmidt, T. Egelrud, M. Simon, G. Serre, Degradation of corneodesmosome proteins by two serine proteases of the kallikrein family, SCTE/KLK5/hK5 and SCCE/KLK7/hK7, J. Invest. Dermatol., 122 (2004) 1235-1244. 
[13] A. Hovnanian, Netherton syndrome: skin inflammation and allergy by loss of protease inhibition, Cell Tissue Res., 351 (2013) 289-300.

[14] S. Wang, S. Olt, N. Schoefmann, A. Stuetz, A. Winiski, B. Wolff-Winiski, SPINK5 knockdown in organotypic human skin culture as a model system for Netherton syndrome: effect of genetic inhibition of serine proteases kallikrein 5 and kallikrein 7 , Exp. Dermatol., (2014).

[15] L. Hansson, A. Backman, A. Ny, M. Edlund, E. Ekholm, B. Ekstrand Hammarstrom, J. Tornell, P. Wallbrandt, H. Wennbo, T. Egelrud, Epidermal overexpression of stratum corneum chymotryptic enzyme in mice: a model for chronic itchy dermatitis, J. Invest. Dermatol., 118 (2002) 444-449.

[16] S. Schultz, A. Saalbach, J.T. Heiker, R. Meier, T. Zellmann, J.C. Simon, A.G. Beck-Sickinger, Proteolytic activation of prochemerin by kallikrein 7 breaks an ionic linkage and results in C-terminal rearrangement, Biochem. J., 452 (2013) 271-280.

[17] P. Goettig, V. Magdolen, H. Brandstetter, Natural and synthetic inhibitors of kallikrein-related peptidases (KLKs), Biochimie, 92 (2010) 1546-1567.

[18] C. Deraison, C. Bonnart, F. Lopez, C. Besson, R. Robinson, A. Jayakumar, F. Wagberg, M. Brattsand, J.P. Hachem, G. Leonardsson, A. Hovnanian, LEKTI fragments specifically inhibit KLK5, KLK7, and KLK14 and control desquamation through a pH-dependent interaction, Mol. Biol. Cell, 18 (2007) 3607-3619.

[19] S.J. de Veer, S.S. Ukolova, C.A. Munro, J.E. Swedberg, A.M. Buckle, J.M. Harris, Mechanism-based selection of a potent kallikrein-related peptidase 7 inhibitor from a versatile library based on the sunflower trypsin inhibitor SFTI-1, Biopolymers, (2013).

[20] T.S. Teixeira, R.F. Freitas, O. Abrahao, Jr., K.F. Devienne, L.R. de Souza, S.I. Blaber, M. Blaber, M.Y. Kondo, M.A. Juliano, L. Juliano, L. Puzer, Biological evaluation and docking studies of natural isocoumarins as inhibitors for human kallikrein 5 and 7, Bioorg. Med. Chem. Lett., 21 (2011) 6112-6115.

[21] R.F. Freitas, T.S. Teixeira, T.G. Barros, J.A. Santos, M.Y. Kondo, M.A. Juliano, L. Juliano, M. Blaber, O.A. Antunes, O. Abrahao, Jr., S. Pinheiro, E.M. Muri, L. Puzer, Isomannide derivatives as new class of inhibitors for human kallikrein 7, Bioorg. Med. Chem. Lett., 22 (2012) 6072-6075.

[22] J.P. Oliveira, R.F. Freitas, L.S. Melo, T.G. Barros, J.A. Santos, M.A. Juliano, S. Pinheiro, M. Blaber, L. Juliano, E.M. Muri, L. Puzer, Isomannide-based peptidomimetics as inhibitors for human tissue kallikreins 5 and 7, ACS Med. Chem. Lett., 5 (2014) 128-132.

[23] X. Tan, C. Bertonati, L. Qin, L. Furio, C. El Amri, A. Hovnanian, M. ReboudRavaux, B.O. Villoutreix, Identification by in silico and in vitro screenings of small organic molecules acting as reversible inhibitors of kallikreins, Eur. J. Med. Chem., 70 (2013) 661-668.

[24] X. Tan, L. Furio, M. Reboud-Ravaux, B.O. Villoutreix, A. Hovnanian, C. El Amri, $1,2,4$-Triazole derivatives as transient inactivators of kallikreins involved in skin diseases, Bioorg. Med. Chem. Lett., 23 (2013) 4547-4551.

[25] N. Masurier, R. Aruta, V. Gaumet, S. Denoyelle, E. Moreau, V. Lisowski, J. Martinez, L.T. Maillard, Selective C-Acylation of 2-Aminoimidazo[1,2-a]pyridine: Application to the Synthesis of Imidazopyridine-Fused [1,3]Diazepinones, J. Org. Chem., 77 (2012) 3679-3685.

[26] N. Masurier, E. Debiton, A. Jacquemet, A. Bussiere, J.M. Chezal, A. Ollivier, D. Tetegan, M. Andaloussi, M.J. Galmier, J. Lacroix, D. Canitrot, J.C. Teulade, R.C. Gaudreault, O. Chavignon, E. Moreau, Imidazonaphthyridine systems (part 2): Functionalization of the phenyl ring linked to the pyridine pharmacophore and its 
replacement by a pyridinone ring produces intriguing differences in cytocidal activity, Eur. J. Med. Chem., 52 (2012) 137-150.

[27] N. Masurier, E. Moreau, C. Lartigue, V. Gaumet, J.-M. Chezal, A. Heitz, J.-C. Teulade, O. Chavignon, New Opportunities with the Duff Reaction, J. Org. Chem., 73 (2008) 5989-5992.

[28] M. Andaloussi, E. Moreau, N. Masurier, J. Lacroix, R.C. Gaudreault, J.-M. Chezal, A. El Laghdach, D. Canitrot, E. Debiton, J.-C. Teulade, O. Chavignon, Novel imidazo[1,2-a]naphthyridinic systems (part 1): Synthesis, antiproliferative and DNAintercalating activities, Eur. J. Med. Chem., 43 (2008) 2505-2517.

[29] G. Chaubet, L.T. Maillard, J. Martinez, N. Masurier, A tandem aza-Friedel-Crafts reaction/Hantzsch cyclization: a simple procedure to access polysubstituted 2-amino1,3-thiazoles, Tetrahedron, 67 (2011) 4897-4904.

[30] L.T. Maillard, S. Bertout, O. Quinonero, G. Akalin, G. Turan-Zitouni, P. Fulcrand, F. Demirci, J. Martinez, N. Masurier, Synthesis and anti-Candida activity of novel 2hydrazino-1,3-thiazole derivatives, Bioorg. Med. Chem. Lett., 23 (2013) 1803-1807.

[31] A. Gallud, O. Vaillant, L.T. Maillard, D.P. Arama, J. Dubois, M. Maynadier, V. Lisowski, M. Garcia, J. Martinez, N. Masurier, Imidazopyridine-fused [1,3]diazepinones: Synthesis and antiproliferative activity, Eur. J. Med. Chem., 75 (2014) 382-390.

[32] D.P. Arama, V. Lisowski, E. Scarlata, P. Fulcrand, L.T. Maillard, J. Martinez, N. Masurier, An efficient synthesis of pyrido-imidazodiazepinediones, Tetrahedron Lett., 54 (2013) 1364-1367.

[33] M.E. Kaighn, K.S. Narayan, Y. Ohnuki, J.F. Lechner, L.W. Jones, Establishment and characterization of a human prostatic carcinoma cell line (PC-3). Invest. Urol., 17 (1979) 16-23.

[34] A. Leibovitz, J.C. Stinson, W.B. McCombs III, C.E. McCoy, K.C. Mazur, N.D. Mabry, Classification of human colorectal adenocarcinoma cell lines., Cancer Res., 36 (1976) 4562-4569.

[35] F. Walker, P. Nicole, A. Jallan, A. Soosaipillai, V. Mosbach, K. Oikonomopoulou, E.P. Diamandis, V. Magdolen, D. Darmoul, Kallikrein-related peptidase 7 (KLK7) is a proliferative factor that is aberrantly expressed in human colon cancer, Biol. Chem., 395 (2014) 1075-1086.

\section{ACKNOWLEDGMENTS}

This work was supported by Université of Montpellier, Institut National pour la Recherche Médicale (INSERM), Université Pierre et Marie Curie (UPMC), Centre National de la Recherche Scientifique (CNRS), and Région Languedoc-Roussillon (Chercheur d'avenir 2011 grant to V.L.). The authors are grateful to the French Ministry of Research and Education for F. S. and the Mali Government for D.A PhD fellowships. CE and NM thanks Prof Michèle Reboud-Ravaux and Dr Alain Chavanieu for fruitful discussions and are grateful to Christina Lymperopoulou and Isabelle Bequignon for technical assistance. 


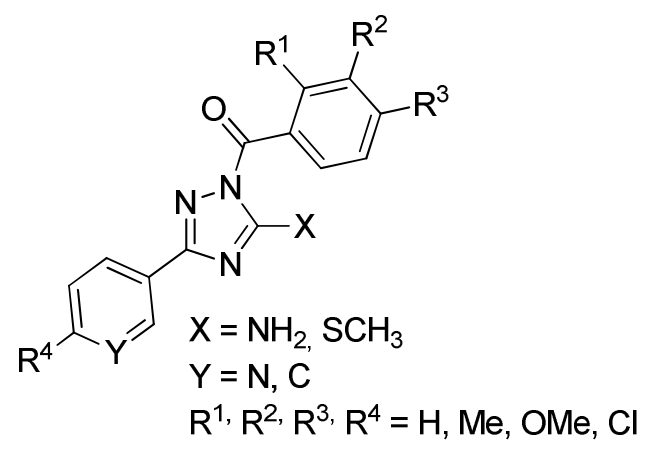

Acyl-1,2,4-triazoles

$0.04 \mu \mathrm{M}<\mathrm{IC}_{50}<0.66 \mu \mathrm{M}$<smiles>COc1cc2c(OC)c3cc(C)oc(=O)c3c(O)c2c(O)c1-c1c(OC)cc2c(OC)c3cc(C)oc(=O)c3c(O)c2c1O</smiles>

8, 8'-Paepalantine $\mathrm{IC}_{50}=112.4 \mu \mathrm{M}$<smiles>[R]CC(NC([R7])=O)C(=O)[X]C1CO[C@@H]2[C@@H](CBr)CO[C@H]12</smiles>

$\mathrm{X}=\mathrm{O}, \mathrm{NH}$ $\mathrm{R}^{5}=$ Alkyl, Aromatic $\mathrm{R}^{6}=\mathrm{Ph}, \mathrm{Me}$, Amino-acids Isomannide derivatives $10.2 \mu \mathrm{M}<\mathrm{IC}_{50}<205.2 \mu \mathrm{M}$<smiles>Nc1ccc2nc(SCn3c(-c4cccc(C(F)(F)F)c4)nc4ccccc4c3=O)[nH]c2c1</smiles>

Figure 1. Heterocyclic compounds reported as KLK7 inhibitors 


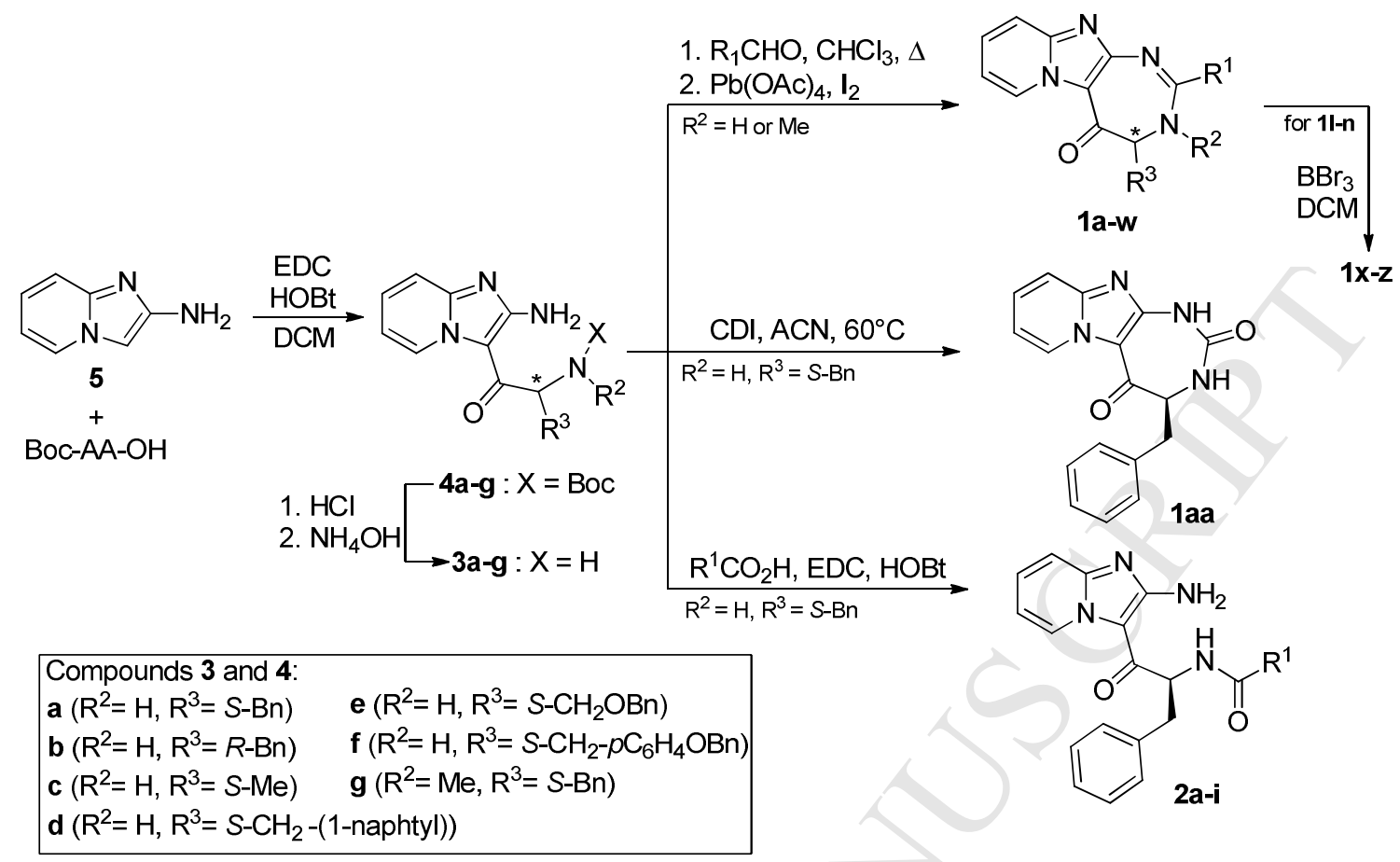

Reagents and conditions: Boc-AA-OH $=$ Boc-Phe-OH, Boc-D-Phe-OH, Boc-Ala-OH, Boc-Ser(Bn)-OH, Boc-1-Nal-OH, Boc-Tyr(Bn)-OH or Boc-N-Me-Ala-OH

Scheme 1. Synthesis of compounds $1 \mathrm{a}-\mathbf{w}, \mathbf{1}$ aa and $\mathbf{2 a}-\mathbf{i}\left(R^{1}, R^{2}\right.$ and $R^{3}$ substituents are referenced in Table 1). 


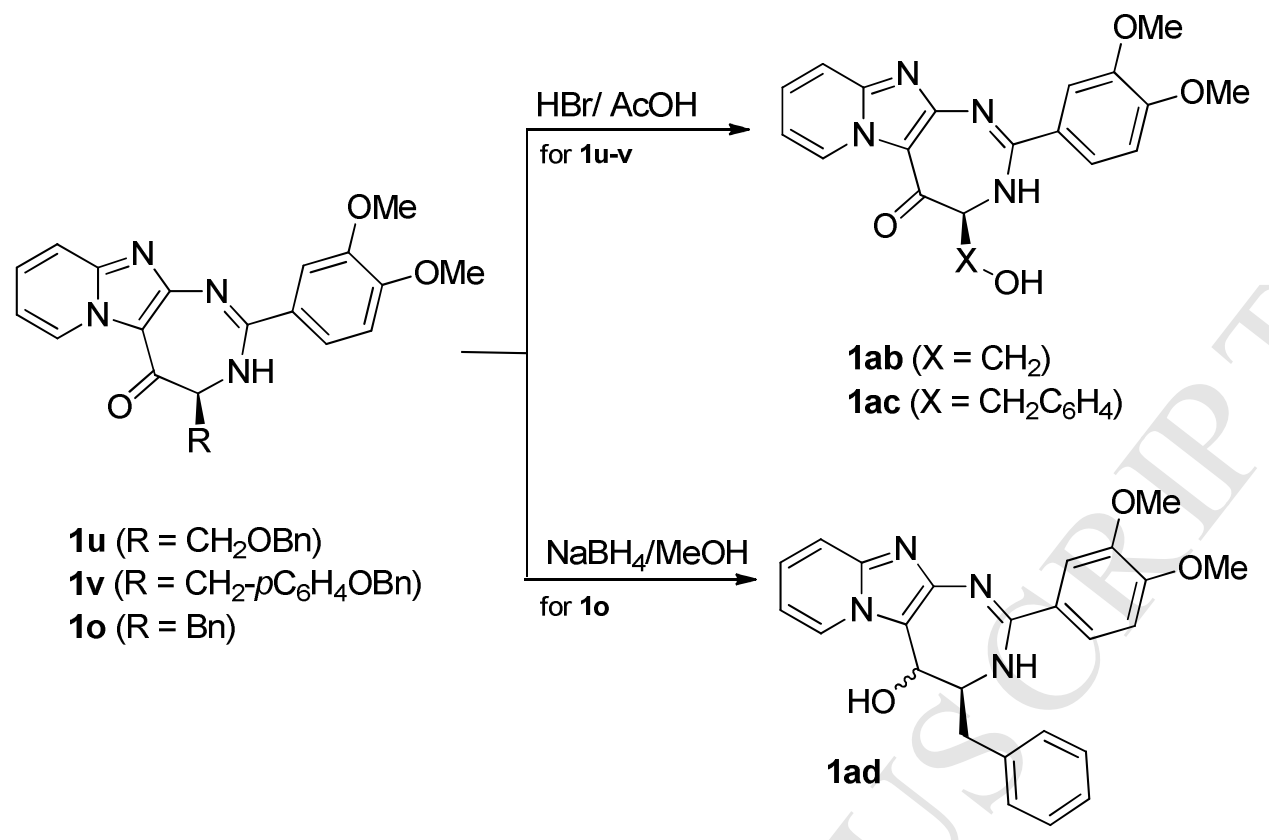

Scheme 2. Synthesis of compounds 1ab-1ad. 
Table 1. Structure and $\mathrm{IC}_{50}$ against KLK7 of compounds 1 and 2 after 15 min of incubation at $\mathrm{pH} 8.0$ and $37^{\circ} \mathrm{C}$. ${ }^{1:} \mathrm{ni}=$ no inhibition $(<30 \%$ inhibition at $50 \mu \mathrm{M})$.

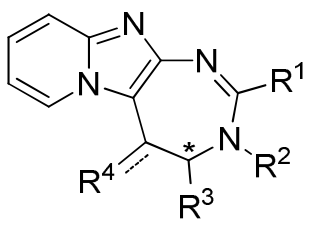

1a-1ad

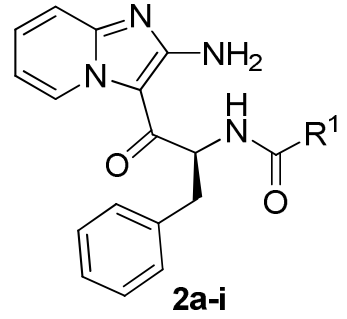

\begin{tabular}{|c|c|c|c|c|c|}
\hline \multicolumn{5}{|c|}{ Compounds } & \multirow{2}{*}{$\mathrm{IC}_{50}(\mu \mathrm{M})$} \\
\hline & $\mathbf{R}^{1}$ & $\mathbf{R}^{2}$ & $\mathbf{R}^{3}$ & $\mathbf{R}^{4}$ & \\
\hline $1 \mathrm{a}$ & 2-Me- $\mathrm{C}_{6} \mathrm{H}_{4}$ & $\mathrm{H}$ & $(S)-\mathrm{Bn}$ & $=\mathrm{O}$ & $57.0 \pm 1.0$ \\
\hline $1 \mathrm{bb}$ & 3-Me- $\mathrm{C}_{6} \mathrm{H}_{4}$ & $\mathrm{H}$ & $(S)-\mathrm{Bn}$ & $=\mathrm{O}$ & $\mathrm{ni}^{1}$ \\
\hline $1 \mathrm{c}$ & 4-Me- $\mathrm{C}_{6} \mathrm{H}_{4}$ & $\mathrm{H}$ & $(S)-\mathrm{Bn}$ & $=\mathrm{O}$ & $68.0 \pm 3.1$ \\
\hline 1d & 4-OMe- $\mathrm{C}_{6} \mathrm{H}_{4}$ & $\mathrm{H}$ & $(S)$-Bn & $=\mathrm{O}$ & $72.0 \pm 1.9$ \\
\hline 1e & $2-\mathrm{Me}-\mathrm{C}_{6} \mathrm{H}_{4}$ & $\mathrm{H}$ & $(R)-\mathrm{Bn}$ & $=\mathrm{O}$ & $95.9 \pm 1.7$ \\
\hline If & $\mathrm{C}_{6} \mathrm{H}_{5}$ & $\mathrm{H}$ & $(S)-\mathrm{Bn}$ & $=\mathrm{O}$ & ni \\
\hline $1 \mathrm{~g}$ & $4-\mathrm{BrC}_{6} \mathrm{H}_{4}$ & $\mathrm{H}$ & $(S)-\mathrm{Bn}$ & $=\mathrm{O}$ & ni \\
\hline 1h & $4-\mathrm{NO}_{2} \mathrm{C}_{6} \mathrm{H}_{4}$ & $\mathrm{H}$ & $(S)-\mathrm{Bn}$ & $=\mathrm{O}$ & ni \\
\hline $1 \mathbf{1 i}$ & 3-pyridinyl & $\mathrm{H}$ & $(S)-\mathrm{Bn}$ & $=\mathrm{O}$ & ni \\
\hline $1 \mathrm{j}$ & $\mathrm{CH}_{2} \mathrm{CH}\left(\mathrm{CH}_{3}\right)_{2}$ & $\mathrm{H}$ & $(S)$-Bn & $=\mathrm{O}$ & ni \\
\hline 1k & 2,4-diMe- $\mathrm{C}_{6} \mathrm{H}_{3}$ & $\mathrm{H}$ & $(S)-\mathrm{Bn}$ & $=\mathrm{O}$ & $83.9 \pm 1.7$ \\
\hline 11 & $2-\mathrm{OMe}-\mathrm{C}_{6} \mathrm{H}_{4}$ & $\mathrm{H}$ & $(S)-\mathrm{Bn}$ & $=\mathrm{O}$ & ni \\
\hline $1 \mathrm{~m}$ & 3 -OMe- $\mathrm{C}_{6} \mathrm{H}_{4}$ & $\mathrm{H}$ & $(S)-\mathrm{Bn}$ & $=\mathrm{O}$ & ni \\
\hline 1n & 2,5-diOMe- $\mathrm{C}_{6} \mathrm{H}_{3}$ & $\mathrm{H}$ & $(S)-\mathrm{Bn}$ & $=\mathrm{O}$ & $80.9 \pm 2.5$ \\
\hline 10 & 3,4-diOMe- $\mathrm{C}_{6} \mathrm{H}_{3}$ & $\mathrm{H}$ & $(S)-\mathrm{Bn}$ & $=\mathrm{O}$ & $33.5 \pm 1.5$ \\
\hline $1 \mathrm{p}$ & $3,4,5$-triOMe- $\mathrm{C}_{6} \mathrm{H}_{2}$ & $\mathrm{H}$ & $(S)-\mathrm{Bn}$ & $=\mathrm{O}$ & $55.7 \pm 2.3$ \\
\hline $1 q$ & 2-Me- $\mathrm{C}_{6} \mathrm{H}_{4}$ & $\mathrm{H}$ & $(S)$-(1-naphtyl) $\mathrm{CH}_{2}$ & $=\mathrm{O}$ & ni \\
\hline $\mathbf{1 r}$ & $2-\mathrm{Me}-\mathrm{C}_{6} \mathrm{H}_{4}$ & $\mathrm{H}$ & $(S)-\mathrm{Me}$ & $=\mathrm{O}$ & ni \\
\hline 1s & 3,4-diMeO- $\mathrm{C}_{6} \mathrm{H}_{3}$ & $\mathrm{H}$ & $(S)-\mathrm{Me}$ & $=\mathrm{O}$ & ni \\
\hline $1 \mathrm{t}$ & $2-\mathrm{Me}-\mathrm{C}_{6} \mathrm{H}_{4}$ & $\mathrm{H}$ & $(S)-\mathrm{BnOCH}_{2}$ & $=\mathrm{O}$ & ni \\
\hline $\mathbf{1 u}$ & 3,4-diMeO- $\mathrm{C}_{6} \mathrm{H}_{3}$ & $\mathrm{H}$ & $(S)-\mathrm{BnOCH}_{2}$ & $=\mathrm{O}$ & ni \\
\hline $1 \mathrm{v}$ & 3,4-diMeO- $\mathrm{C}_{6} \mathrm{H}_{3}$ & $\mathrm{H}$ & $(S)-4-\mathrm{BnOC}_{6} \mathrm{H}_{4} \mathrm{CH}_{2}$ & $=\mathrm{O}$ & ni \\
\hline $1 w$ & 3,4-diMeO- $\mathrm{C}_{6} \mathrm{H}_{3}$ & $\mathrm{Me}$ & $(S)-\mathrm{Bn}$ & $=\mathrm{O}$ & ni \\
\hline $\mathbf{1 x}$ & $2-\mathrm{HO}-\mathrm{C}_{6} \mathrm{H}_{4}$ & $\mathrm{H}$ & $(S)-\mathrm{Bn}$ & $=\mathrm{O}$ & ni \\
\hline
\end{tabular}




\begin{tabular}{|c|c|c|c|c|c|}
\hline $1 y$ & $3-\mathrm{HO}-\mathrm{C}_{6} \mathrm{H}_{4}$ & $\mathrm{H}$ & $(S)-\mathrm{Bn}$ & $=\mathrm{O}$ & $124.8 \pm 1.4$ \\
\hline $\mathbf{1 z}$ & 2,5-diHO- $\mathrm{C}_{6} \mathrm{H}_{3}$ & $\mathrm{H}$ & $(S)-\mathrm{Bn}$ & $=\mathrm{O}$ & ni \\
\hline 1aa & $=\mathrm{O}$ & $\mathrm{H}$ & $(S)-\mathrm{Bn}$ & $=\mathrm{O}$ & ni \\
\hline 1ab & 3,4-diMeO- $\mathrm{C}_{6} \mathrm{H}_{3}$ & $\mathrm{H}$ & $(S)-\mathrm{HOCH}_{2}$ & $=\mathrm{O}$ & ni \\
\hline 1 ac & 3,4-diMeO- $\mathrm{C}_{6} \mathrm{H}_{3}$ & $\mathrm{H}$ & $(S)-4-\mathrm{HOC}_{6} \mathrm{H}_{4} \mathrm{CH}_{2}$ & $=\mathrm{O}$ & ni \\
\hline 1ad & 3,4-diMeO- $\mathrm{C}_{6} \mathrm{H}_{3}$ & $\mathrm{H}$ & $(S)-\mathrm{Bn}$ & $\mathrm{OH}$ & ni \\
\hline $2 \mathbf{a}$ & $\mathrm{Ph}$ & - & - & - & ni \\
\hline $2 \mathbf{b}$ & 2-pyridinyl & - & - & - & ni \\
\hline $2 c$ & 4-pyridinyl & - & - & - & ni \\
\hline $2 d$ & 2-pyrrolyl & - & - & - & ni \\
\hline $2 e$ & 2-Me- $\mathrm{C}_{6} \mathrm{H}_{4}$ & - & - & - & $135.4 \pm 9.2$ \\
\hline $2 f$ & $3,4-$ diOMe- $\mathrm{C}_{6} \mathrm{H}_{3}$ & - & - & - & ni \\
\hline $2 g$ & $\mathrm{CH}_{2}-\mathrm{Ph}$ & - & - & - & $149.2 \pm 19.2$ \\
\hline $2 \mathrm{~h}$ & $\mathrm{CH}=\mathrm{CH}-\mathrm{Ph}$ & - & - & - & ni \\
\hline $2 \mathbf{i}$ & $\mathrm{CH}_{2}-\mathrm{CH}_{2}-\mathrm{Ph}$ & - & 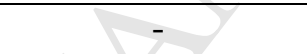 & - & ni \\
\hline
\end{tabular}


Table 2. Evaluation of cytotoxic effect of compounds $1 \mathbf{k}, \mathbf{1} \mathbf{n}-\mathbf{p}$ on human cancer cell lines HeLa, PC-3 and SW-620. Cytotoxicity is expressed as $\mathrm{EC}_{50}$, which refers to the concentration that induces $50 \%$ of cell death determined by XTT assay.

\begin{tabular}{cccc}
\hline Compounds & \multicolumn{3}{c}{ Cell lines } \\
\hline HeLa & PC-3 & SW-620 \\
\hline $\mathbf{1 k}$ & $\mathrm{nc}^{1}$ & $\mathrm{nc}$ & $67.8 \pm 3.4$ \\
$\mathbf{1 n}$ & $40.0 \pm 1.5$ & $\mathrm{nc}$ & $\mathrm{nc}$ \\
$\mathbf{1 0}$ & $24.3 \pm 1.6$ & $64.8 \pm 2.3$ & $\mathrm{nc}$ \\
$\mathbf{1 p}$ & $53.8 \pm 3.5$ & $\mathrm{nc}$ & $\mathrm{nc}$ \\
\hline
\end{tabular}






Figure 2: Study of the compound 1a pharmacomodulation 
A.

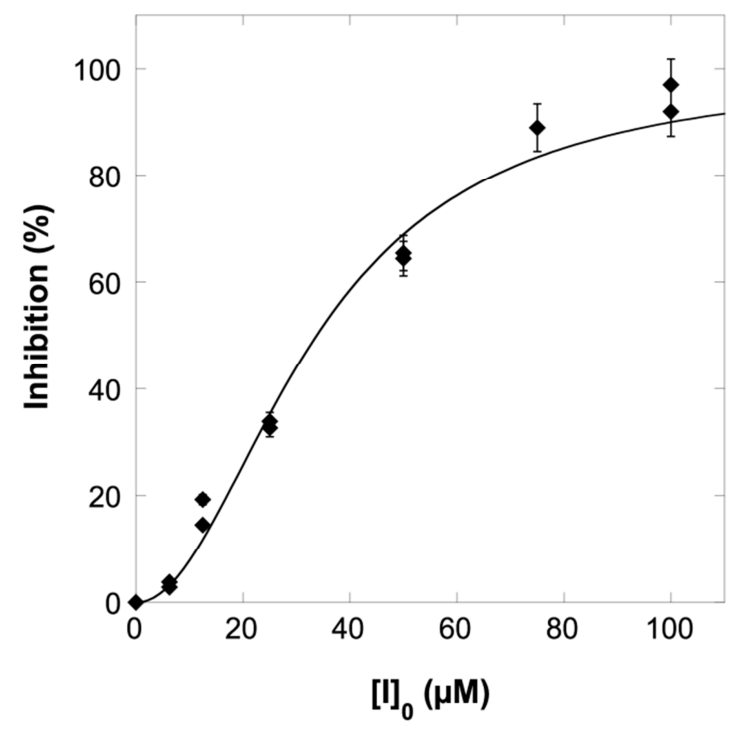

B.



C.

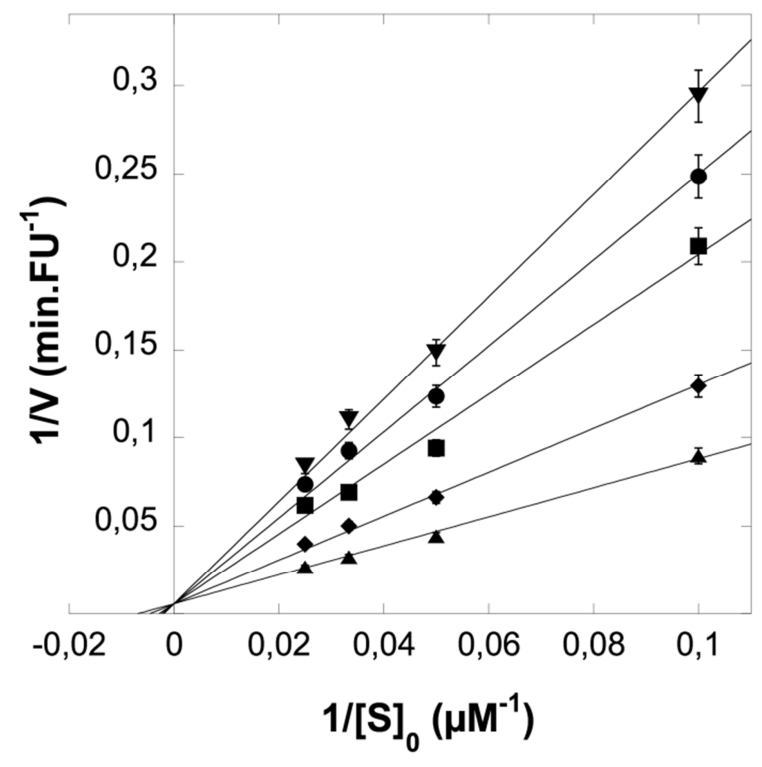

Figure 3. Inhibition of KLK7 by compound 10. A- $I C_{50}$ curve after $15 \mathrm{~min}$ incubation of $\mathrm{KLK} 7(7.6 \mathrm{nM})$ at $\mathrm{pH} 8.0$ and $37^{\circ} \mathrm{C}$ in $50 \mathrm{mM}$ TRIS-HCl pH 8.0, Tween $200.01 \%(\mathrm{v} / \mathrm{v})$ and $1 \mathrm{M} \mathrm{NaCl}$. The enzyme activity was monitored at $40 \mu \mathrm{M}$ final concentration of substrat (Suc-Leu-Leu-Leu-Val-Tyr-AMC). B- Remaining activity of hK7 in absence of inhibitor (black), after 15 min incubation with $50 \mu \mathrm{M}$ of compound 10 (grey), after dilution (1/40) of the formed complex KLK7-10 (striped). CLineweaver-Burk plot at different concentrations of 10: $0(\mathbf{\Delta}) ; 6,25 \mu \mathrm{M}(\bullet) ; 12,5 \mu \mathrm{M}$ $(\boldsymbol{\square}) ; 25 \mu \mathrm{M}(\bullet) ; 50 \mu \mathrm{M}(\boldsymbol{\nabla})$. 
A.
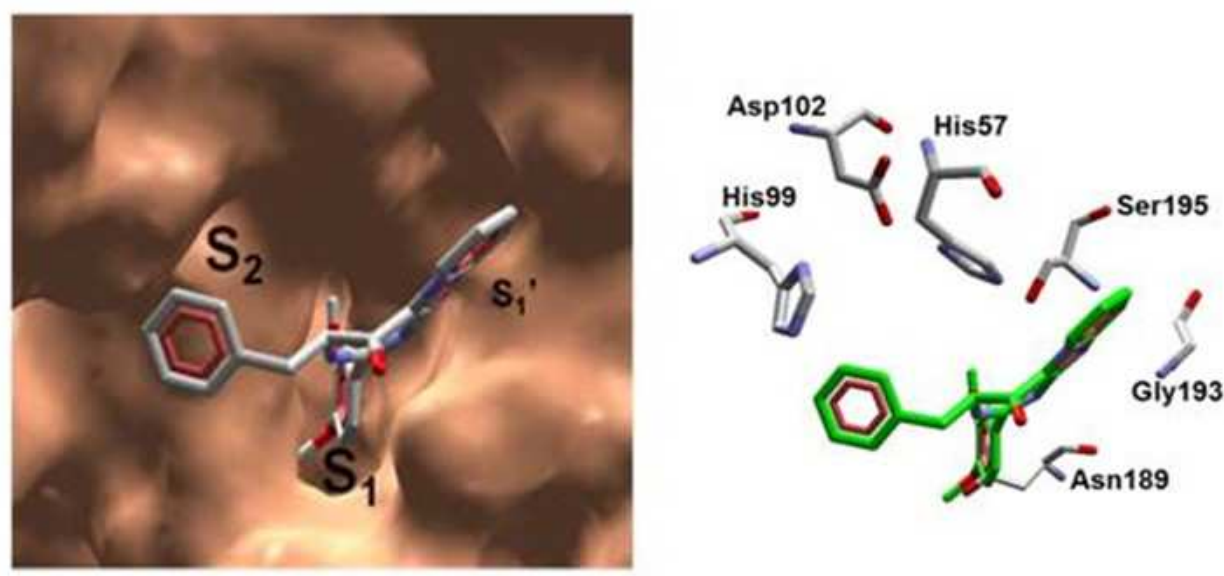

B.
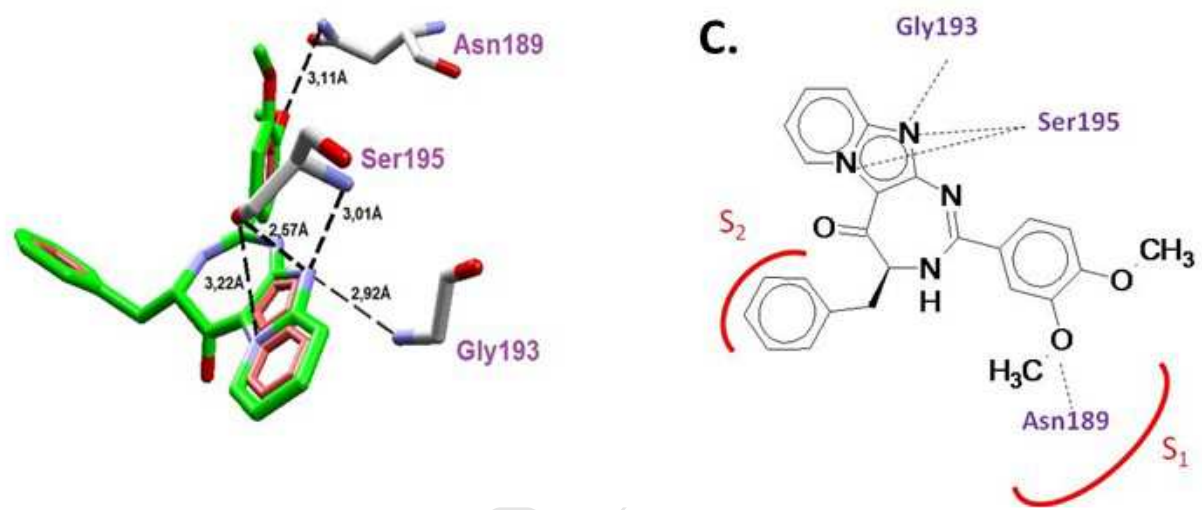

Figure 4. Putative binding mode of compound 10 within KLK7 active site.

A- Positioning of 10 (CPK colors) in the $S_{1}, S_{1}$ and $S_{2}$ pockets of KLK7. B-Residues (sticks, carbon in gray) nearby of 10 (sticks, carbon in green). Hydrogen bonds (black dotted lines) between residues Asn189, Gly193, Ser195 and 10. C- Binding topology of compound 10 within the KLK7 active site. The protease surfaces are colored in light brown and the ligands are shown in stick representation. Subsites $S_{1}, S_{1}$, and $S_{2}$ are indicated. The chymotrypsinogen numbering is used; the residues Ser195, His57 and Asp102 form the catalytic triad. 
Pyrido-imidazodiazepinone as a new chemical scaffold for designing KLK7 inhibitors Selective non-covalent inhibitors of human kallikrein 7

Cytotoxicity evaluation against cancer cells lines overexpressing KLK7

Potential starting points for the development of anticancer drugs 


\section{SUPPORTING INFORMATION}

\section{PYRIDO-IMIDAZODIAZEPINONES AS A NEW CLASS OF REVERSIBLE INHIBITORS OF HUMAN KALLIKREIN 7}

Dominique P. Arama, ${ }^{\text {a† }}$ Feryel Soualmia, ${ }^{\text {b† }}$ Vincent Lisowski, ${ }^{\text {a }}$ Jean-François Longevial, ${ }^{a}$ Elodie Bosc ${ }^{\mathrm{b}}$, Ludovic T. Maillard, ${ }^{\mathrm{a}}$ Jean Martinez, ${ }^{\mathrm{a}}$ Nicolas Masurier $^{\mathrm{a} *}$, Chahrazade El Amrib*.

a Institut des Biomolécules Max Mousseron, UMR 5247, CNRS, Université de Montpellier, UFR des Sciences Pharmaceutiques et Biologiques, 15 Avenue Charles Flahault, 34093 Montpellier Cedex 5, France

${ }^{\mathrm{b}}$ Sorbonne Universités, UPMC Univ Paris 06, UMR 8256, B2A, Biological Adaptation and Ageing, Integrated Cellular Ageing and Inflammation, Molecular \& Functional Enzymology, 7 Quai St Bernard, F-75005 Paris.

$\dagger$ These authors contributed equally to the work.

*Corresponding authors: Nicolas Masurier. Tel: + (33) 4117596 42, Fax: + (33) 4117596 41, Email: nicolas.masurier@univ-montp1.fr; Chahrazade El Amri. Tel: + (33) 1442769 52, Fax: + (33) 44 275140 ,E-mail: chahrazade.el_amri@upmc.fr

\section{Table of contents}

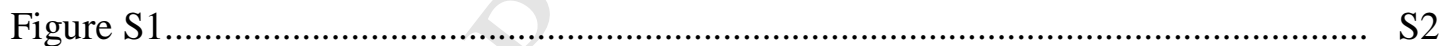

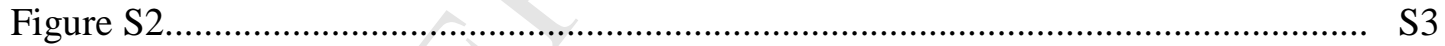

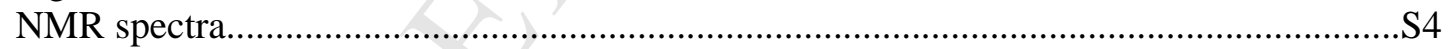


A.



B.

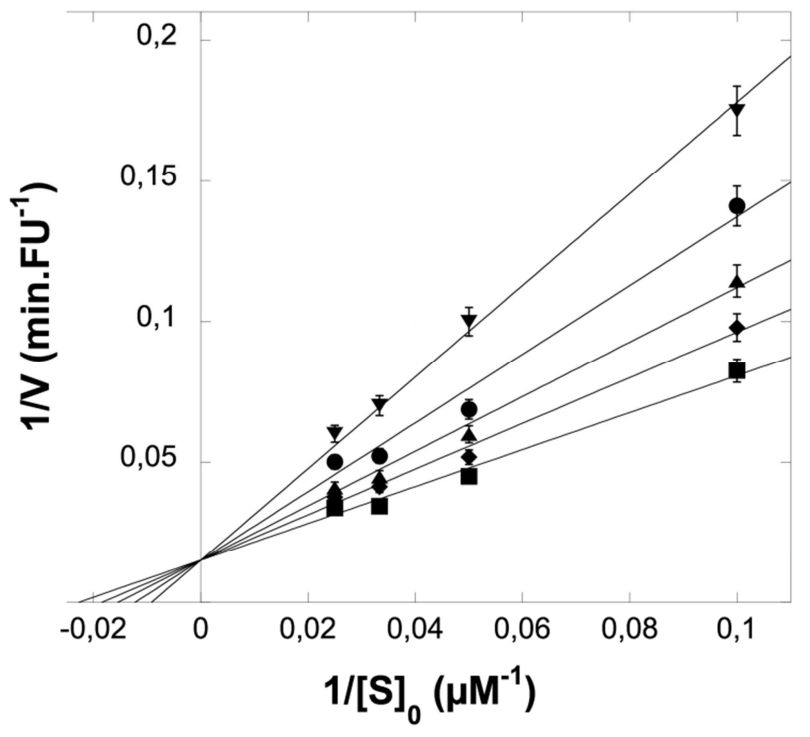

Figure S1. Inhibition of KLK7 by compound 1a. A. IC 50 determination after 15 min incubation at $37^{\circ} \mathrm{C}$. Experimental points were fitted to equation 1. [KLK7 $]_{0}=7.6 \mathrm{nM}$; [Succ-LLVY-AMC] $]_{0}=40 \mu \mathrm{M}$. B. Determination of the mechanism of inhibition. Lineweaver and Burk plot with $\left[\mathrm{I}_{0}=\boldsymbol{\nabla}, 50 \mu \mathrm{M}\right.$;, $25 \mu \mathrm{M} ; \boldsymbol{\Delta}, 12.5 \mu \mathrm{M} ; \diamond, 6.25 \mu \mathrm{M} ; \mathbf{\square}, 0 \mu \mathrm{M}$. F.U = arbitrary fluorescence unit. 

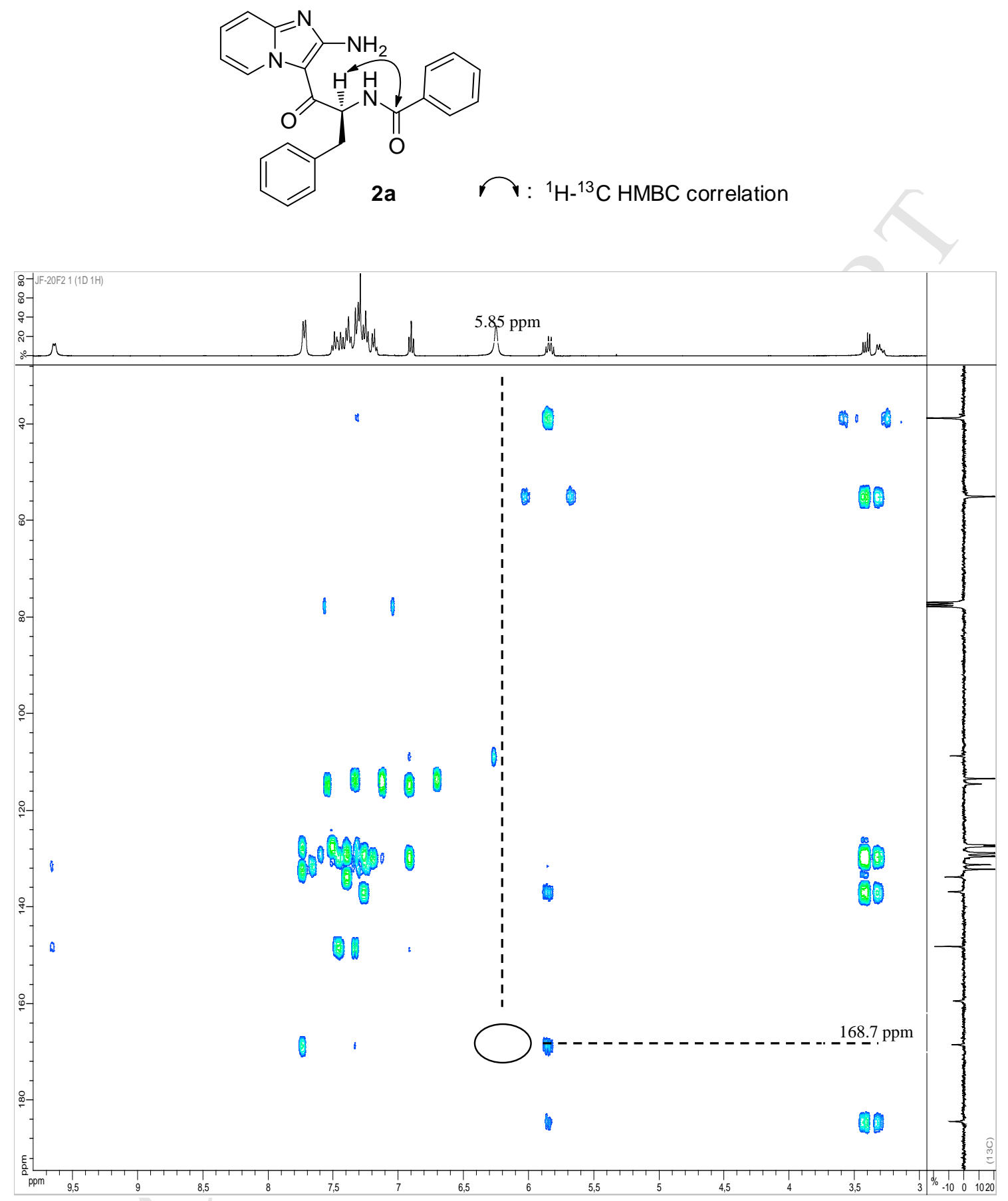

Figure S2. ${ }^{1} \mathrm{H}-{ }^{13} \mathrm{C}$ HMBC NMR spectrum of compound $2 \mathbf{a}$ in $\mathrm{CDCl}_{3}$. 
Compound 4d $\left(\mathrm{CDCl}_{3}, 300 \mathrm{MHz}\right)$

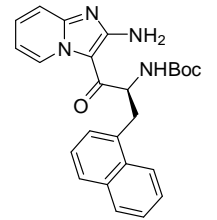

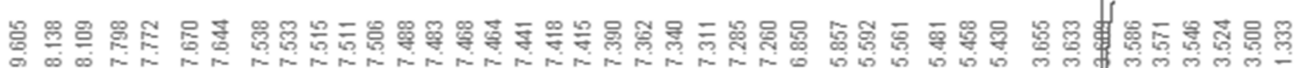
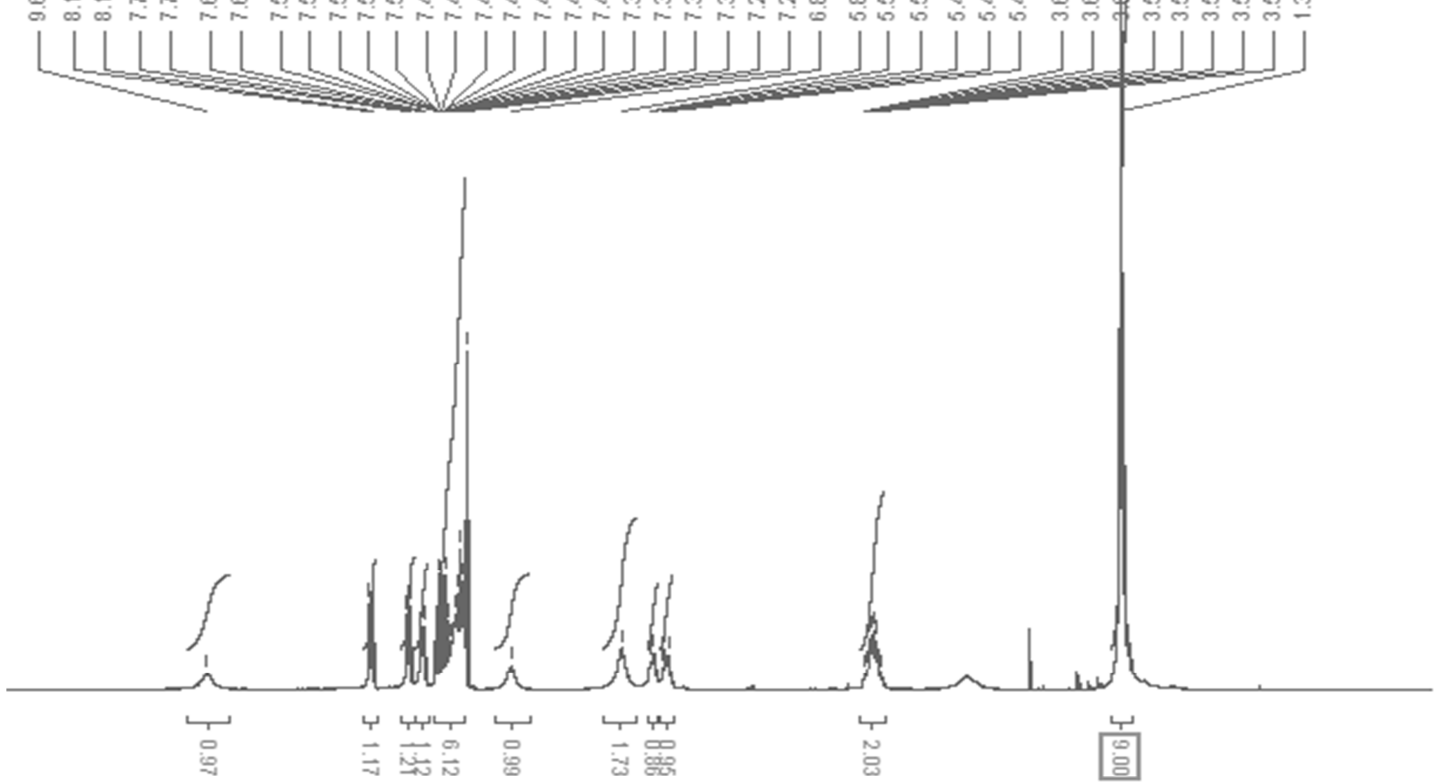

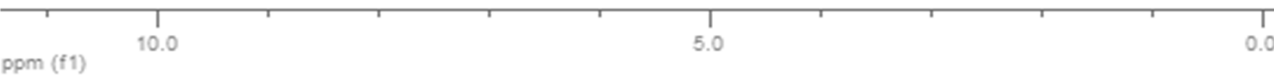

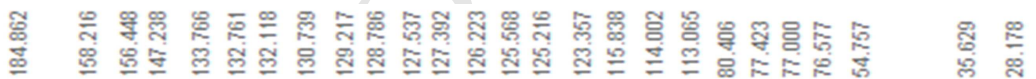
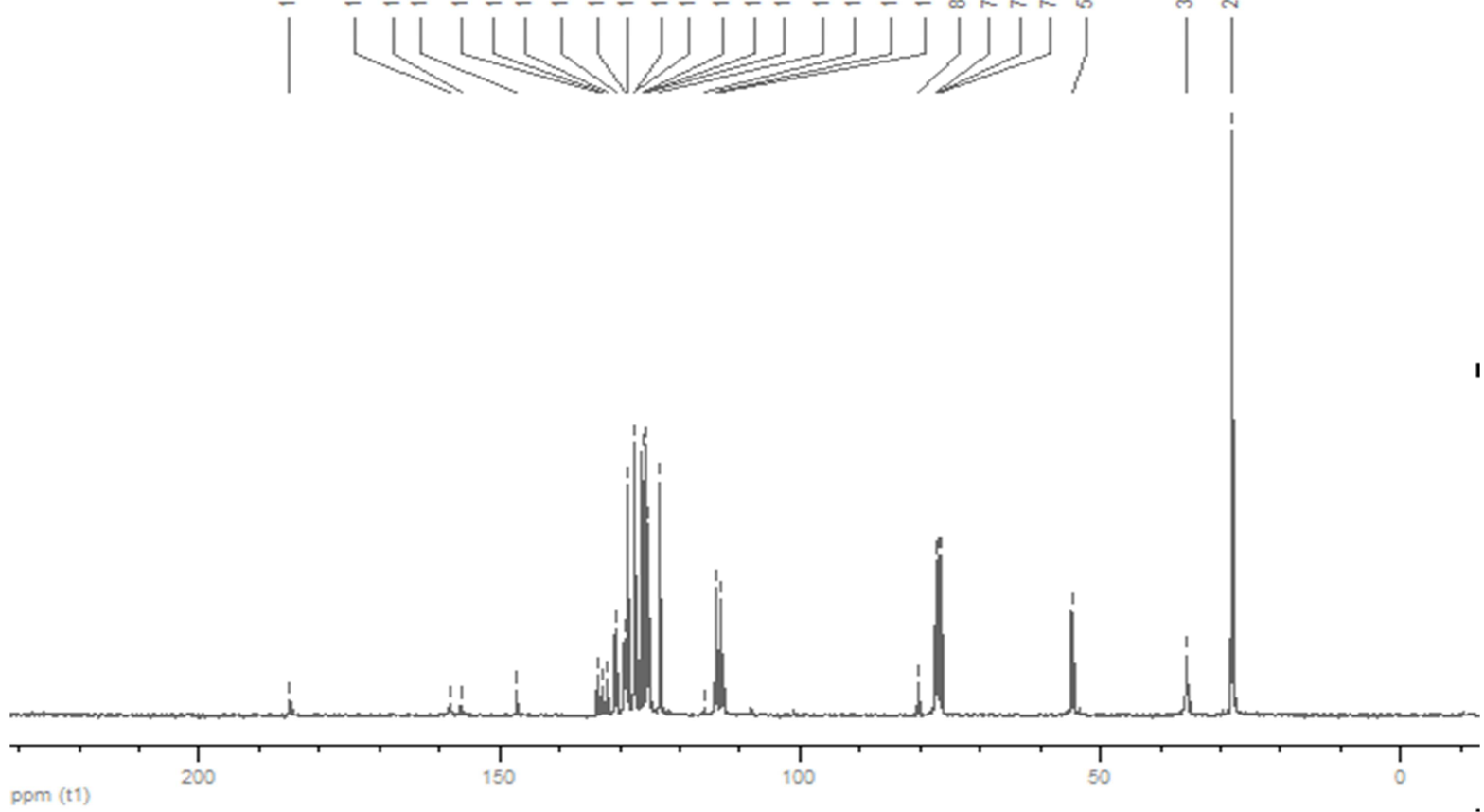
Compound $4 \mathbf{e}\left(\mathrm{CDCl}_{3}, 300 \mathrm{MHz}\right)$

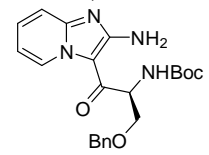

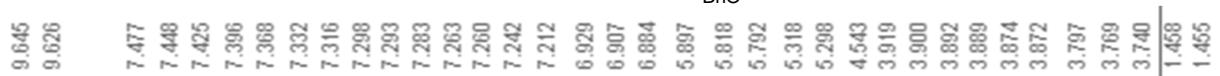

1
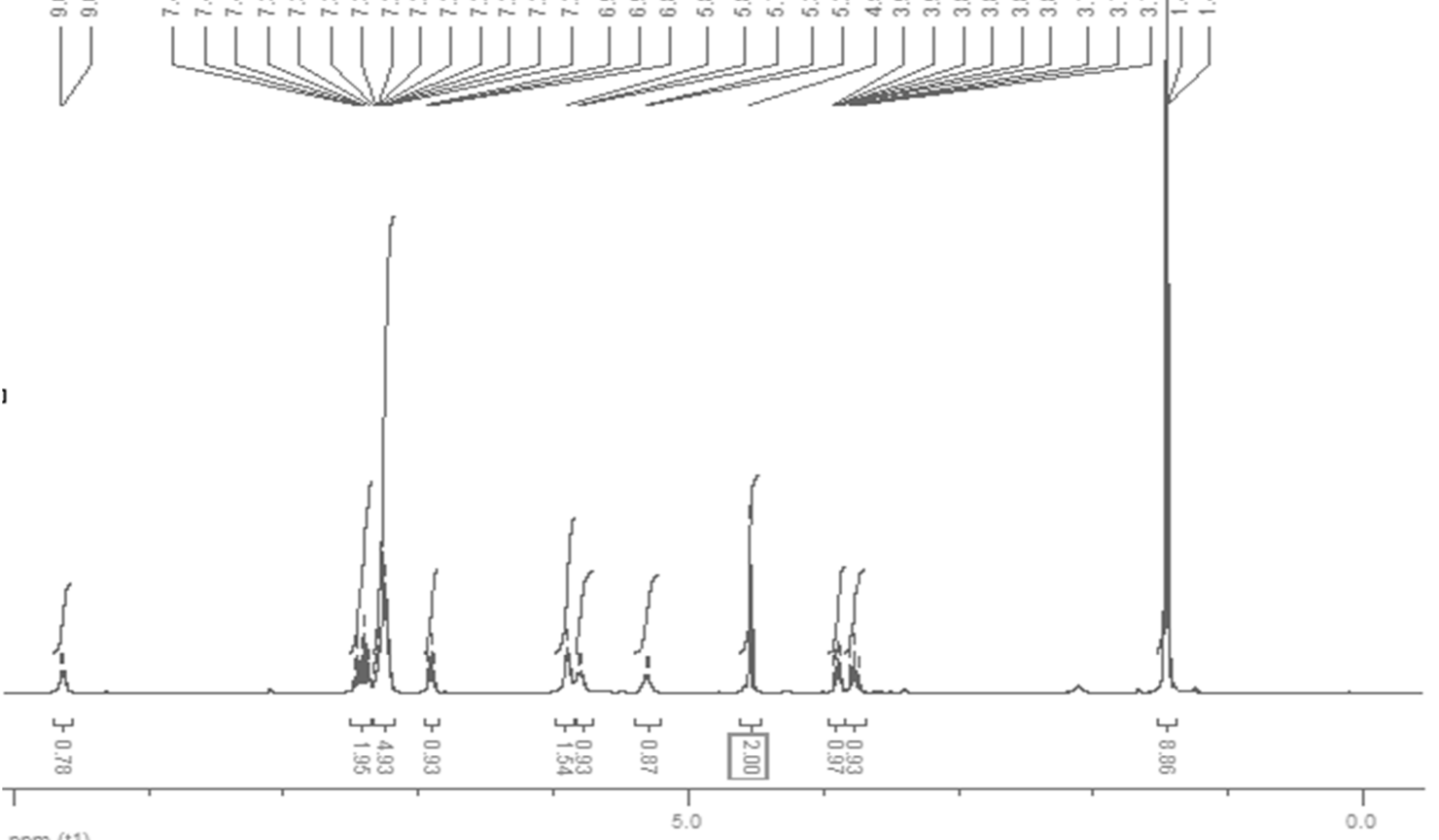

$\mathrm{ppm}(\mathrm{t} 1)$

Compound $\mathbf{4 f}\left(\mathrm{CDCl}_{3}, 300 \mathrm{MHz}\right)$
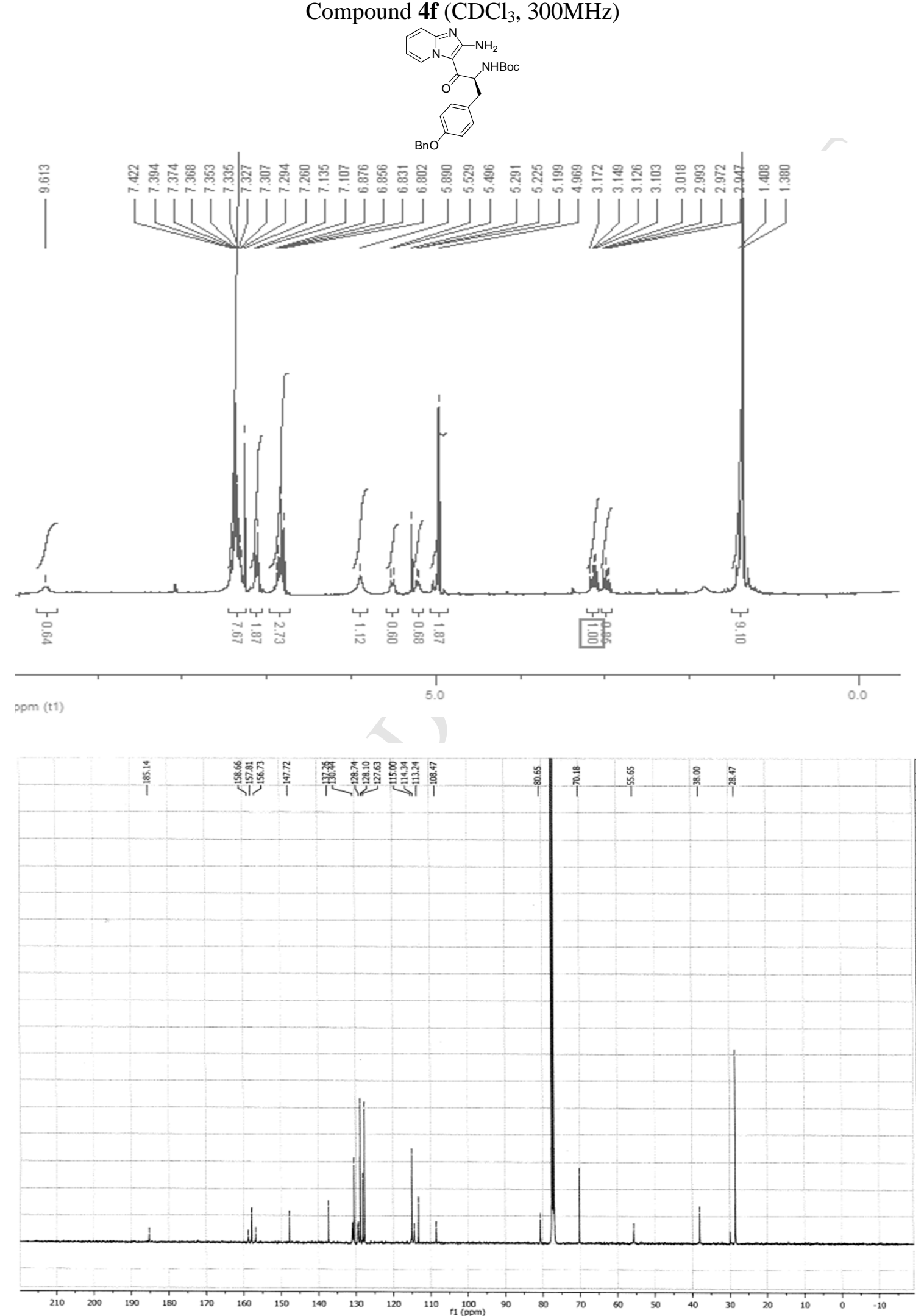


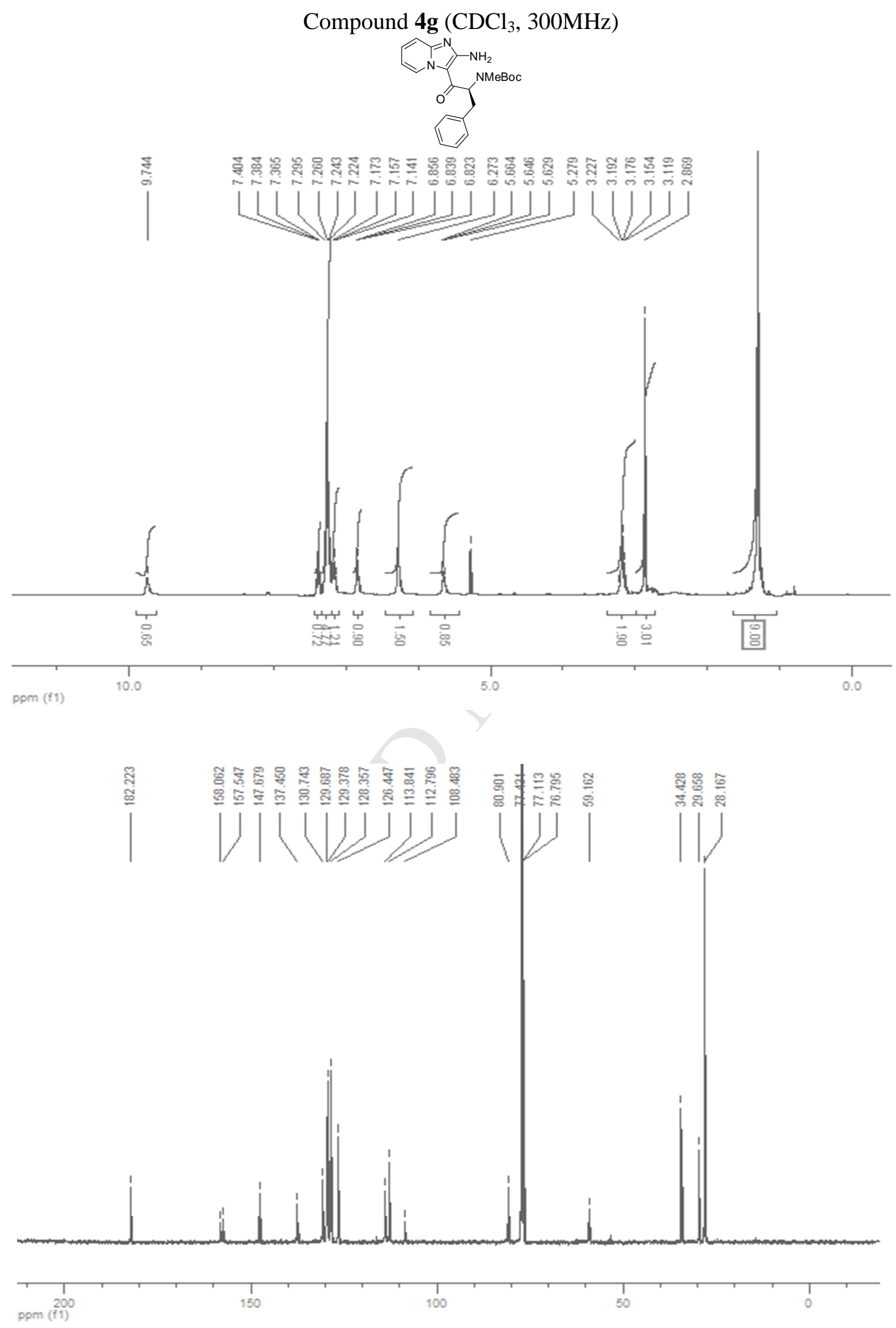


Compound 1k $\left(\mathrm{CDCl}_{3}, 300 \mathrm{MHz}\right)$

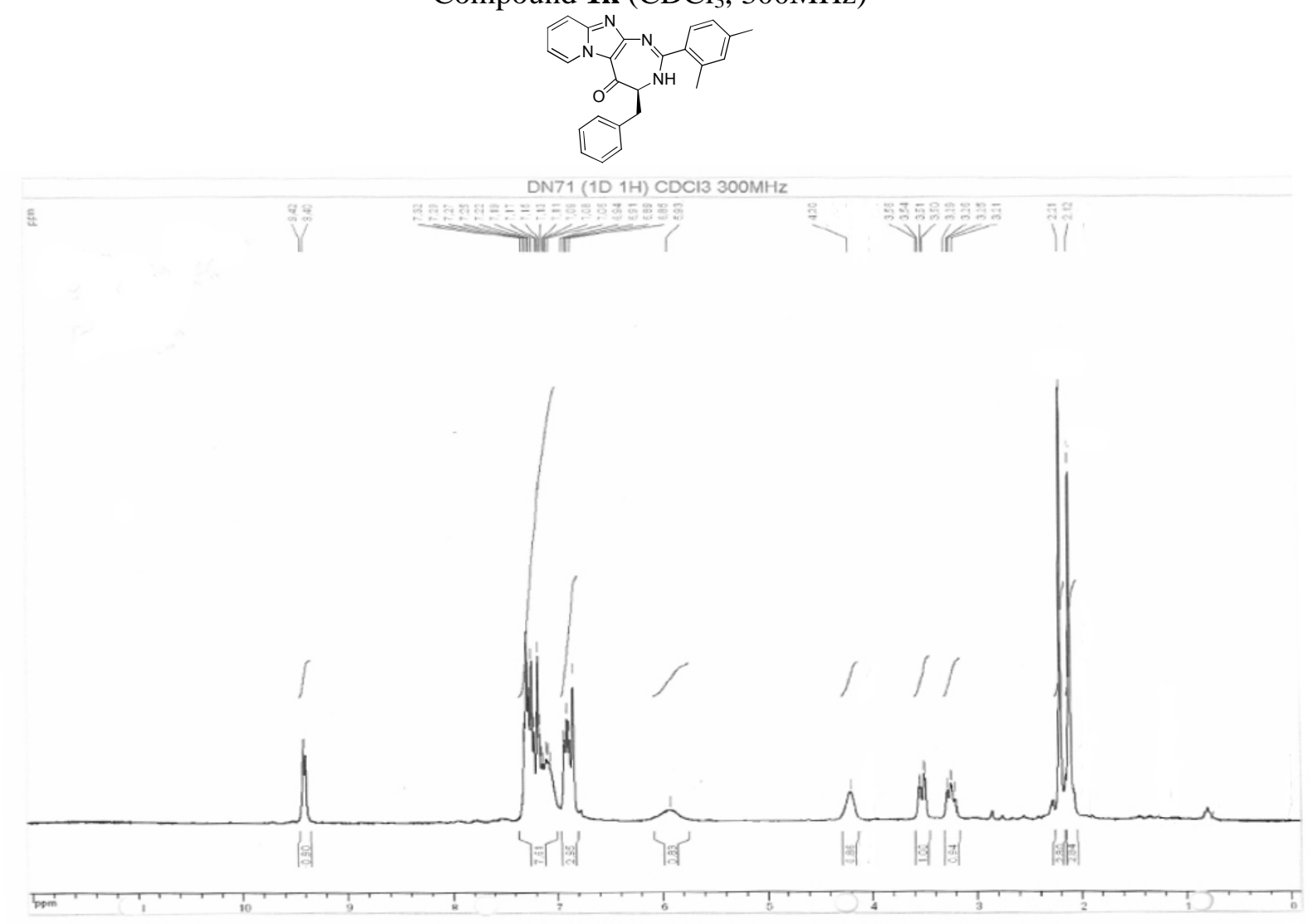

DN71 (1D 13C) CDCl3 300MHz $|\quad| Y||)$ |
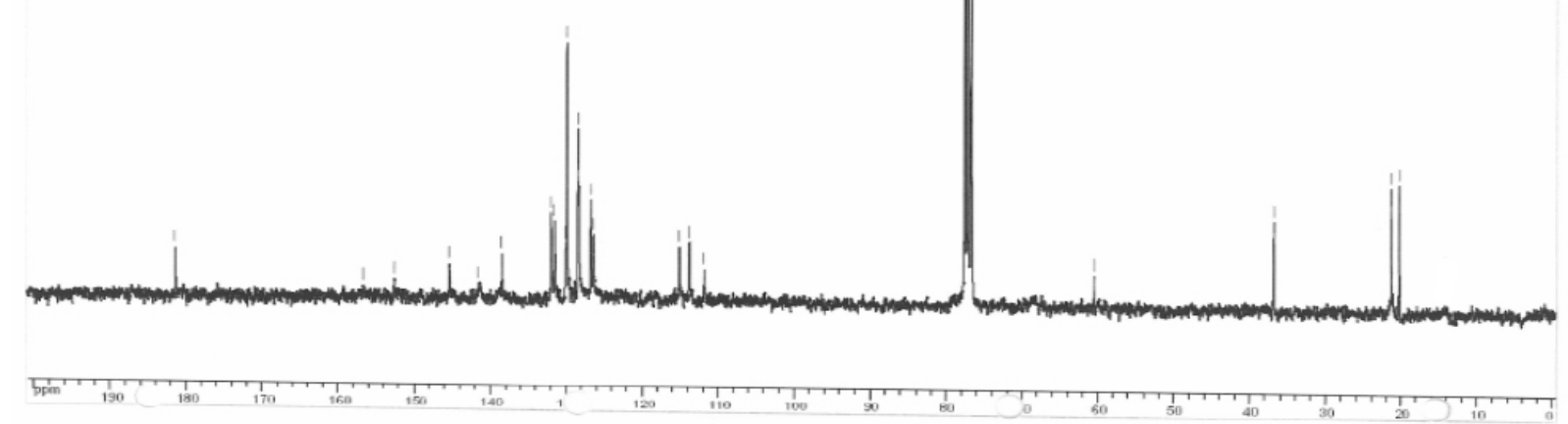

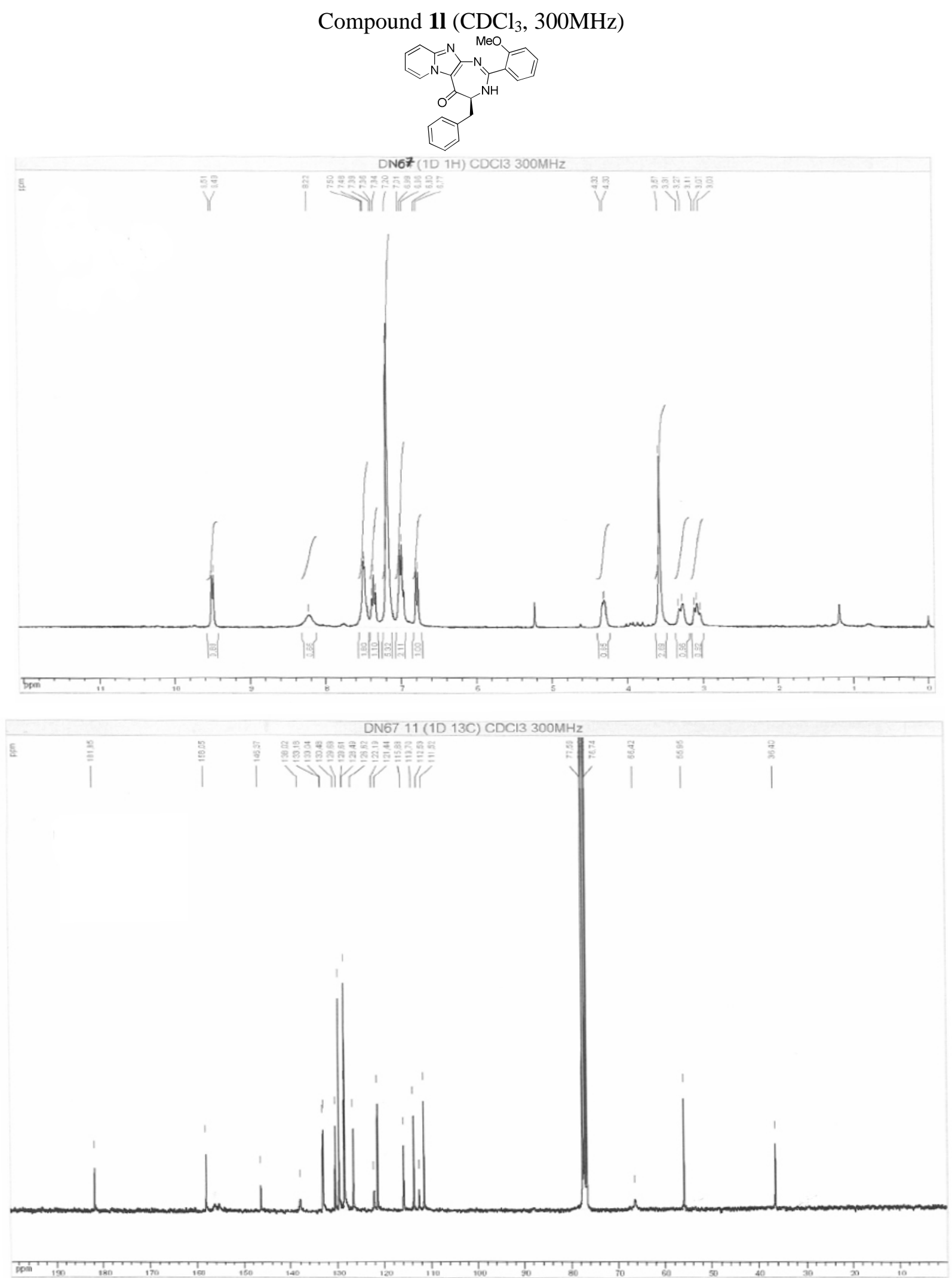
Compound 1m (DMSO d 6 , 400MHz)

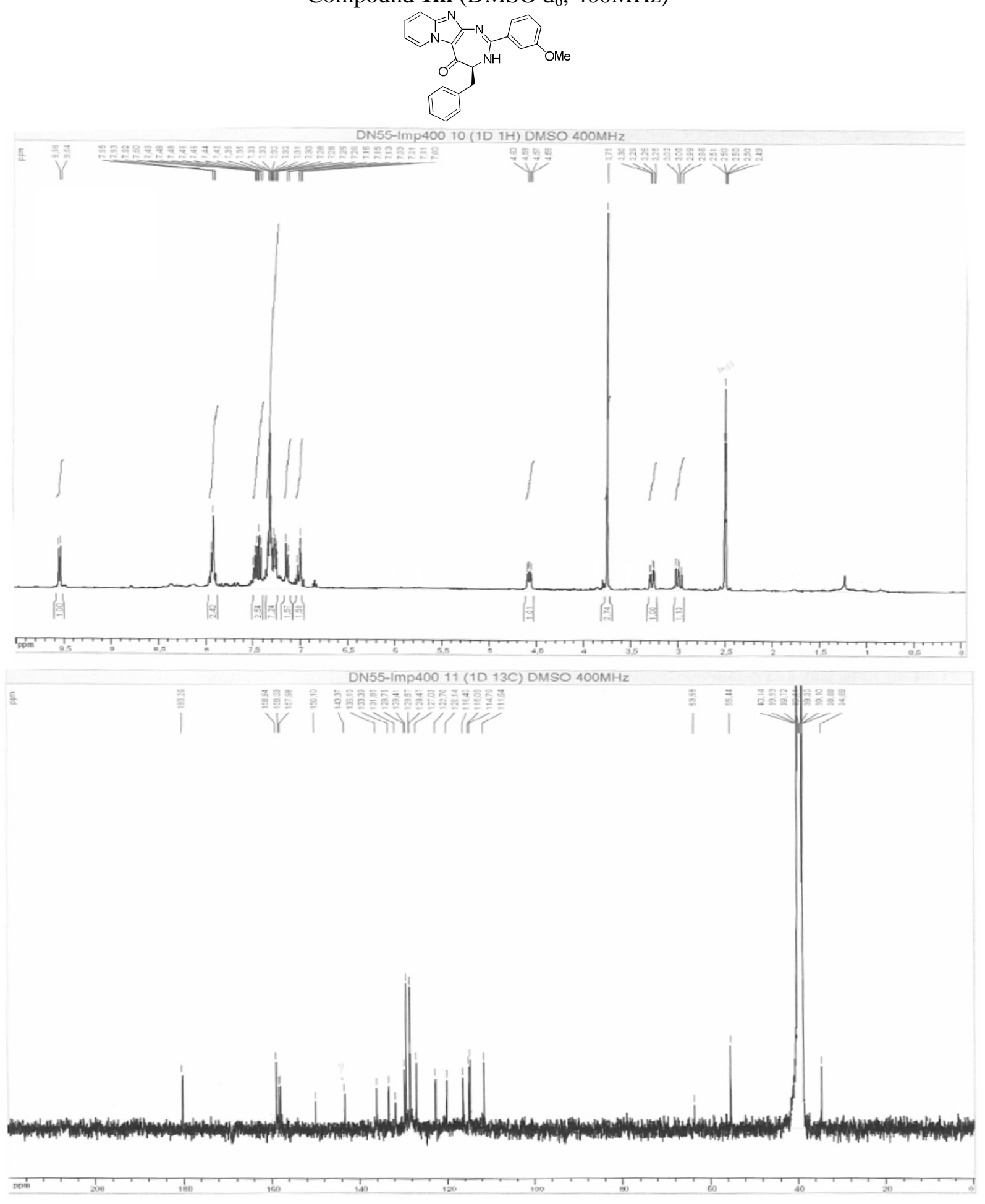


Compound 1n $\left(\mathrm{CDCl}_{3}, 300 \mathrm{MHz}\right)$
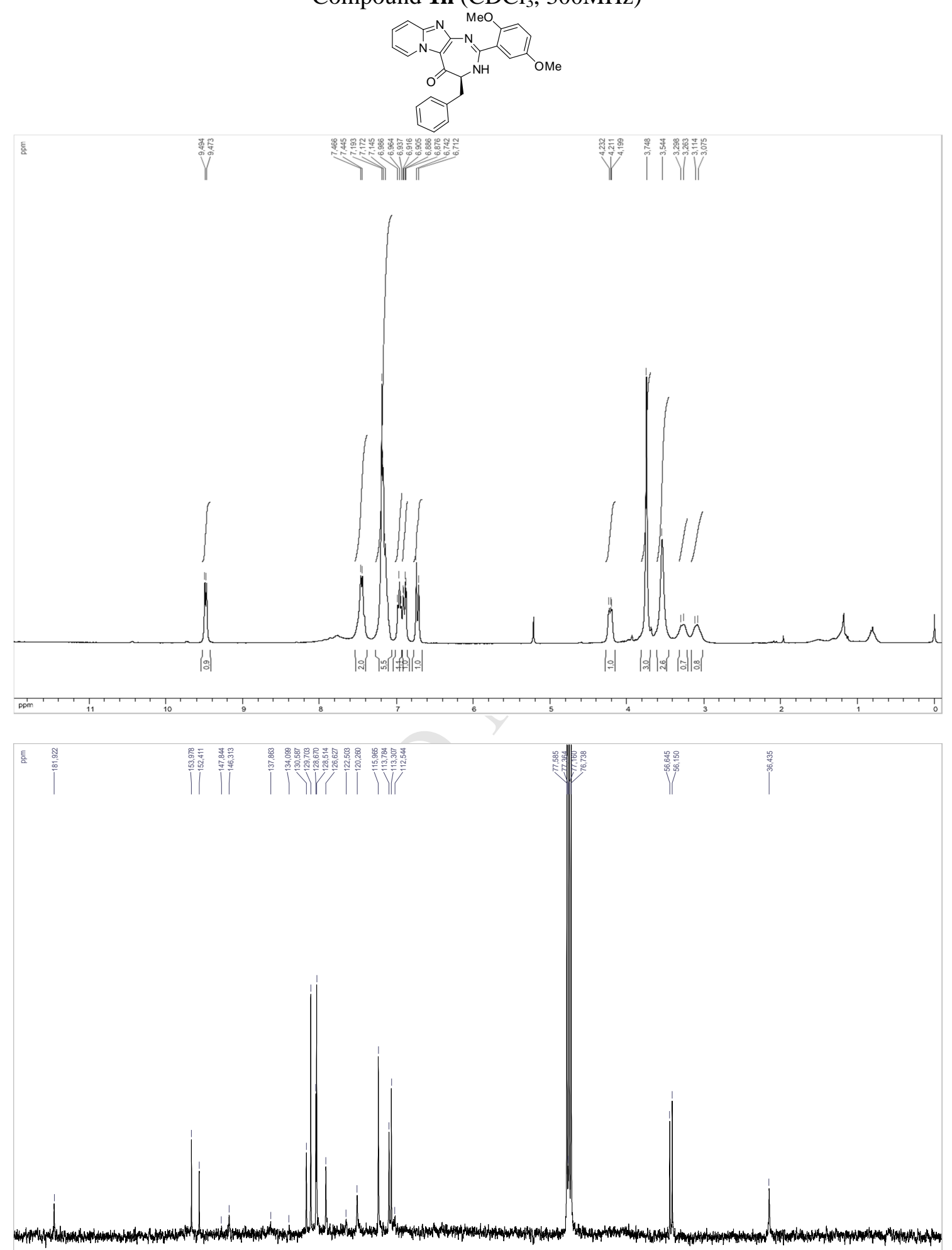

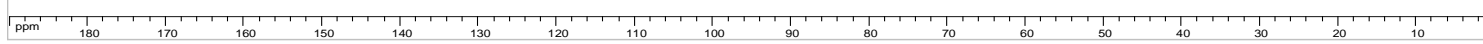




Compound 1p $\left(\mathrm{CDCl}_{3}, 300 \mathrm{MHz}\right)$

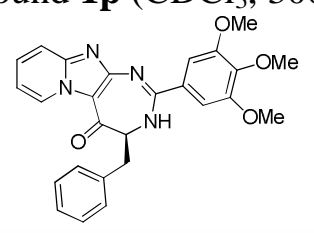



Compound 1q $\left(\mathrm{CDCl}_{3}, 300 \mathrm{MHz}\right)$



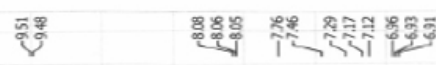

裙骂

†ิ

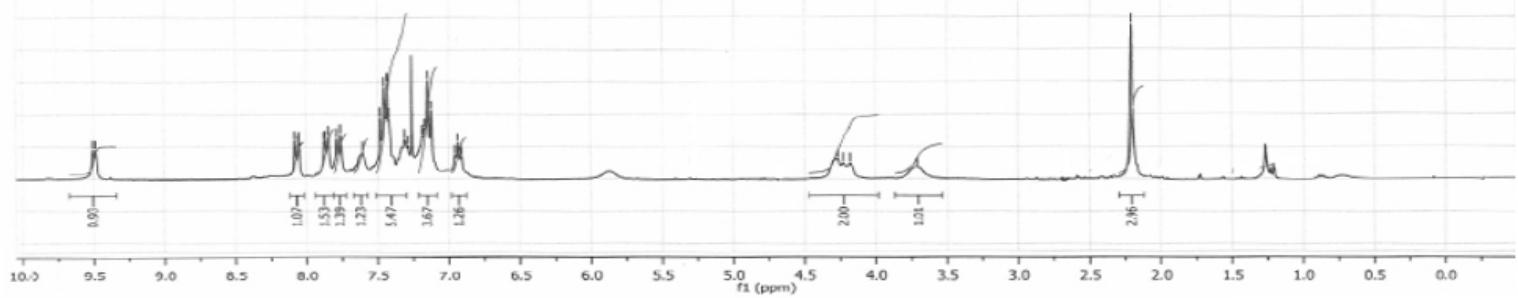

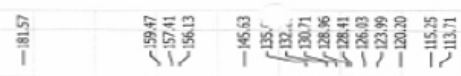

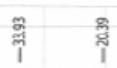




Compound 1r $\left(\mathrm{CDCl}_{3}, 300 \mathrm{MHz}\right)$<smiles>Cc1ccccc1C1N=C2N=C3C=CC=CN3C(=O)C(C)C2N1</smiles>

Compound 1s $\left(\mathrm{CDCl}_{3}, 300 \mathrm{MHz}\right)$

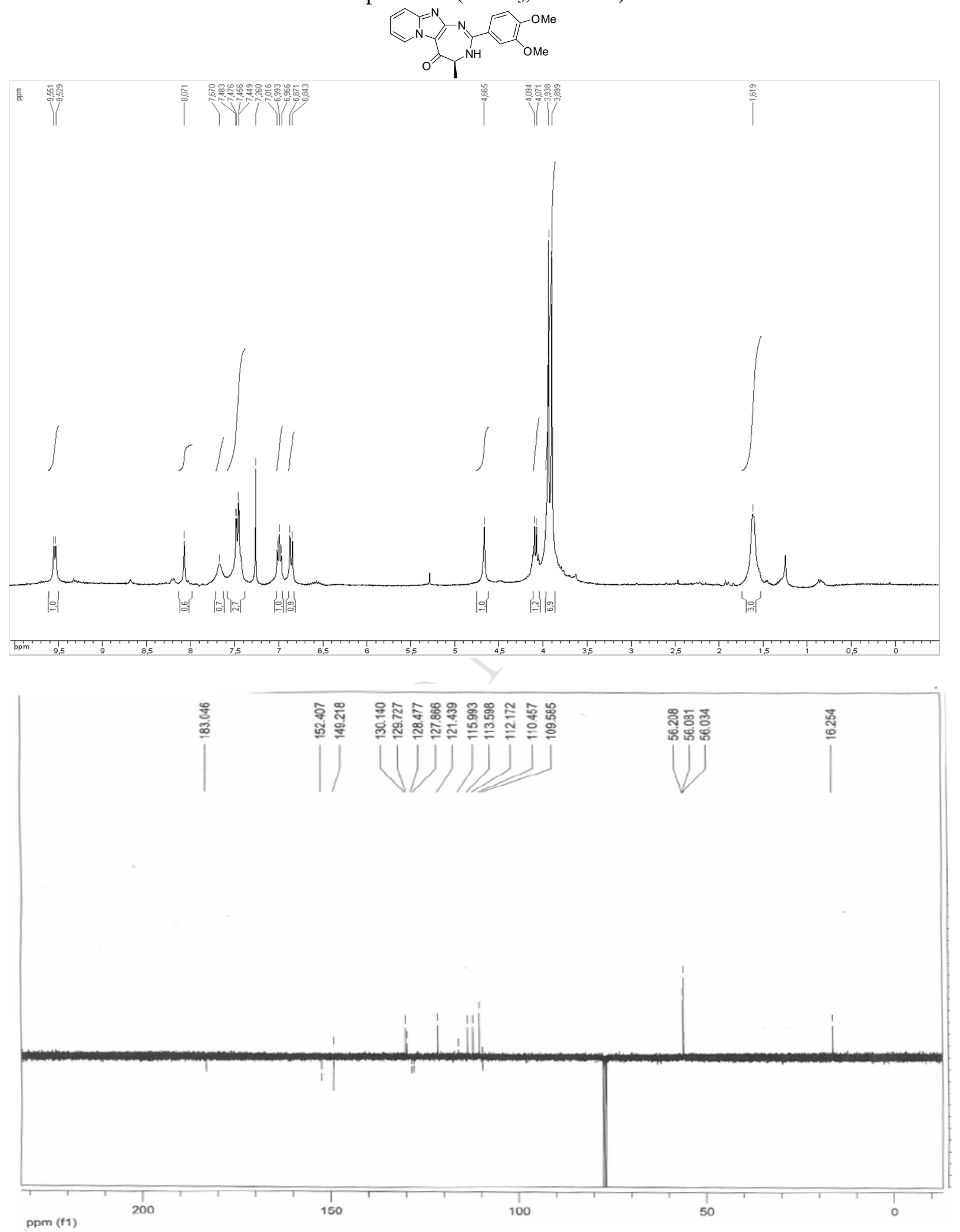



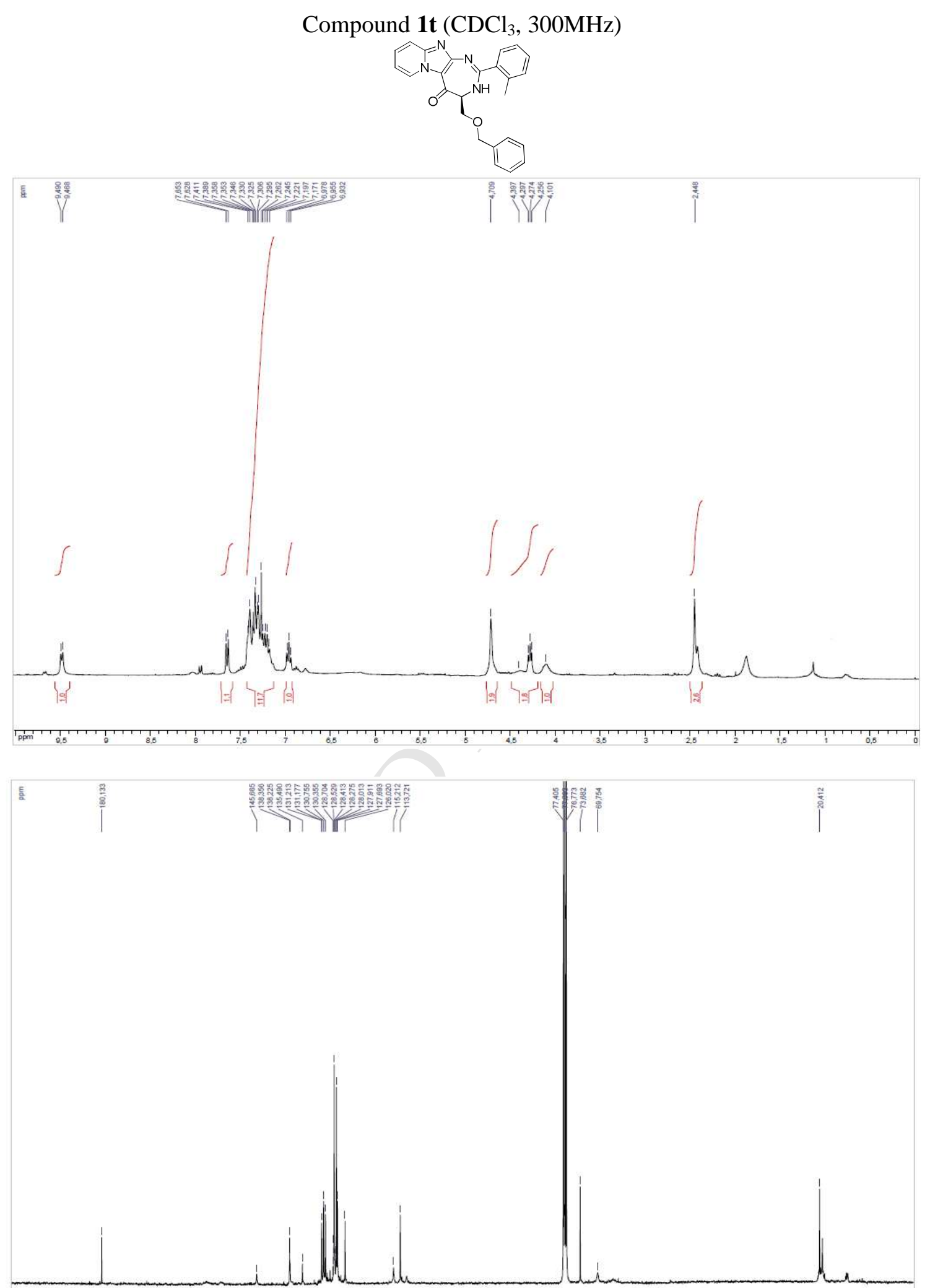




Compound 1u $\left(\mathrm{CDCl}_{3}, 300 \mathrm{MHz}\right)$




Compound 1v (DMSO d 6 , 300MHz)

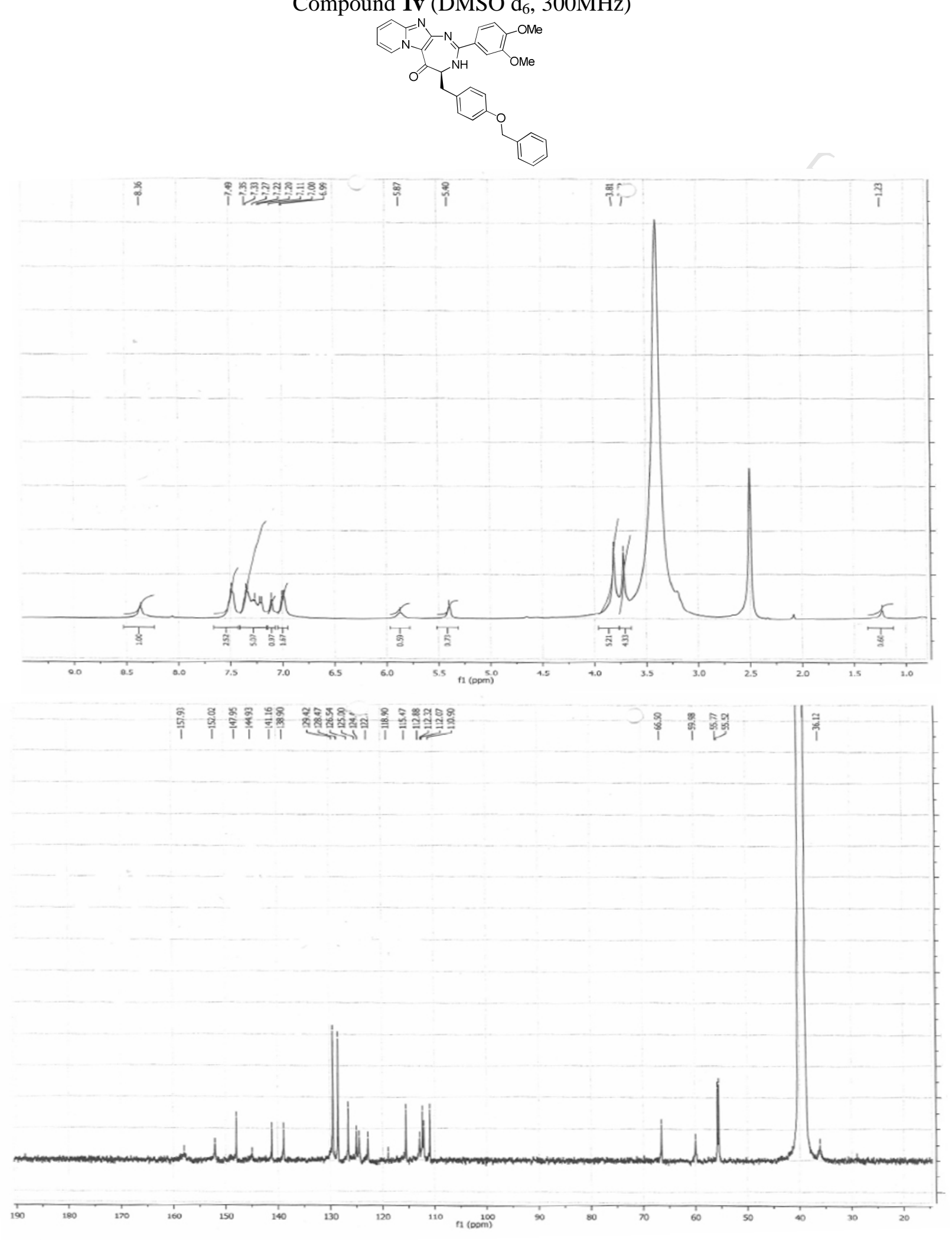



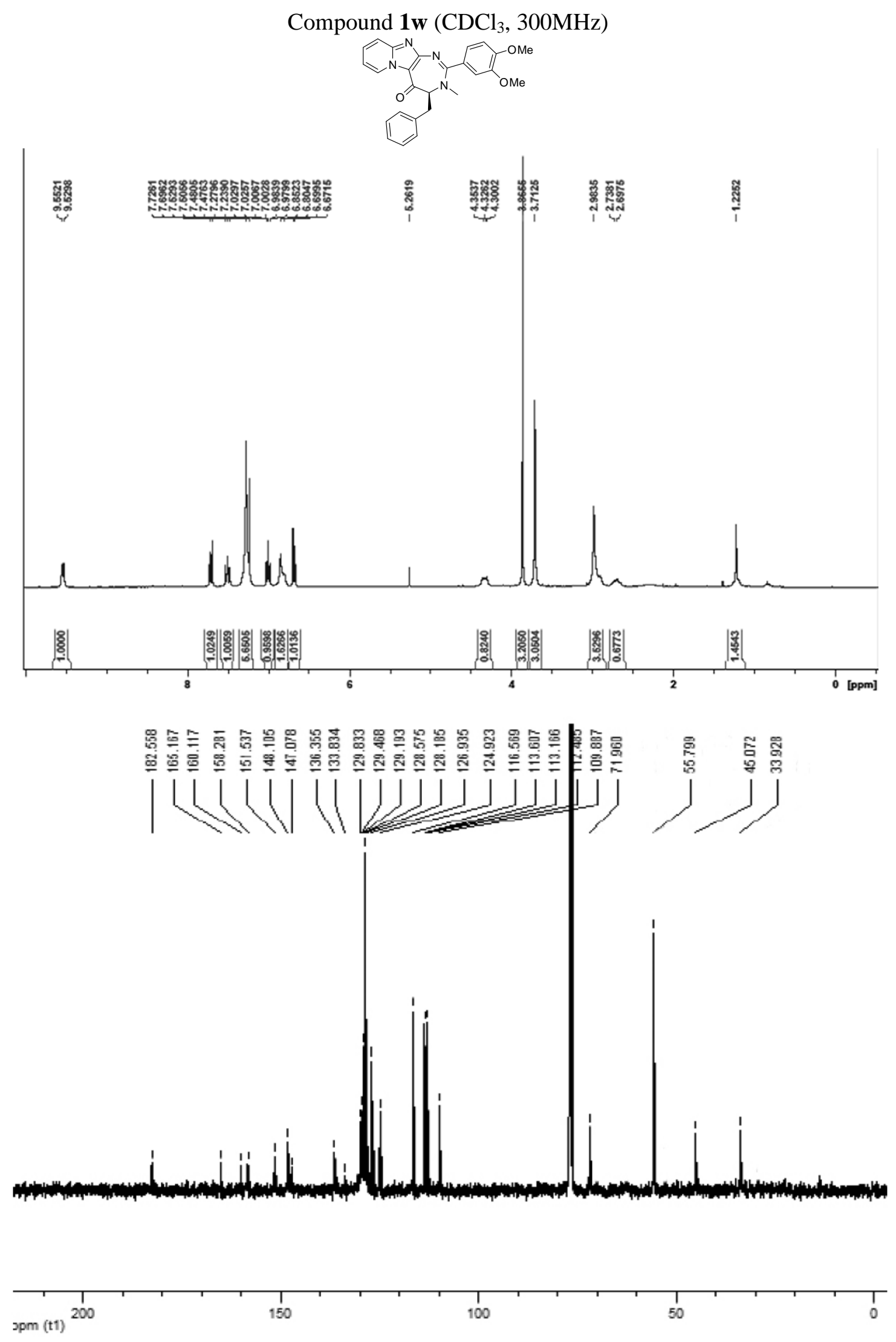
Compound 1x (DMSO d 6 , 300MHz)
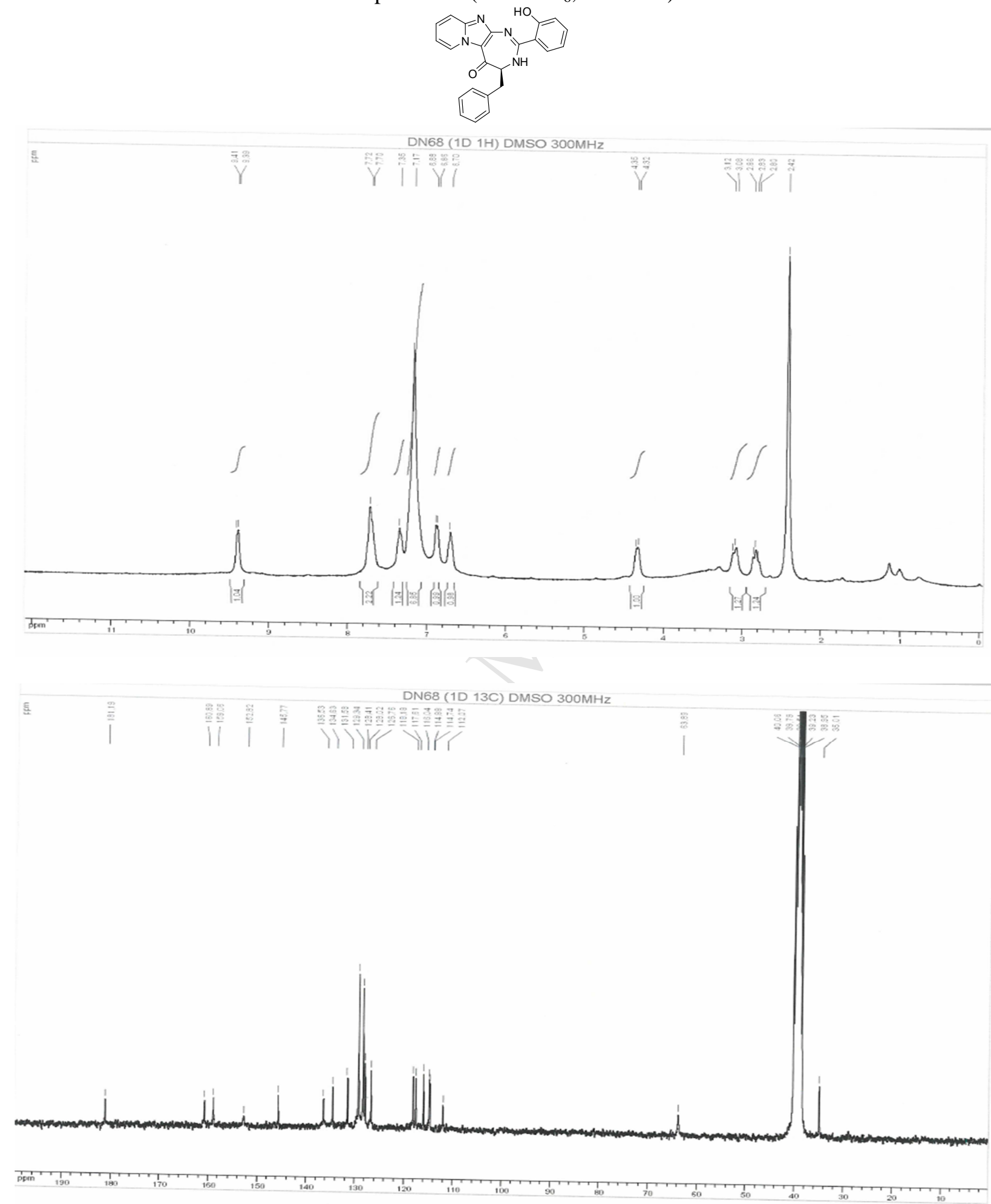
Compound 1y (MeOD, 300MHz)

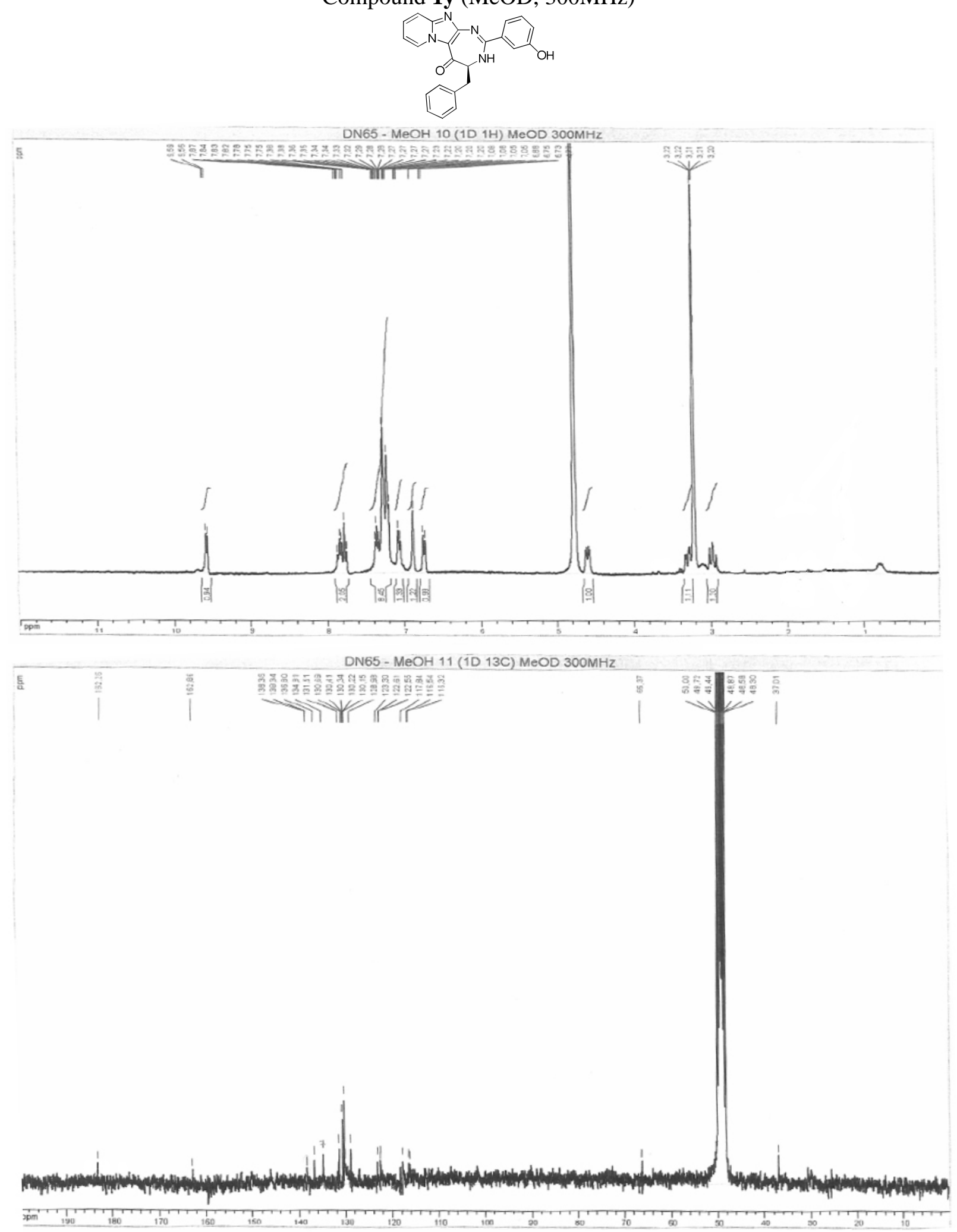


Compound 1z (DMSO d 6 , 300MHz)
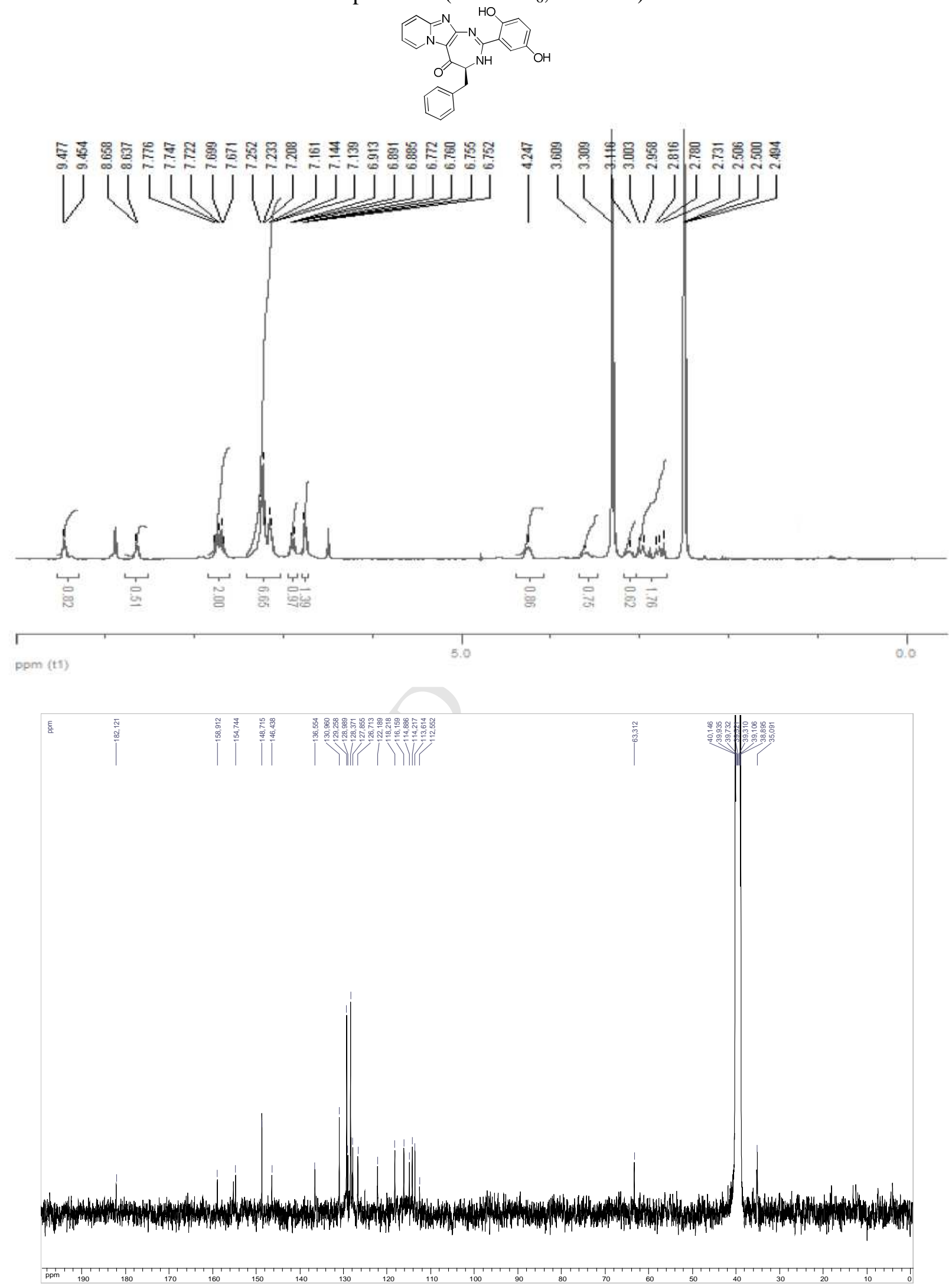
Compound 1ab (DMSO d 6 , 300MHz)
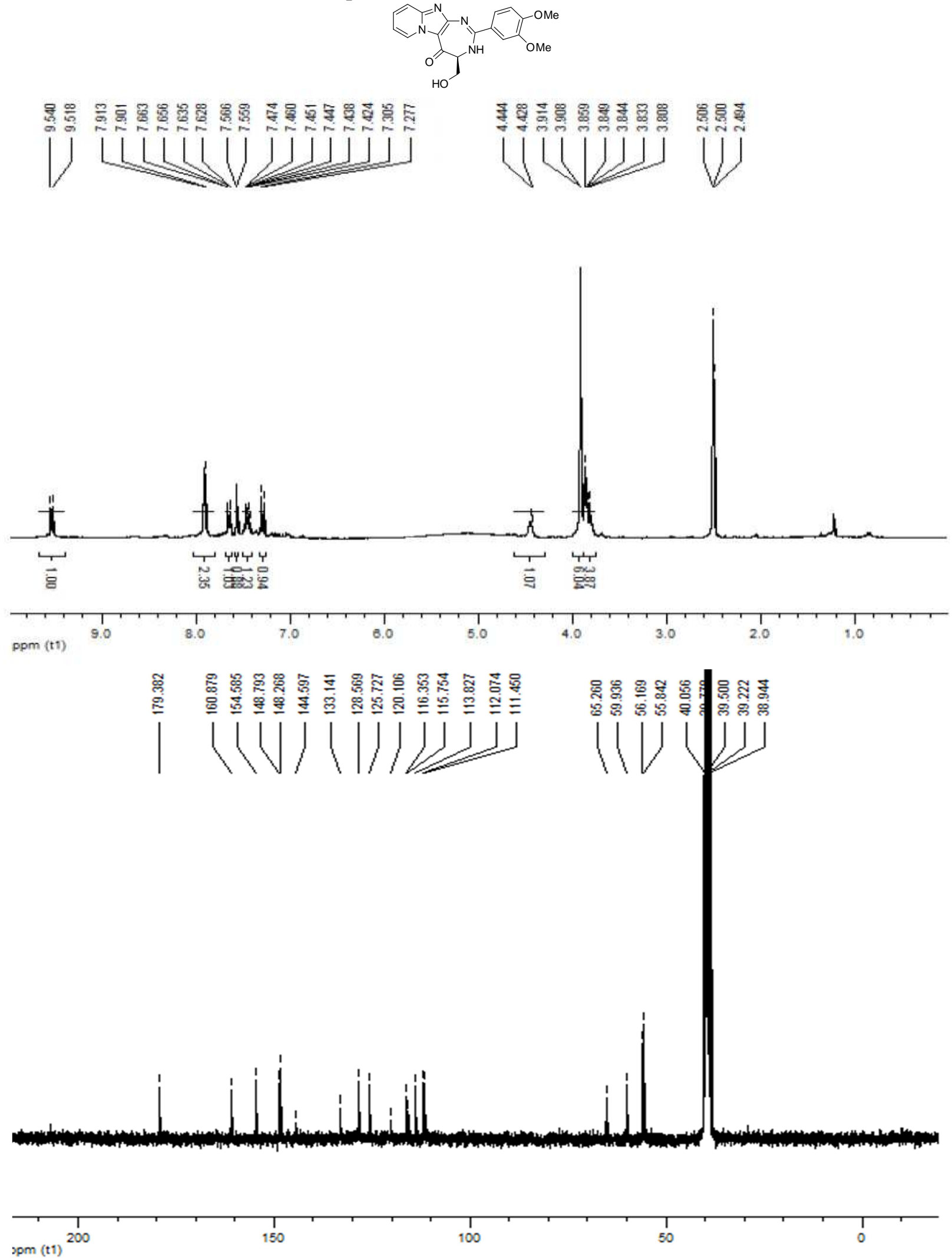
Compound 1ac (DMSO d 6 , 300MHz)<smiles>COc1ccc(C2=Nc3nc4ccccn4c3C(=O)C(Cc3ccc(O)cc3)N2)cc1OC</smiles>

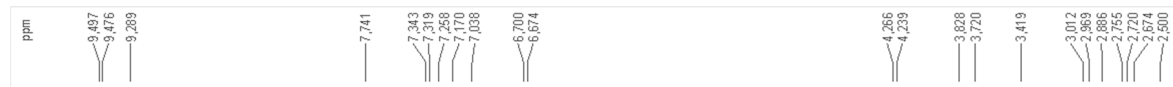
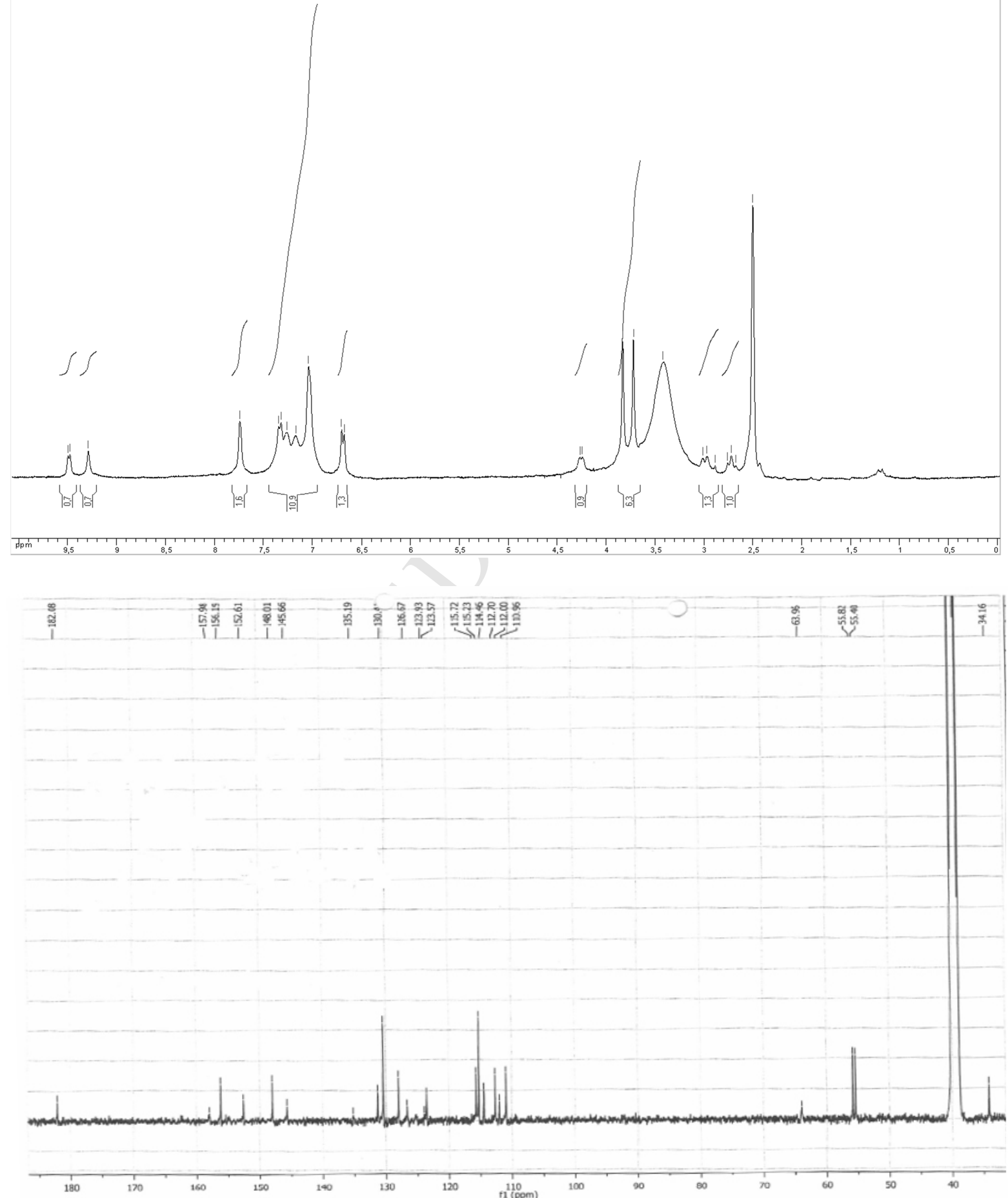
Compound 1ad (DMSO d $6,300 \mathrm{MHz})$




Compound 2a $\left(\mathrm{CDCl}_{3}, 300 \mathrm{MHz}\right)$

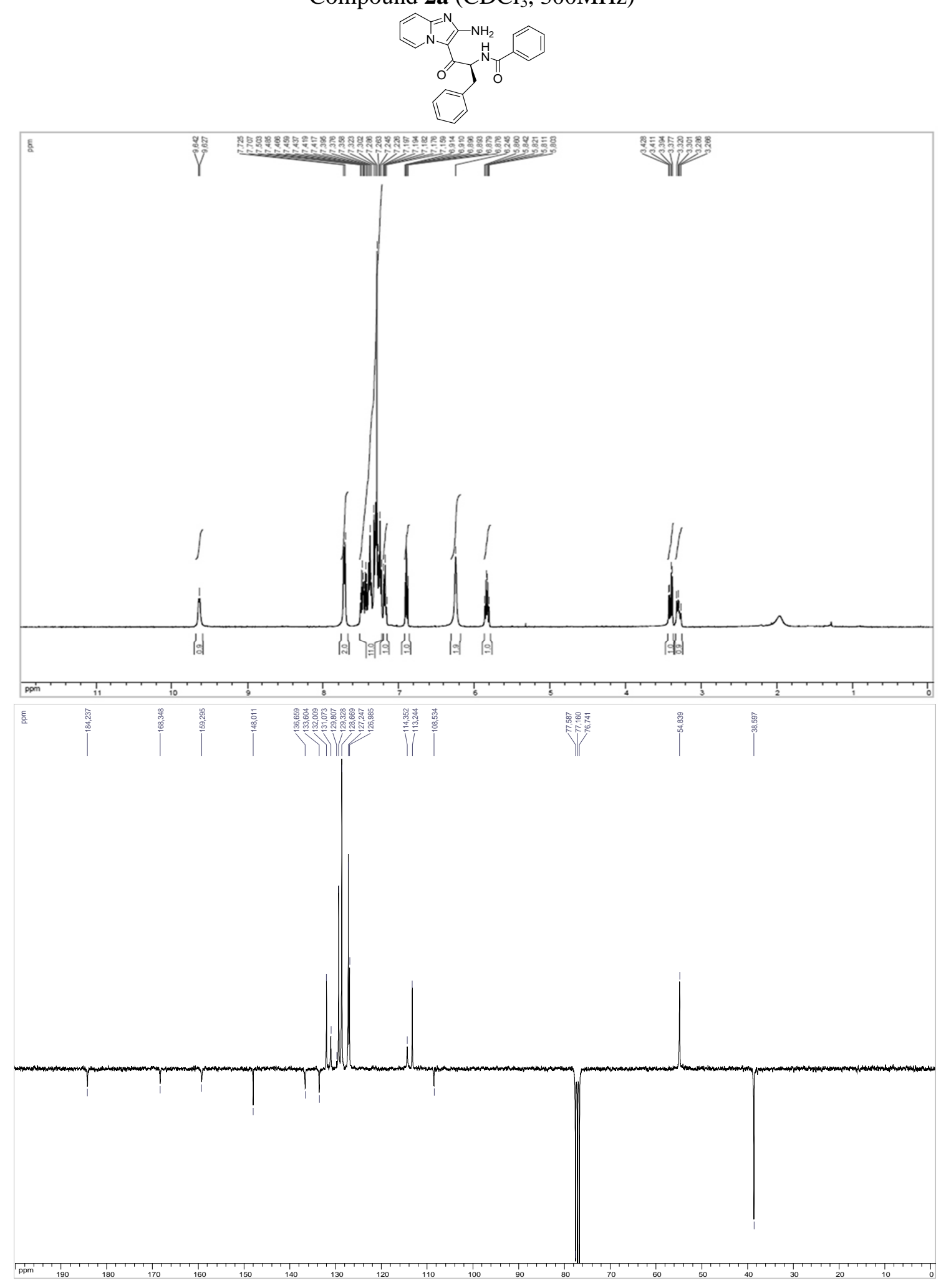


Compound $\mathbf{2 b}\left(\mathrm{CDCl}_{3}, 300 \mathrm{MHz}\right)$
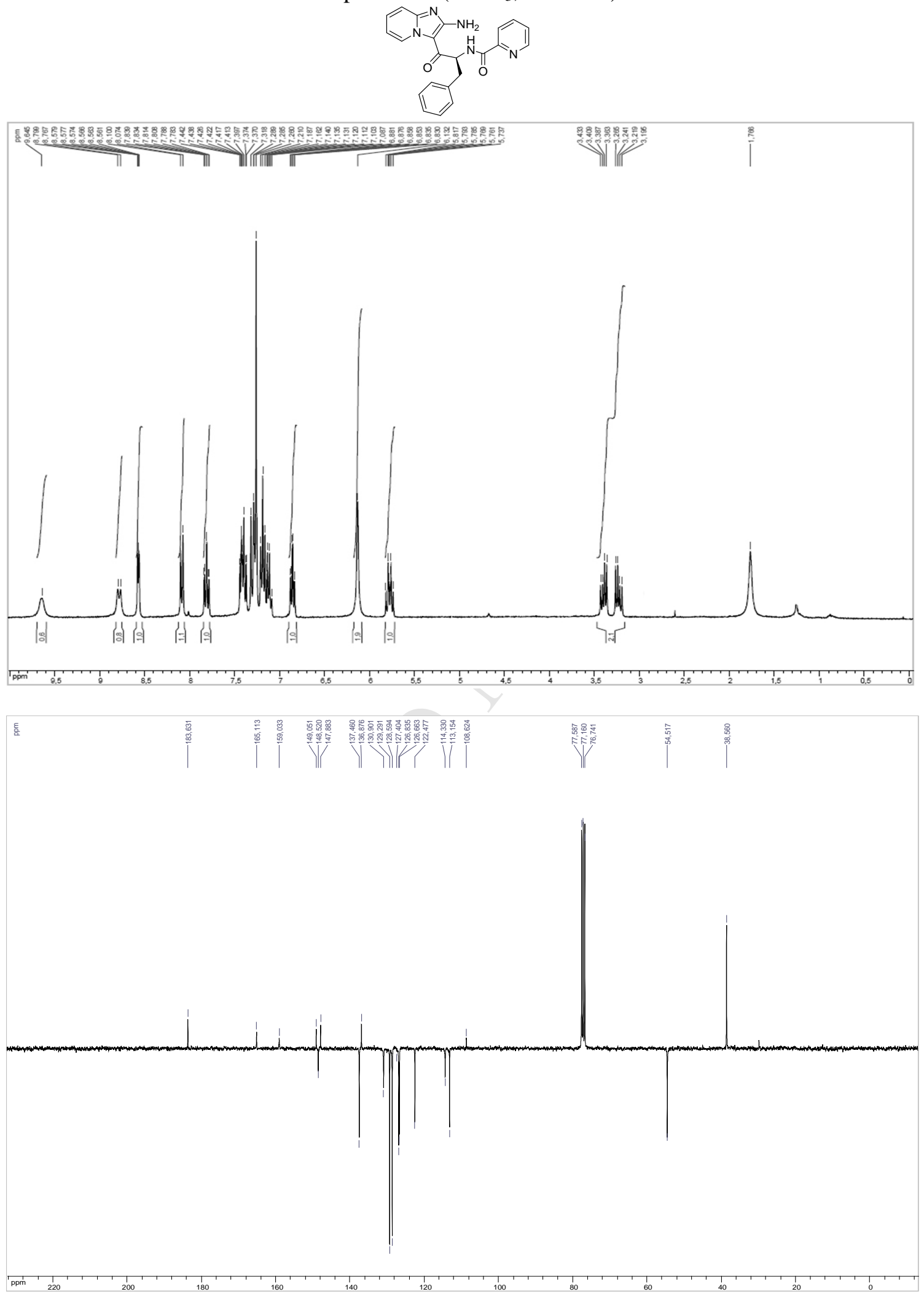
Compound $2 \mathrm{c}\left(\mathrm{CDCl}_{3}, 300 \mathrm{MHz}\right)$
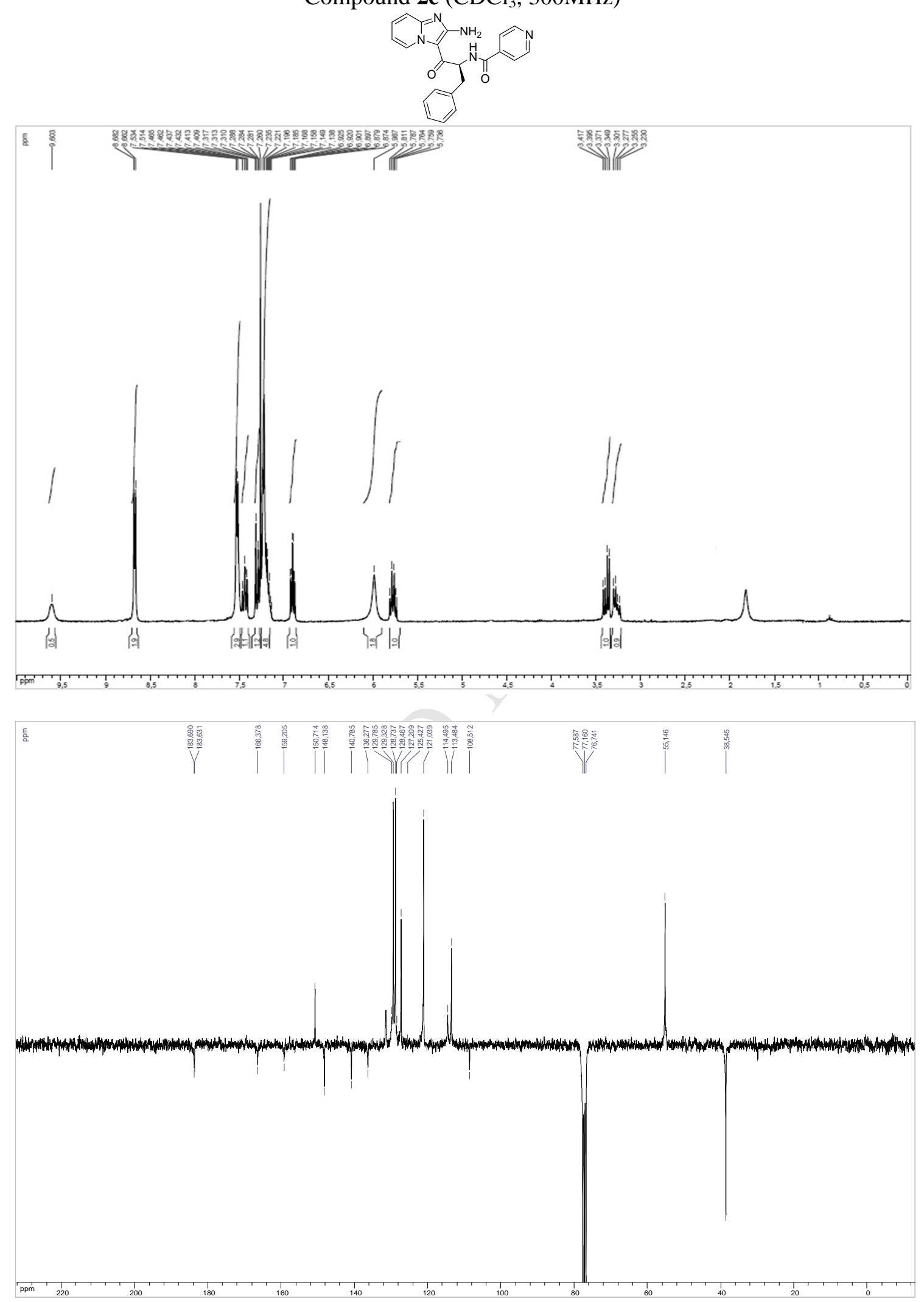


\section{Compound 2d (DMSO $\left.d_{6}, 300 \mathrm{MHz}\right)$}
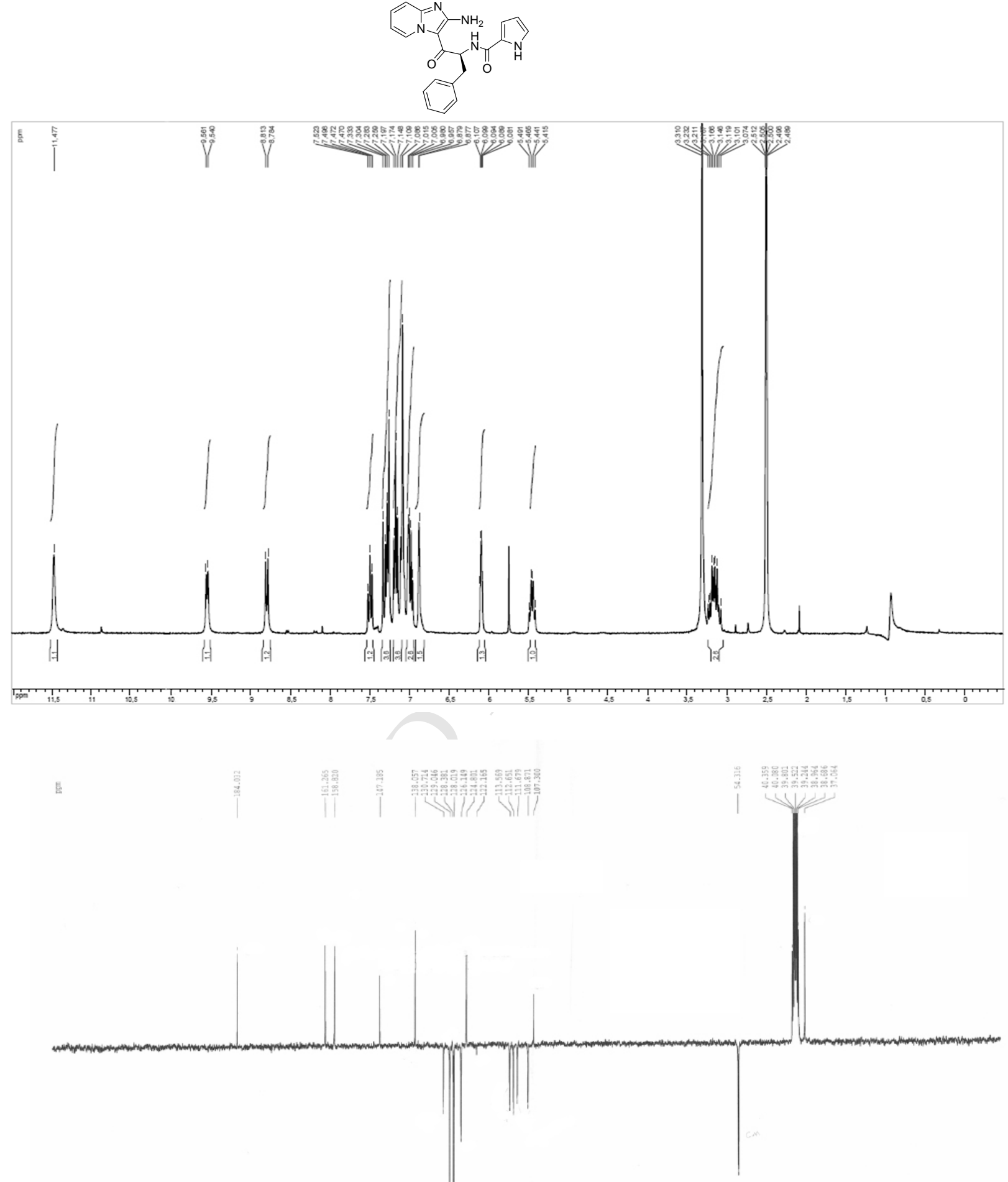
ACCEPTED MANUSCRIPT
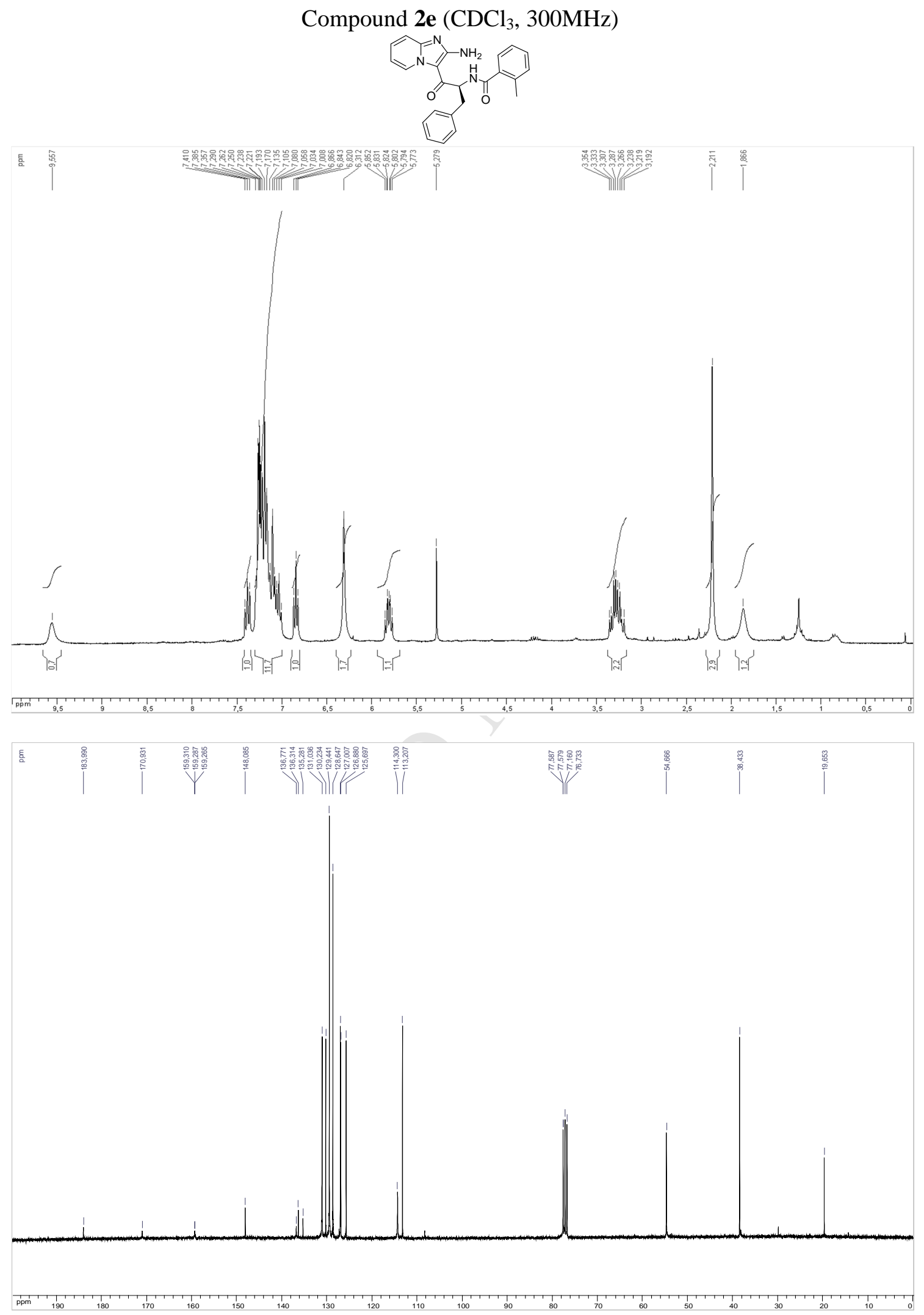

S31 
Compound $\mathbf{2 f}\left(\mathrm{CDCl}_{3}, 300 \mathrm{MHz}\right)$
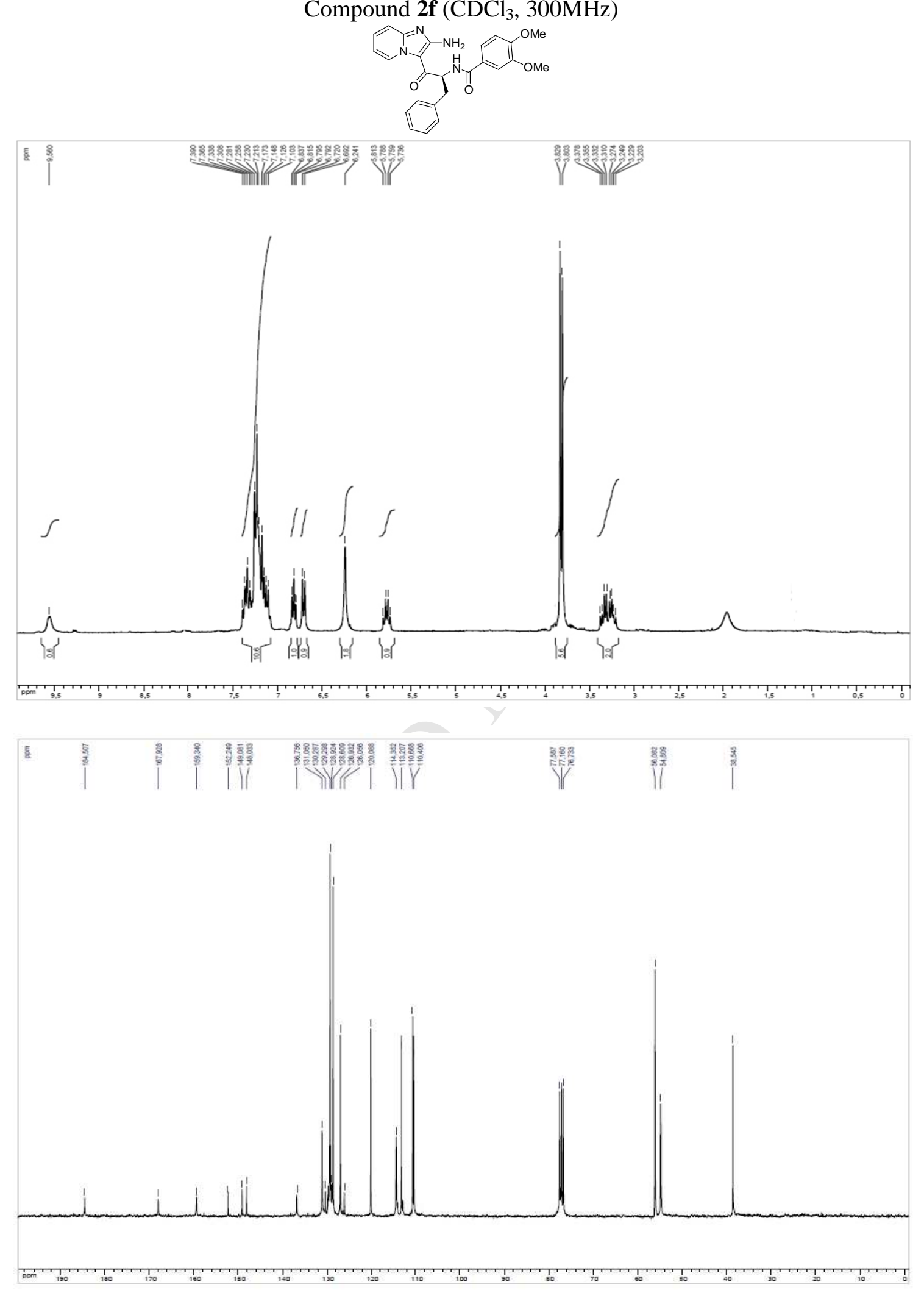
ACCEPTED MANUSCRIPT

Compound dg (DMSO $\left.d_{6}, 300 \mathrm{MHz}\right)$

붑
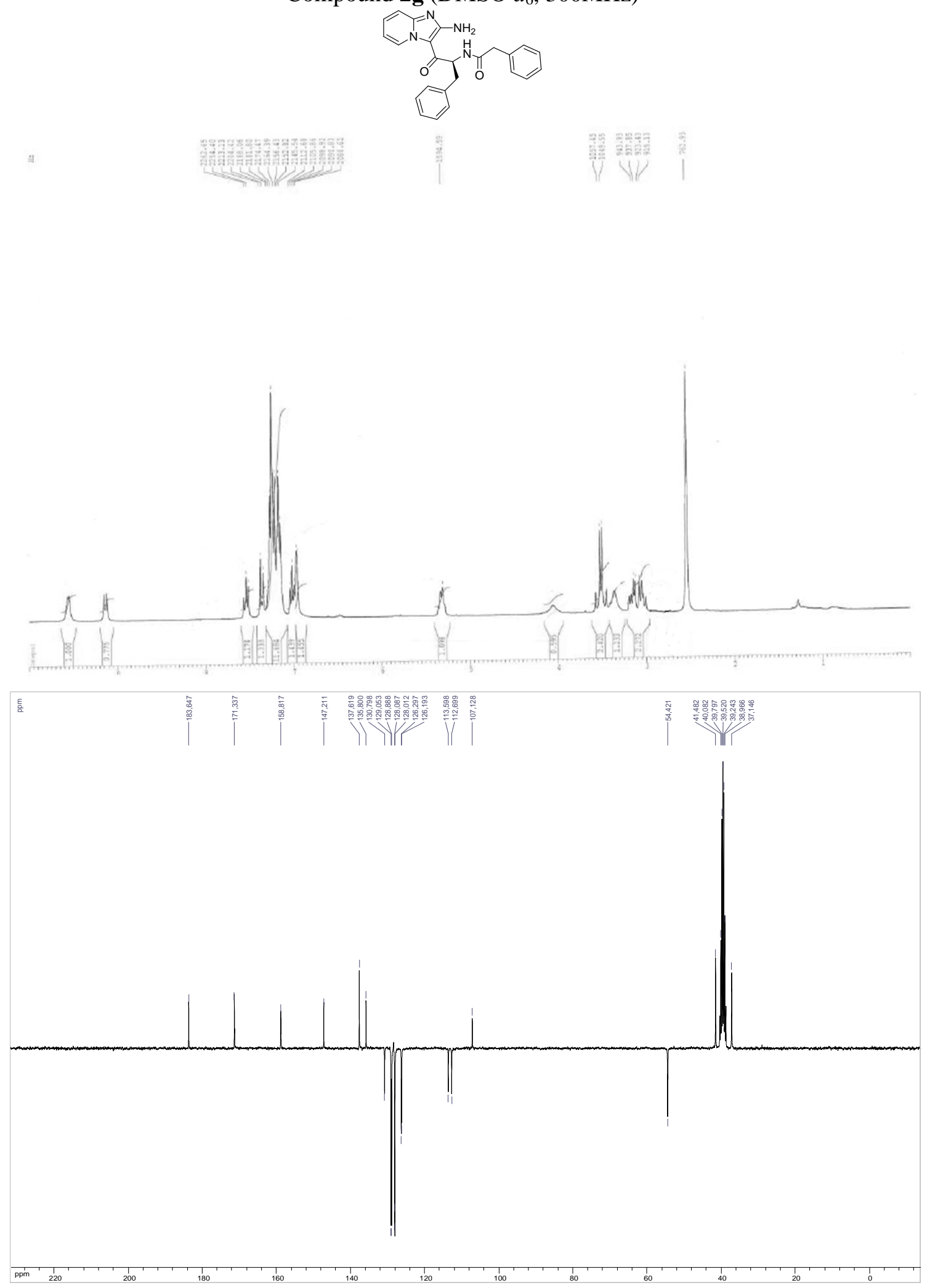

S33 
Compound $2 \mathbf{h}\left(\mathrm{CDCl}_{3}, 300 \mathrm{MHz}\right)$
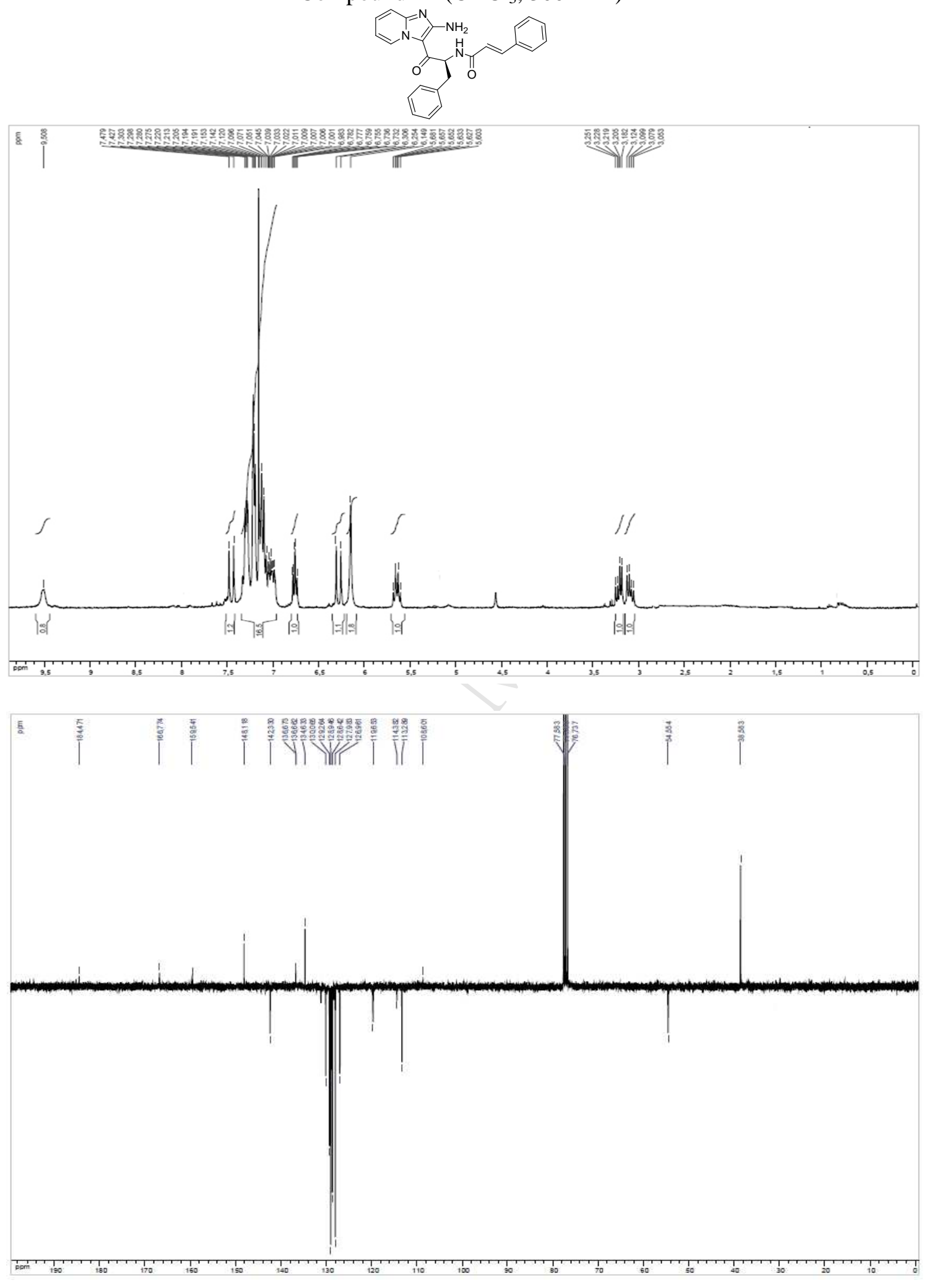


\section{Compound $2 \mathbf{i}\left(\mathrm{CDCl}_{3}, 300 \mathrm{MHz}\right)$}

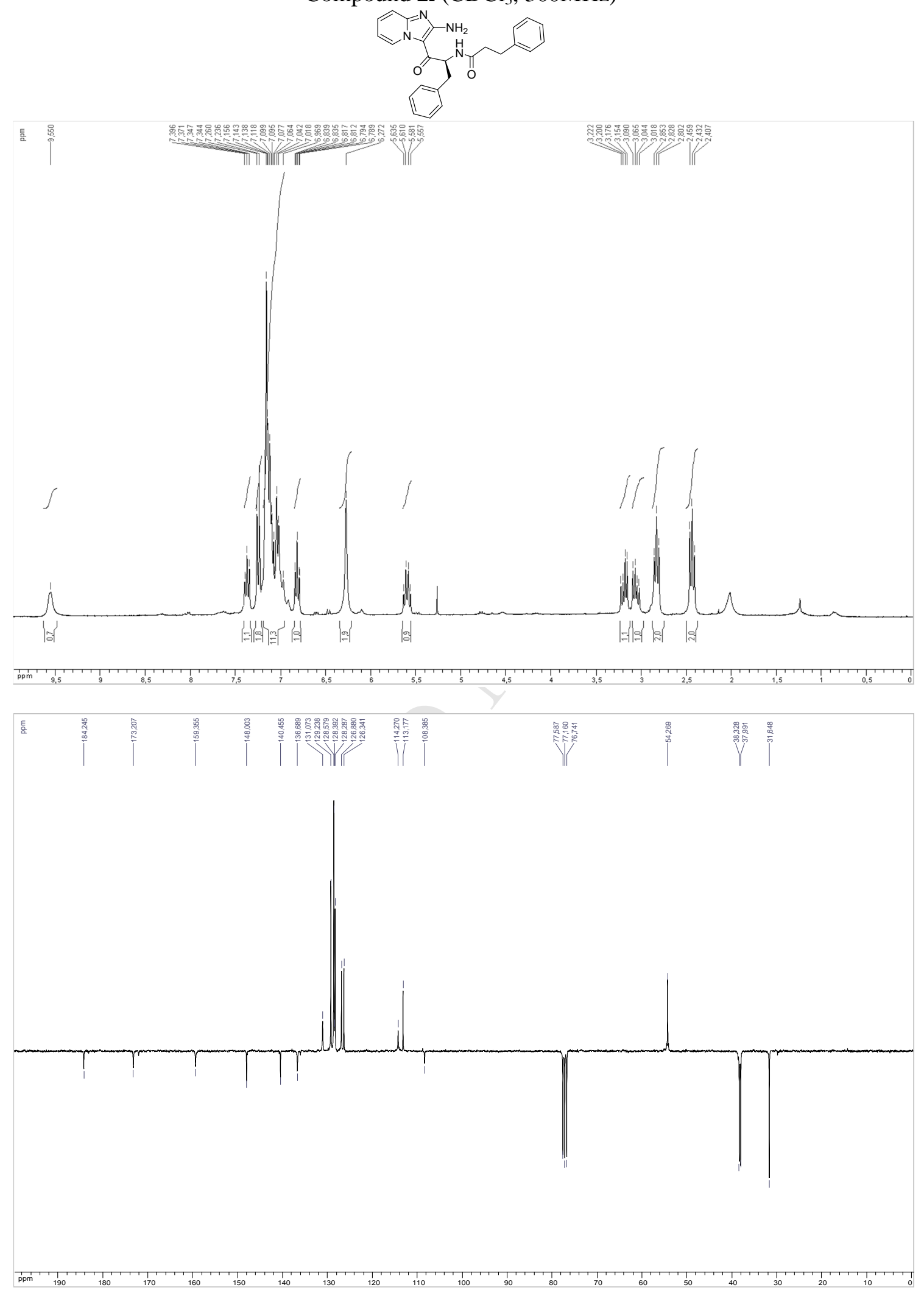

